العدد (16) أكتوبر 2020

Volume (16) October 2020

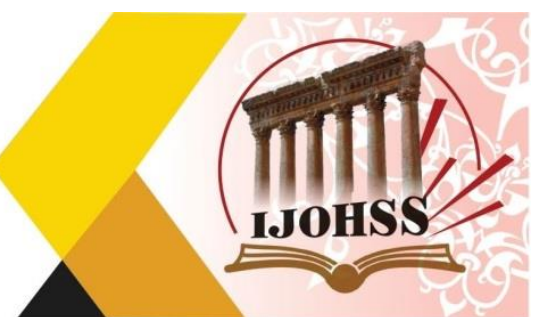

\title{
الانقلاب العسكري في اوغندا عام 1971
}

أ.د. مؤيد شاكر كاظم

كلية الاداب - جامعة ذي قار - العراق

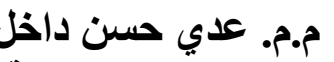

(الملخص

حكمت بريطانيا أو غندا، بوصفها محمية بريطانية، باسم محمية أو غندا، نحو سبعين عاماً، حتى نالت استقلالها،

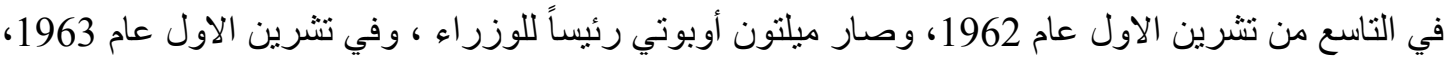

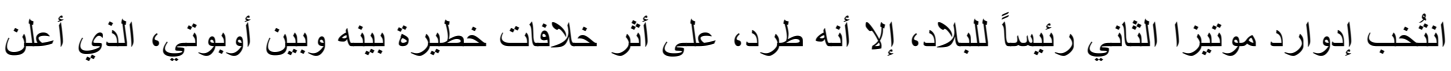

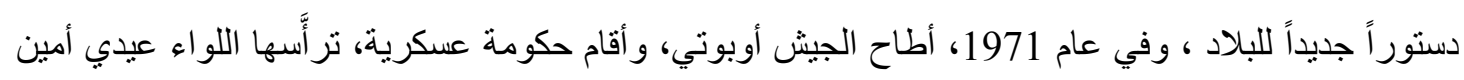

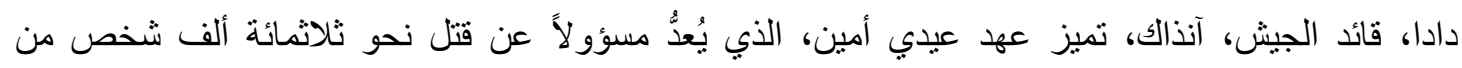

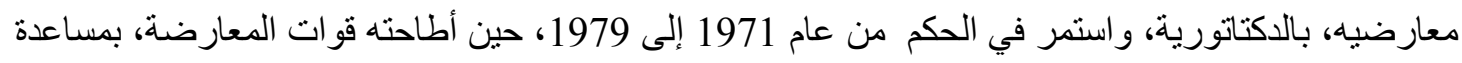

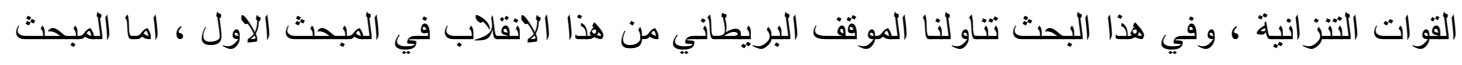

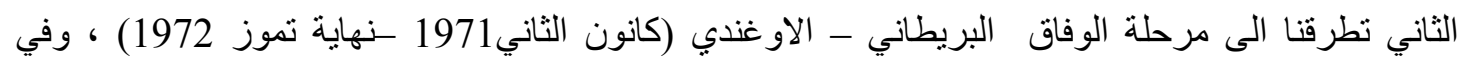

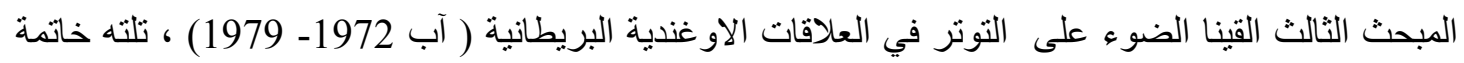

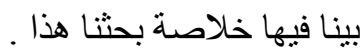

الكلمات المفتاحية: الانقلاب العسكري، او غندا، انقلاب عام 1971. 


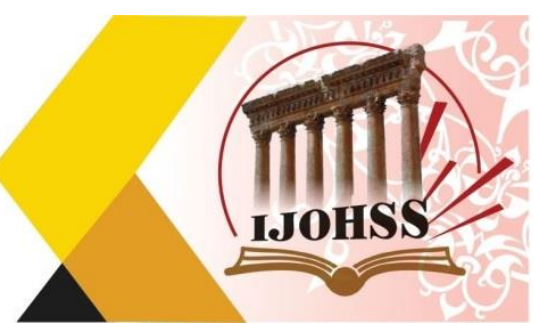

\title{
The Military Coup in Uganda in 1971
}

\author{
Assist. Lect. Uday Hassan Dakhil \\ Prof. Dr. Moayad Shaker Kadhim \\ College of Arts - Dhi Qar University - Iraq
}

\begin{abstract}
Britain ruled Uganda as a British protectorate, in the name of the Protectorate of Uganda, for about seventy years, until it gained independence, on the ninth of October 1962, and Milton Obote became prime minister, and in October 1963, Edward Mutisa II was elected president, but he was expelled After serious disagreements between him and Obote, who announced a new constitution for the country, and in 1971, the army overthrew Obote, and established a military government, headed by Major General Idi Amin Dada, the commander of the army, at the time, that distinguished Idi Amin's era, who is responsible for killing about three hundred One thousand of his opponents, with dictatorship, and he continued to rule from 1971 to 1979, when opposition forces overthrew him, with the help of the Tanzanian forces, and in this research we dealt with the British position on this coup in the first topic, while the second topic dealt with the stage of the British-Ugandan accord (Canon The second, 1971 - the end of July 1972), and in the third topic we shed light on the tension in British-Ugandan relations (August 1972-1979), followed by a conclusion in which we presented the summary of this research.
\end{abstract}

Keywords: Military coup, Uganda, coup of 1971. 


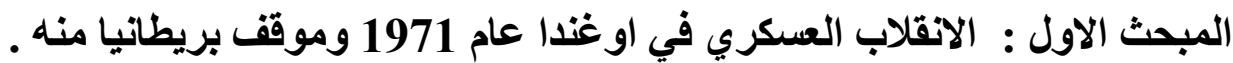

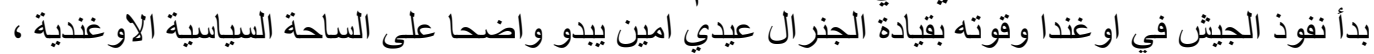

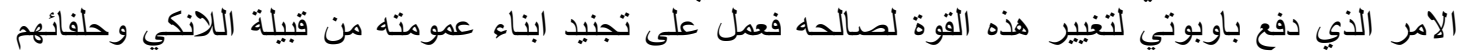

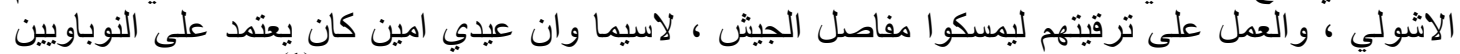

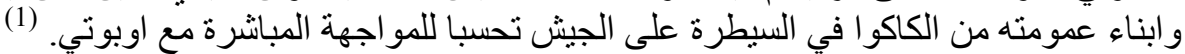

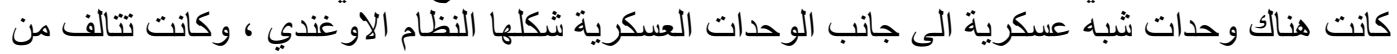

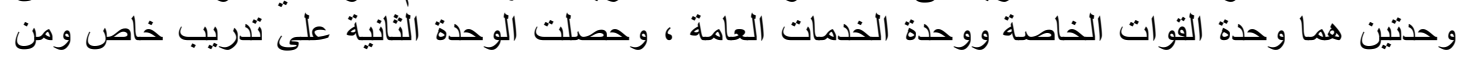

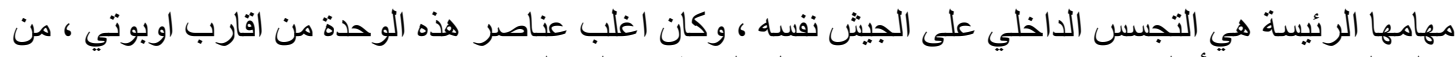

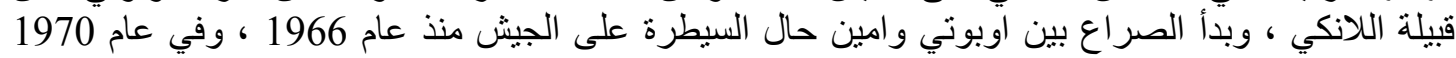

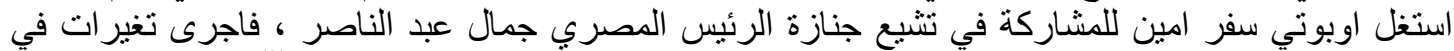

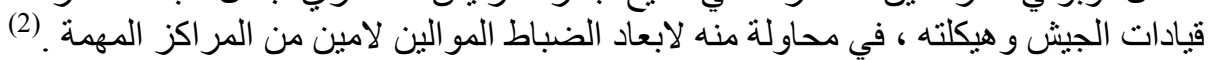

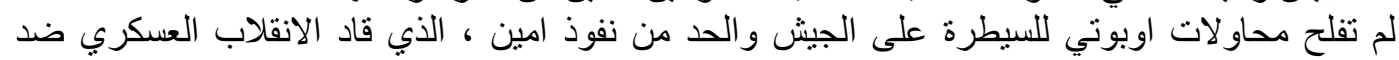

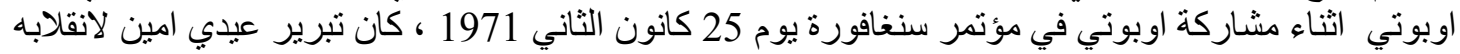

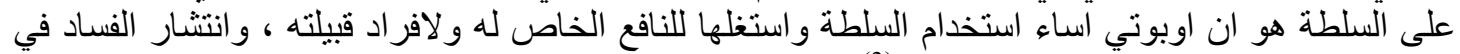

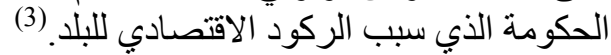

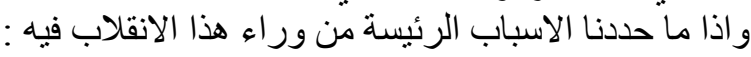

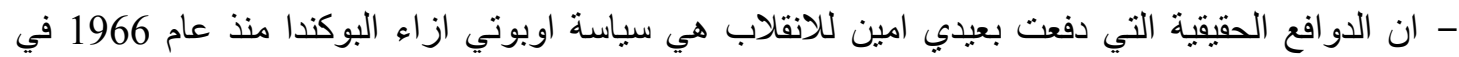

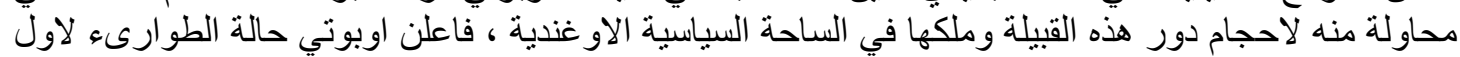

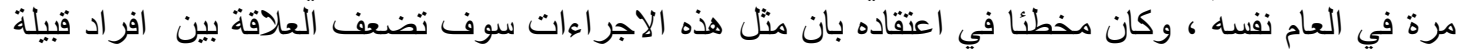

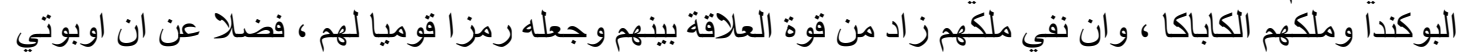

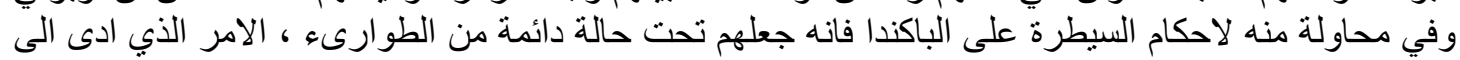

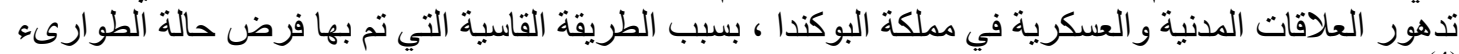

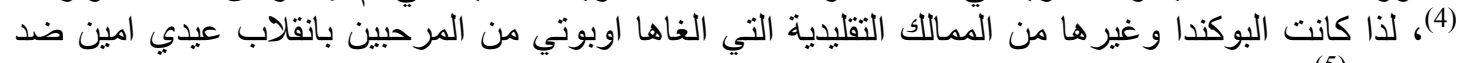

اوبوتي . (5)

- عندما تسلم اوبوتي السلطة انتهج سياسة خنق المعارضة منذ البداية ، فقام بحظر جميع الاحز ابل السياسة

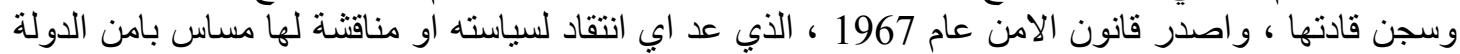

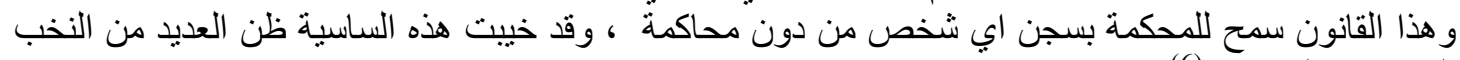

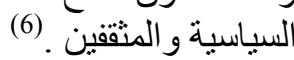

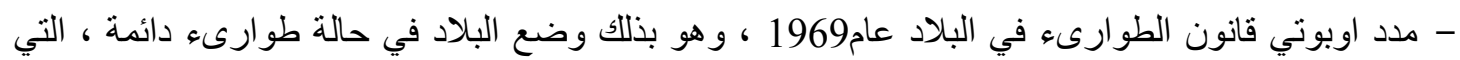

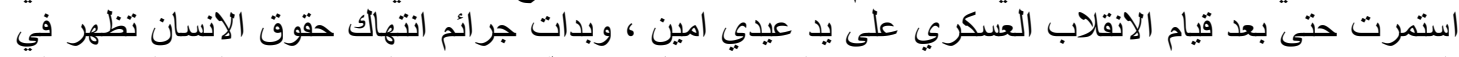

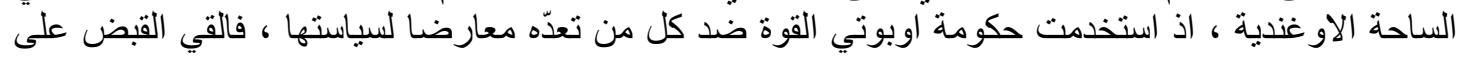

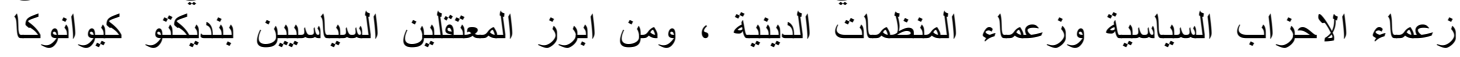
(Benedicta Kiwanuka)

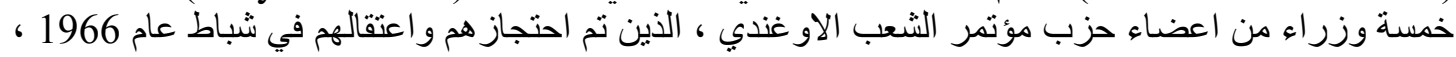

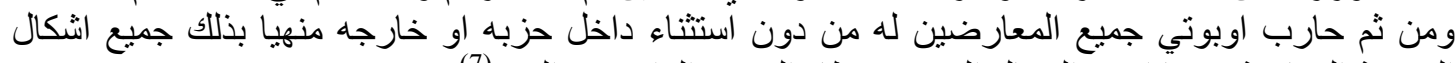

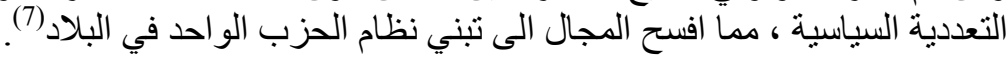

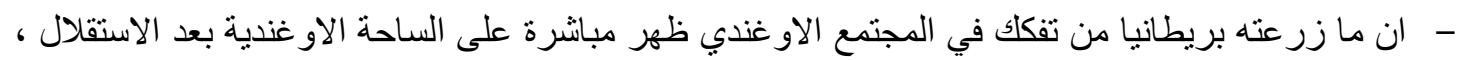

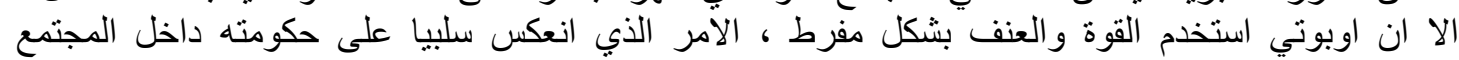

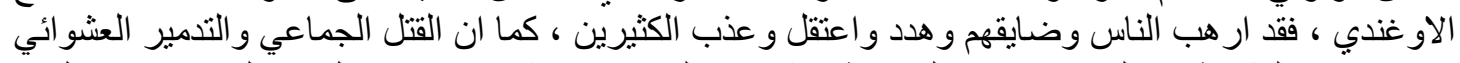

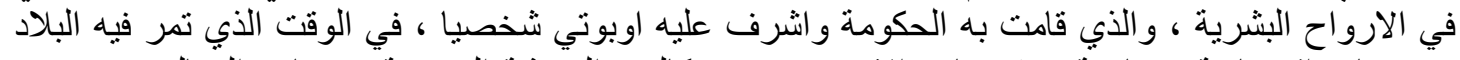

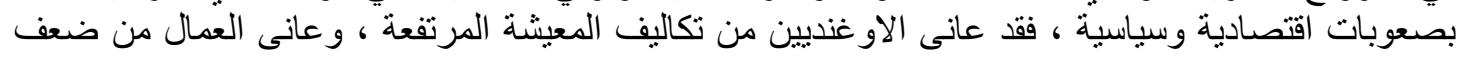

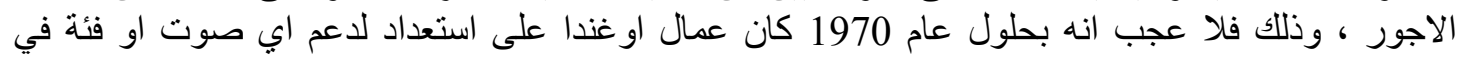

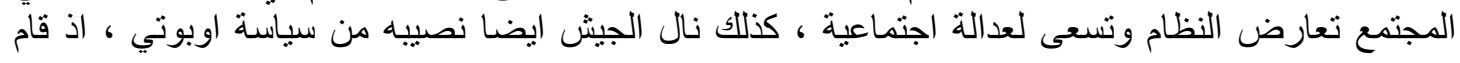




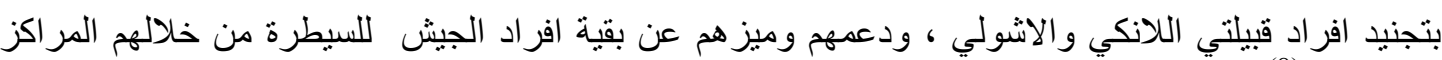

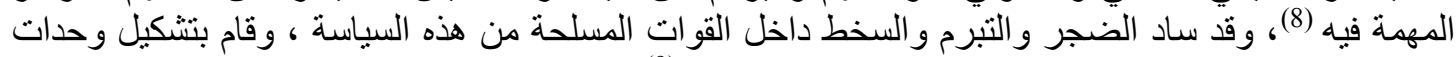

شبه عسكرية مهامها التجسس الداخلي على الفئ الجيش و الضباط.

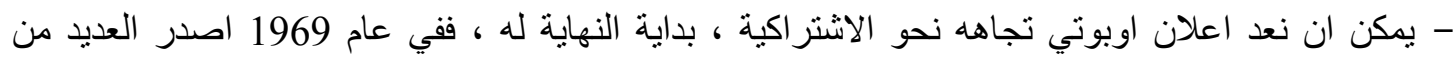

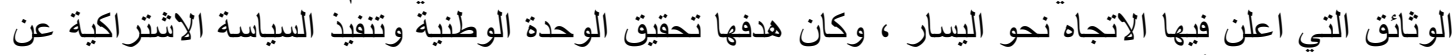

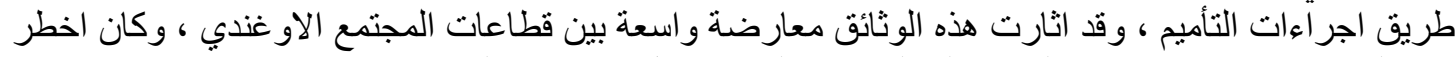

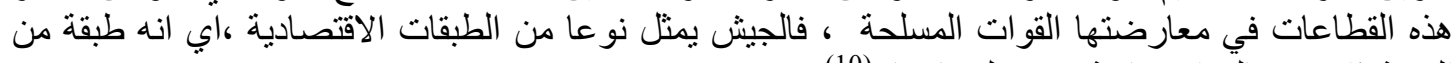

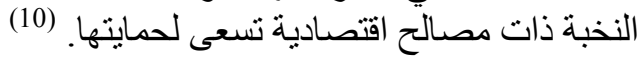

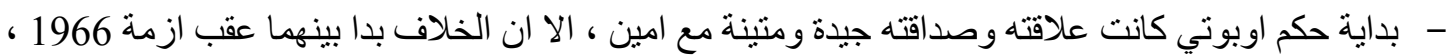

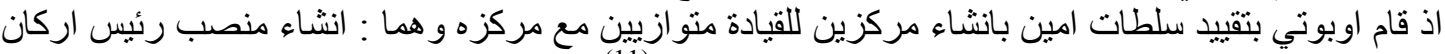

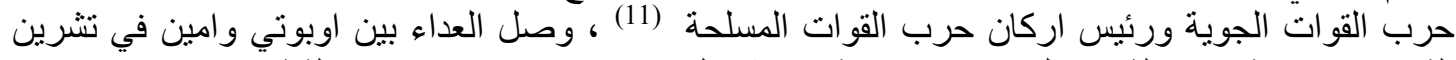

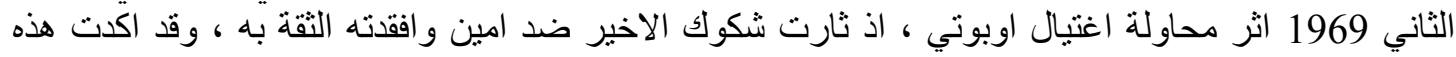

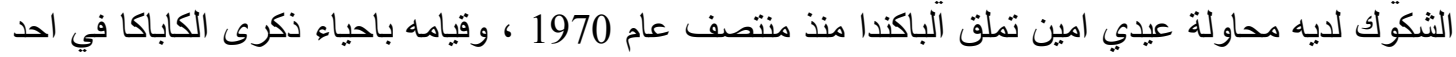

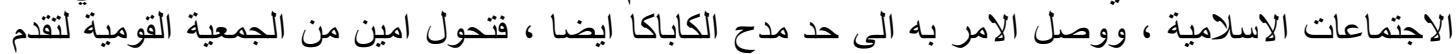

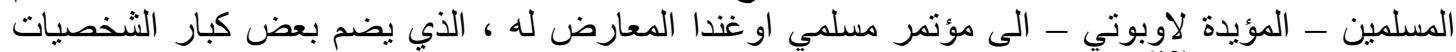

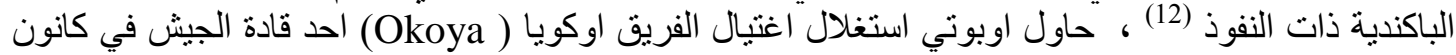

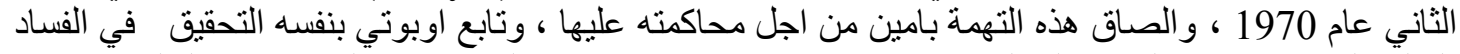

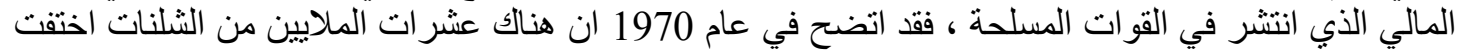

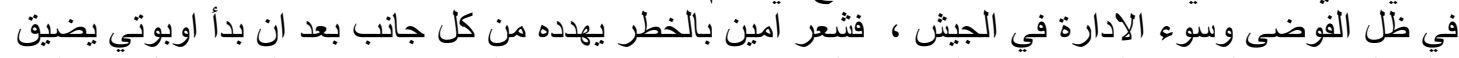

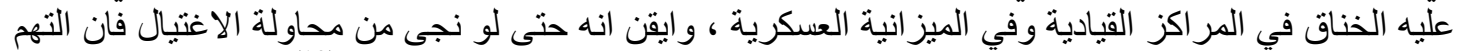

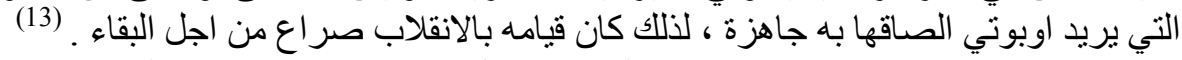

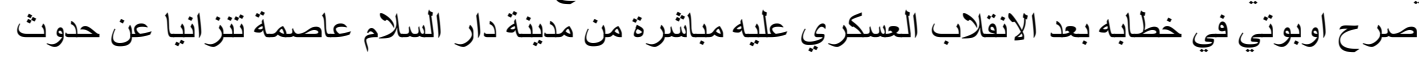

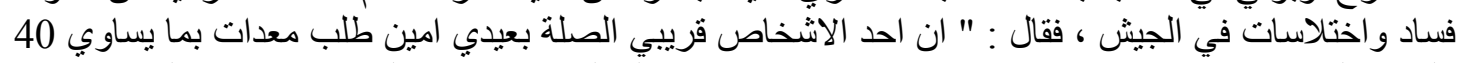

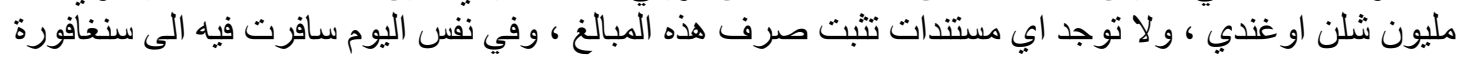

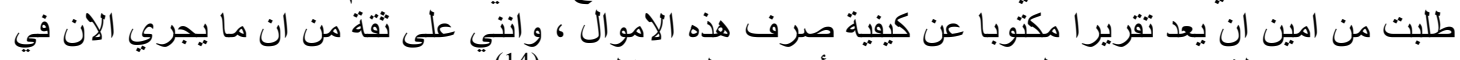

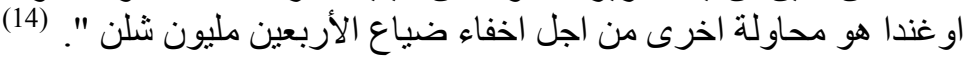

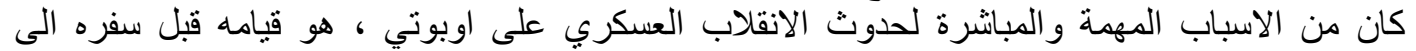

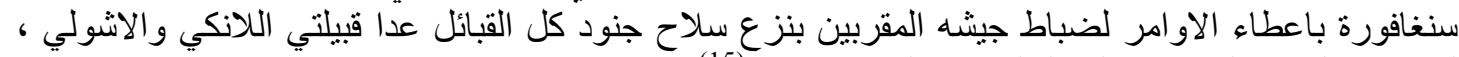

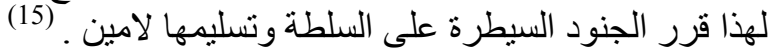

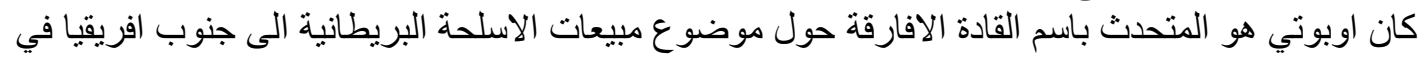

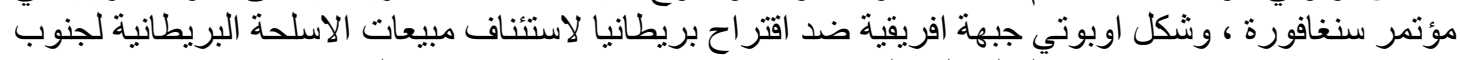

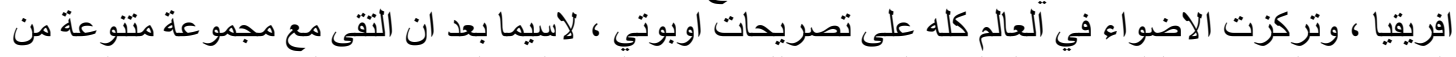

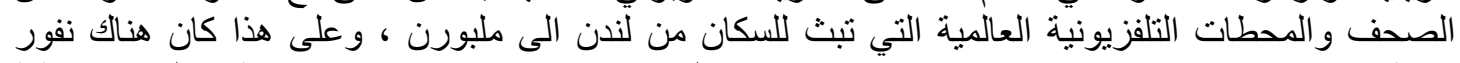

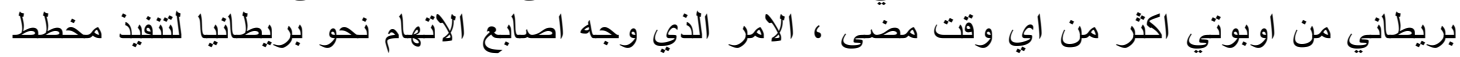

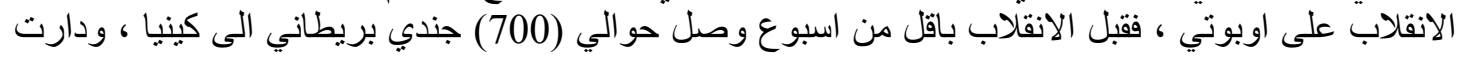

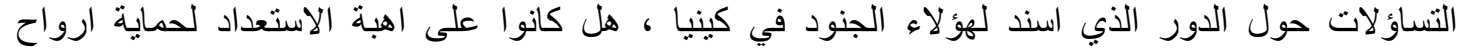

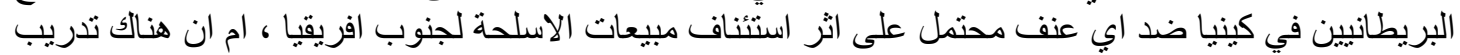

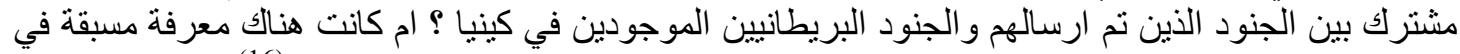

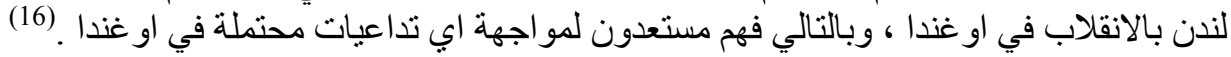

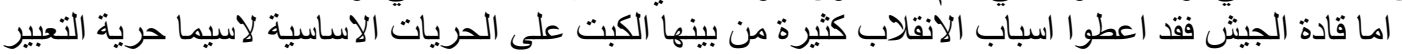

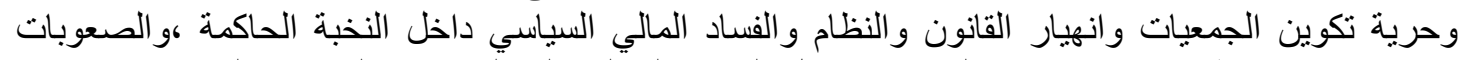

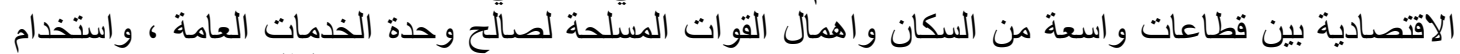

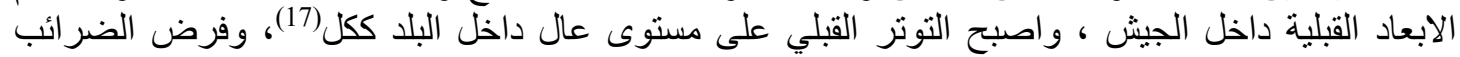

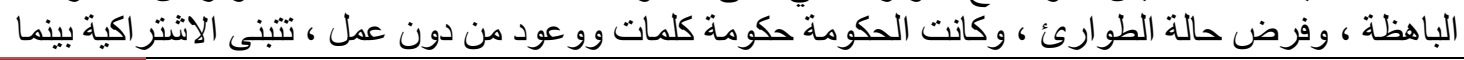




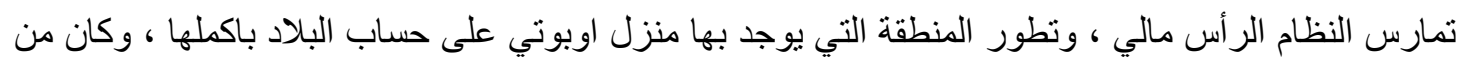

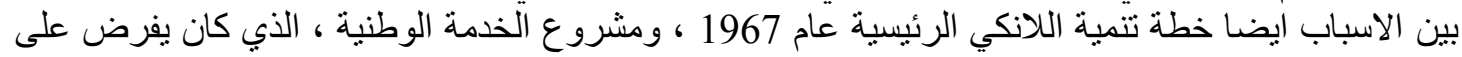

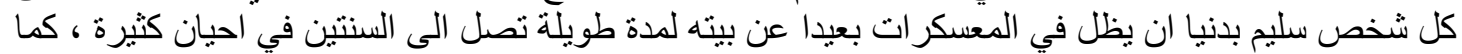

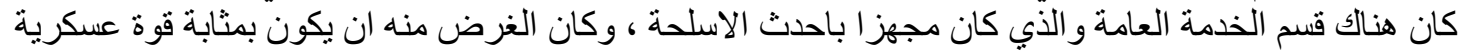

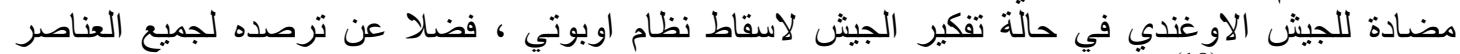

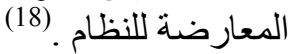

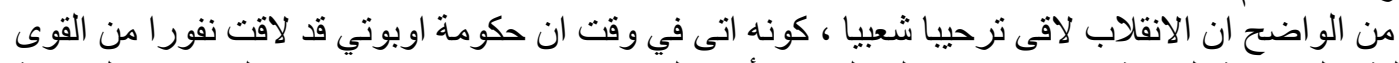

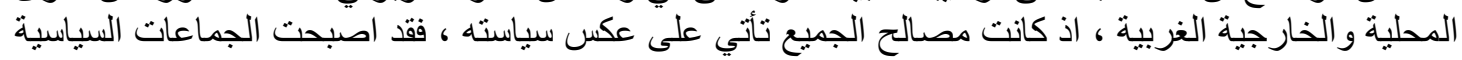

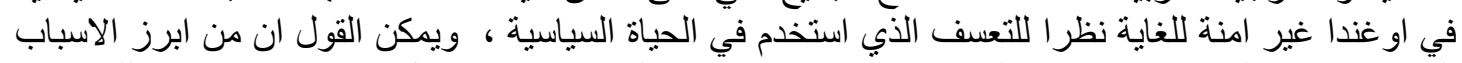

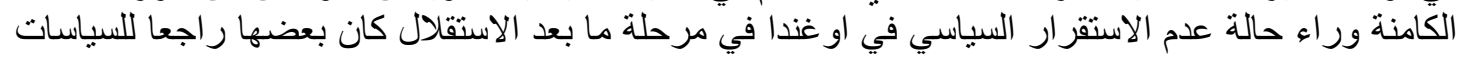

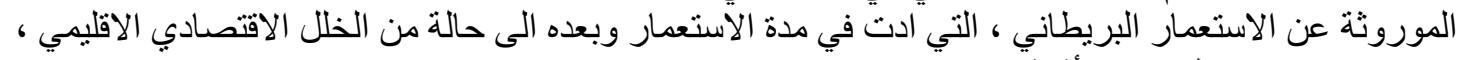
فضلا عن استخدام العرق و الأثنية.

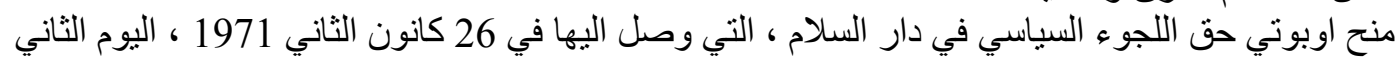

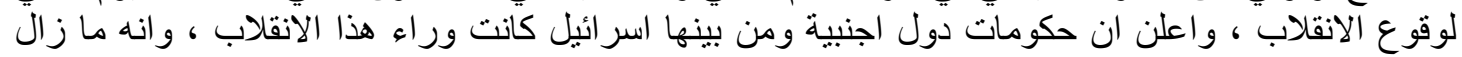

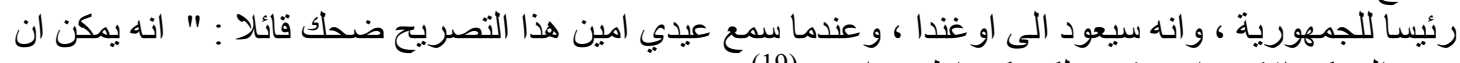

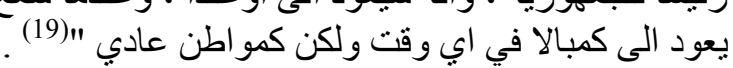

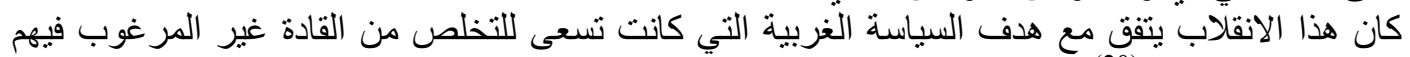

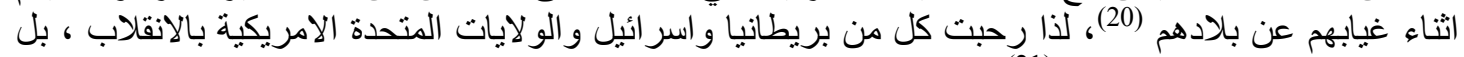

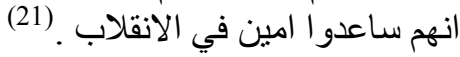

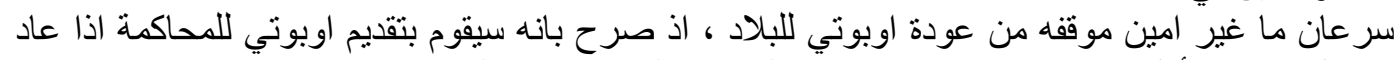

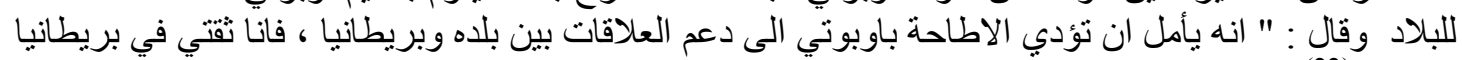

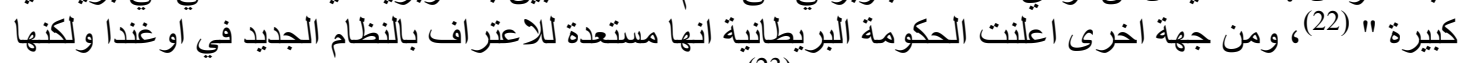

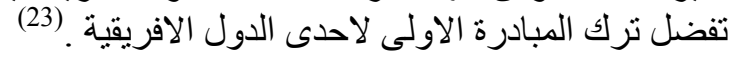

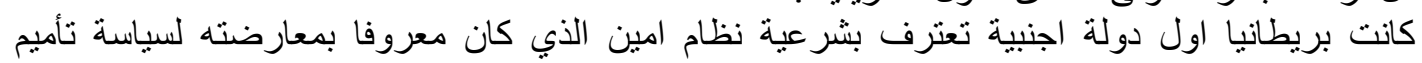

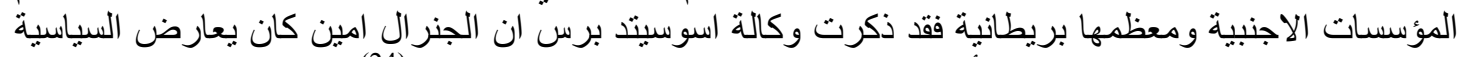

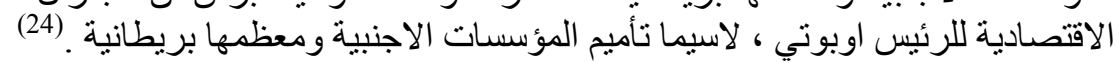

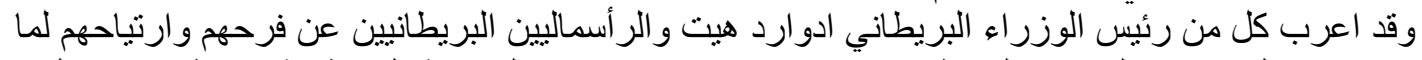

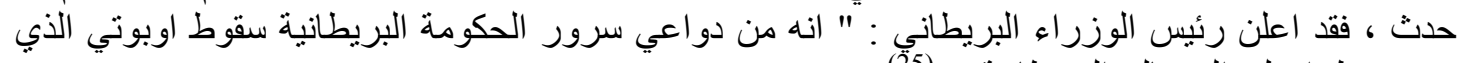

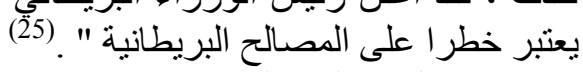

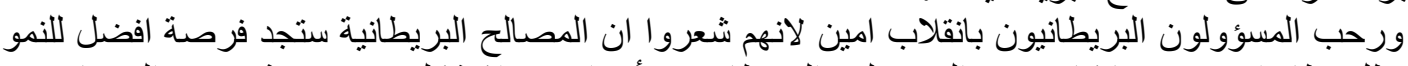

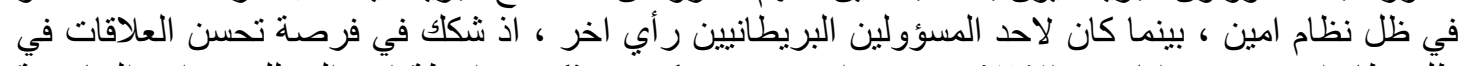

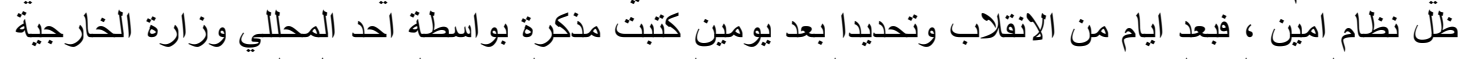

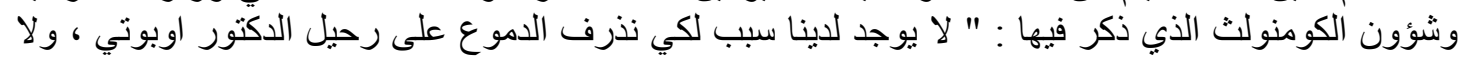

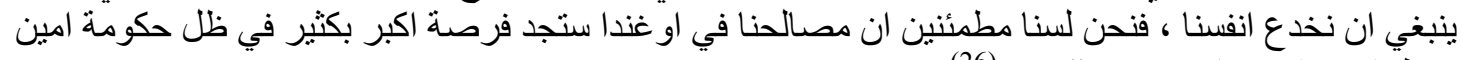

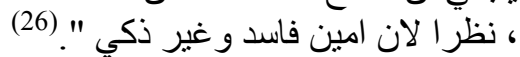

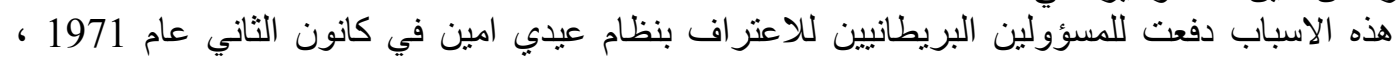

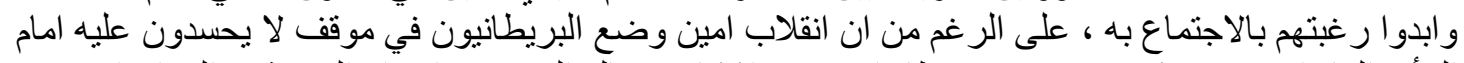

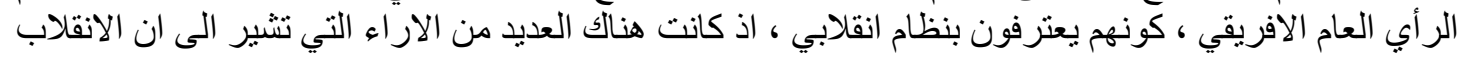

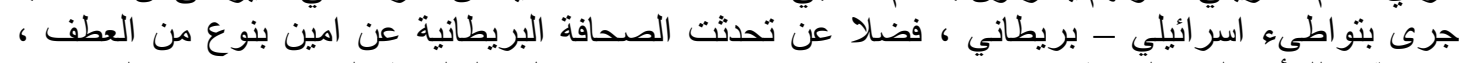

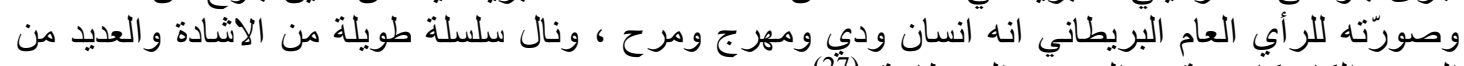

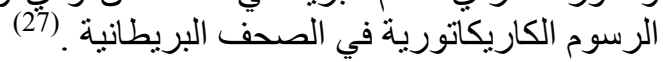

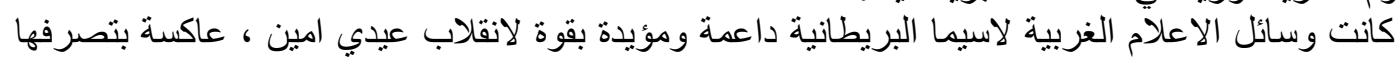

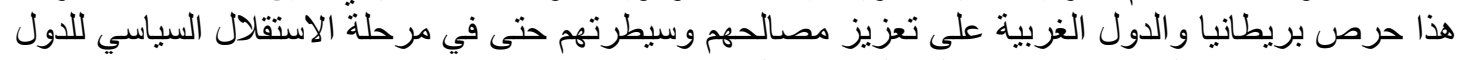

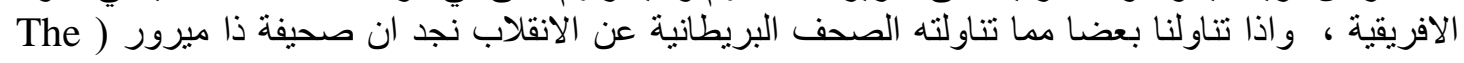




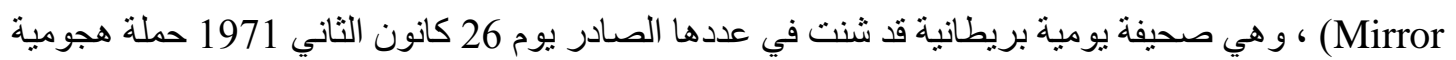

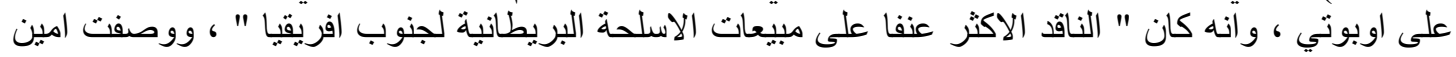

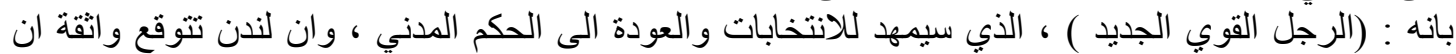

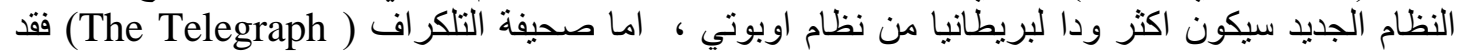

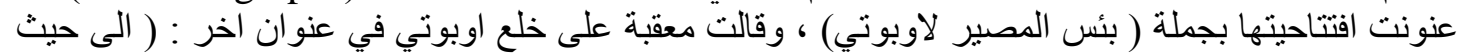

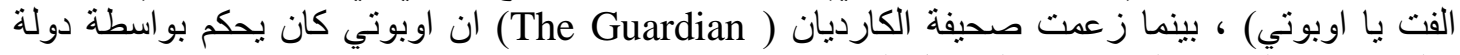

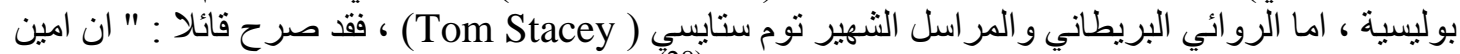

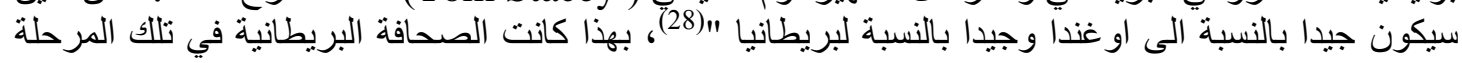

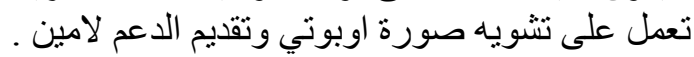

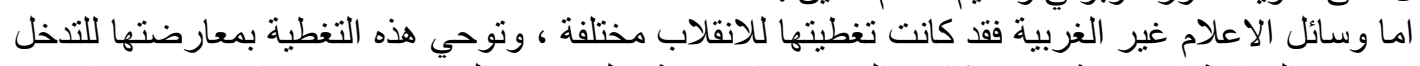

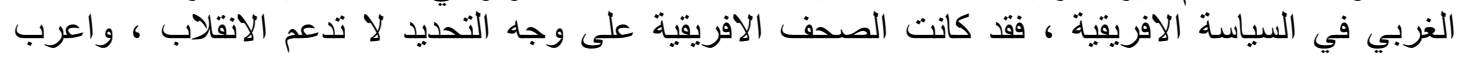

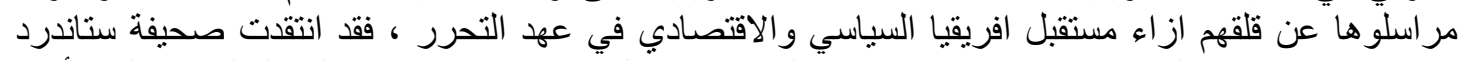

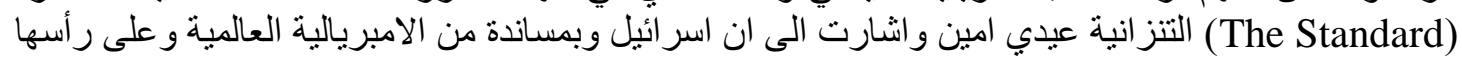

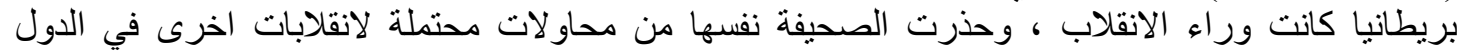

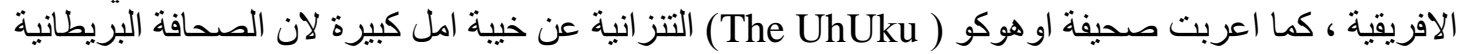

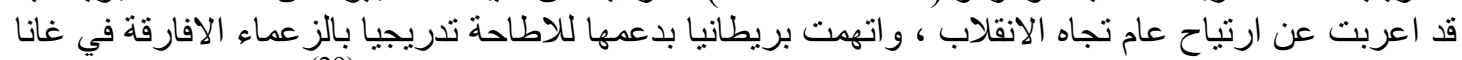

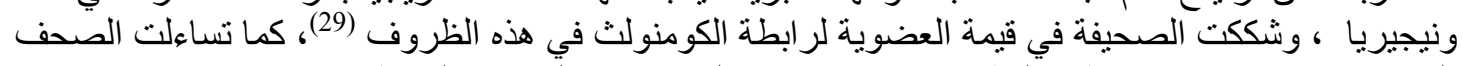

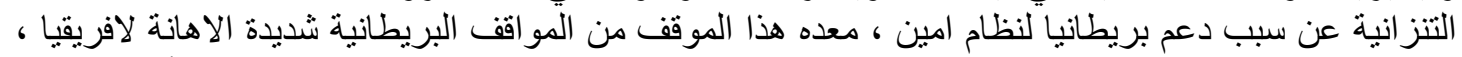

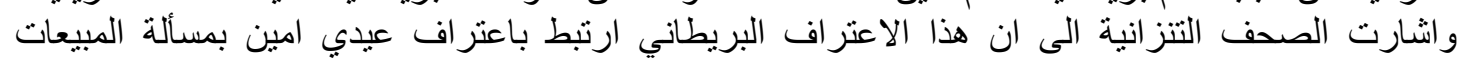

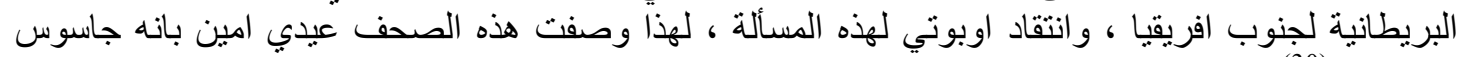
بريطاني .

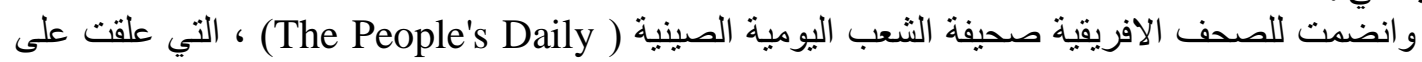

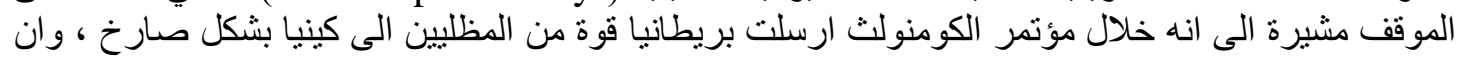

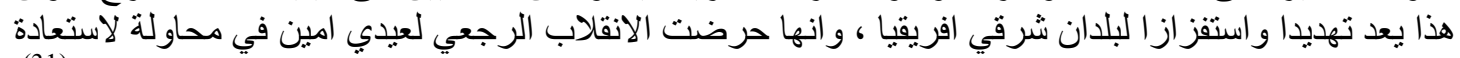

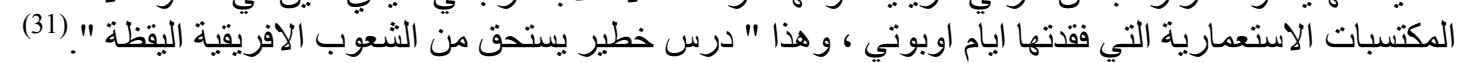

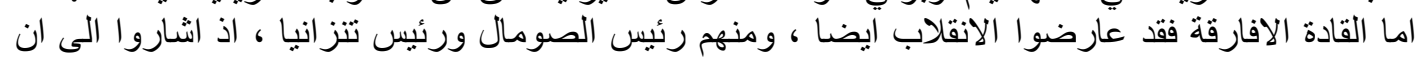

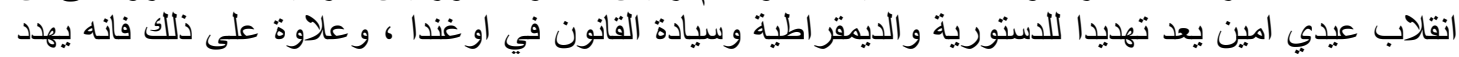

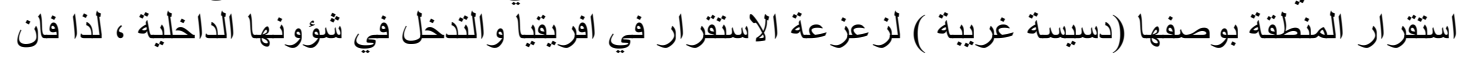

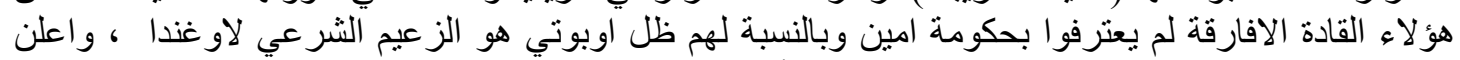

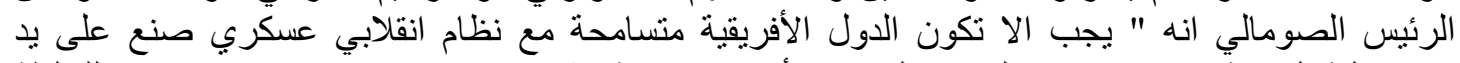

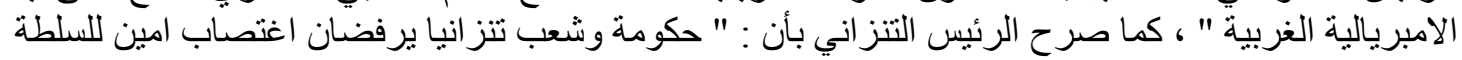

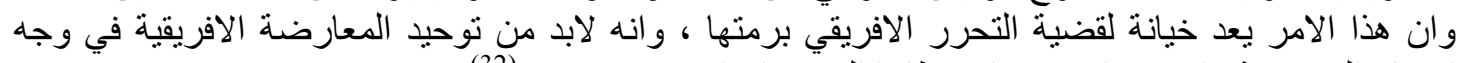

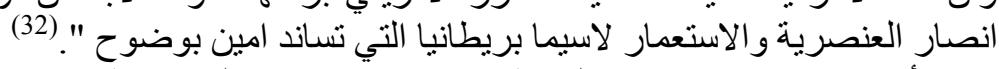

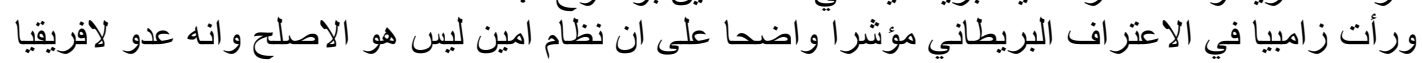

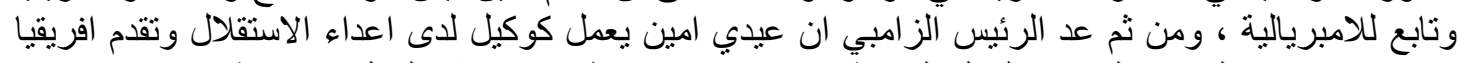

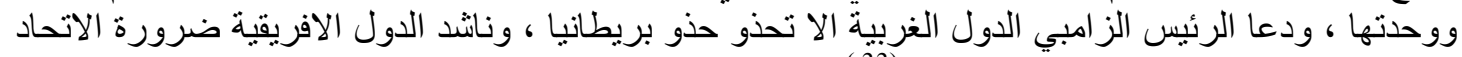

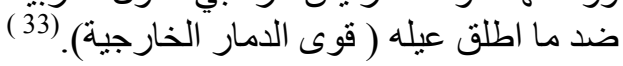

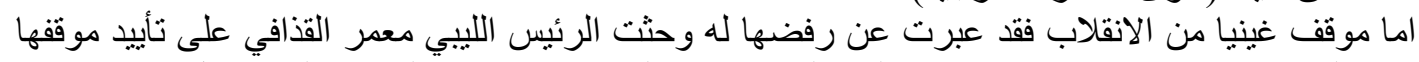

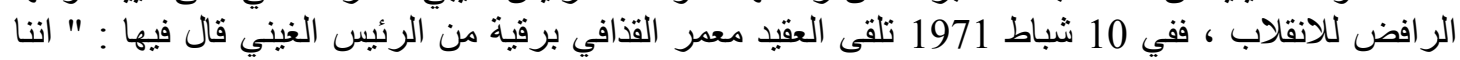

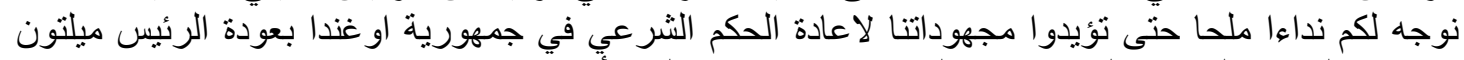

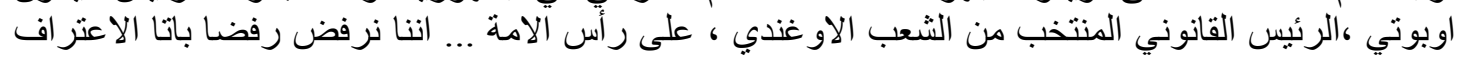

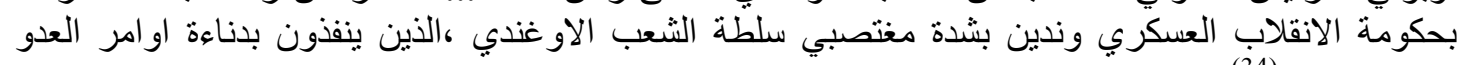

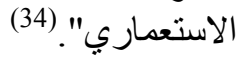




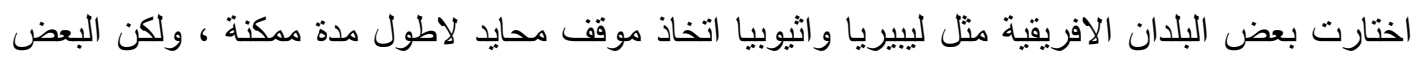

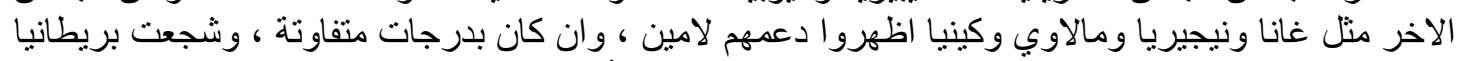

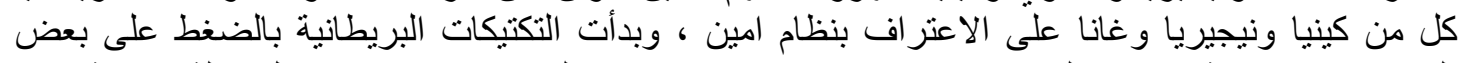

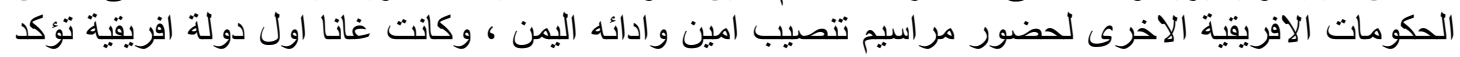

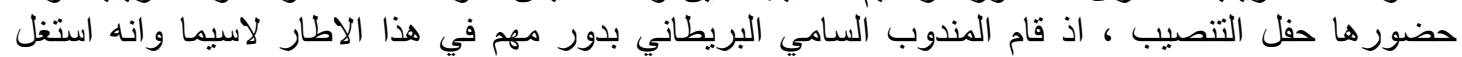

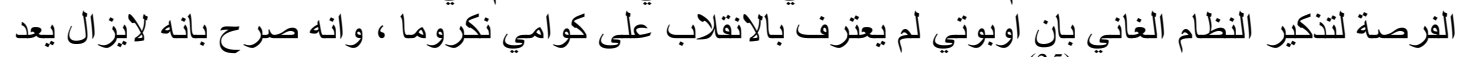

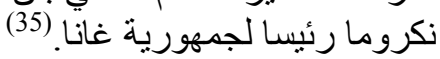

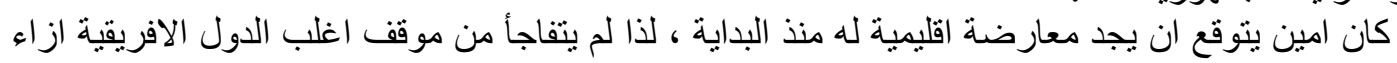

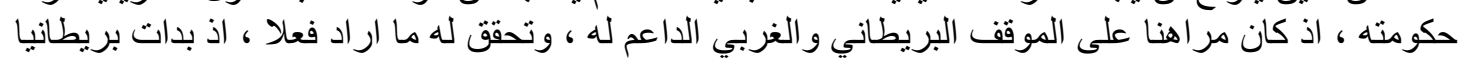

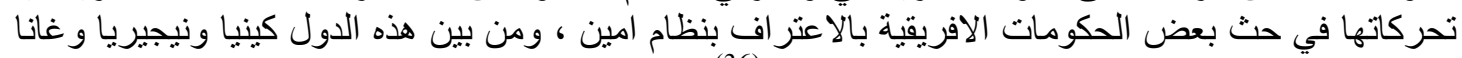

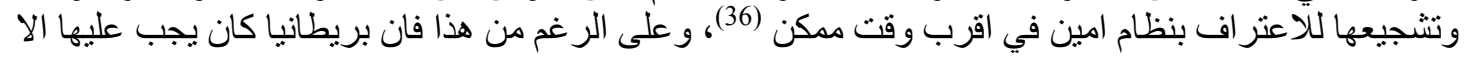

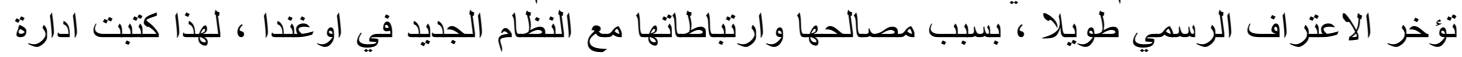

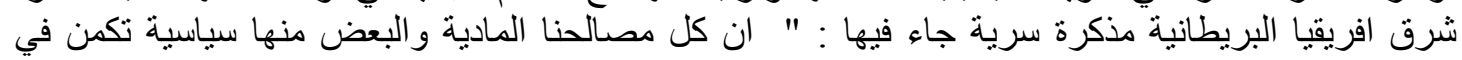

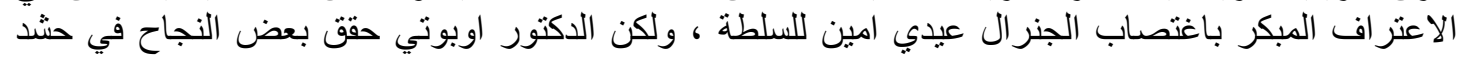

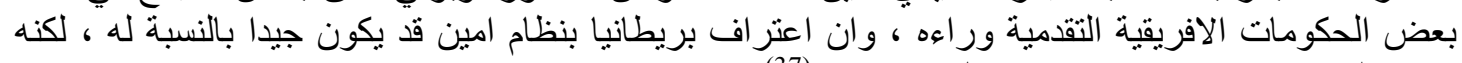

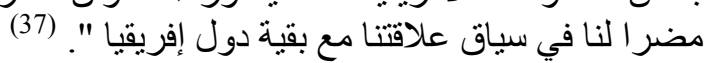

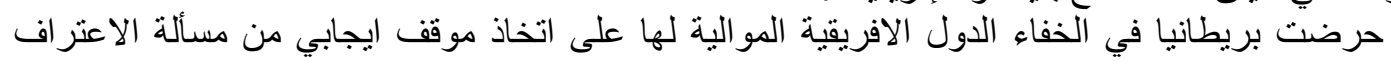

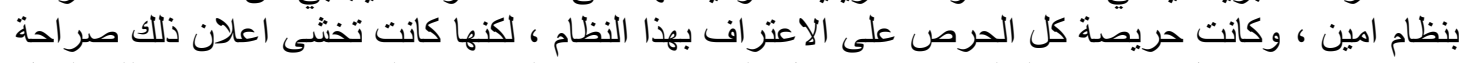

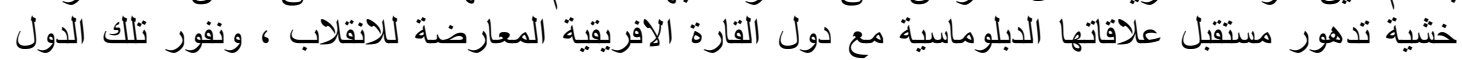

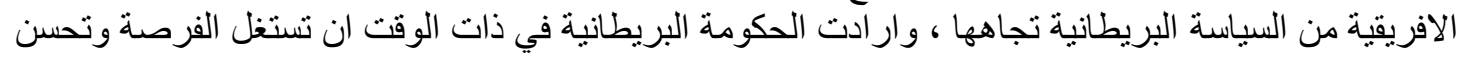

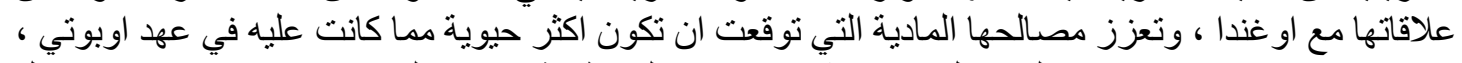

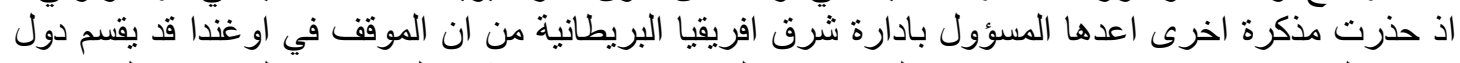

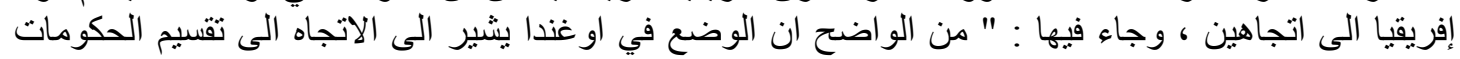

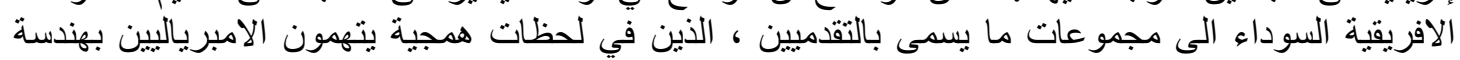

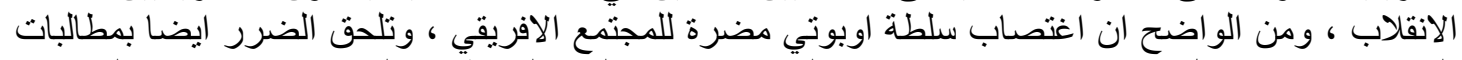

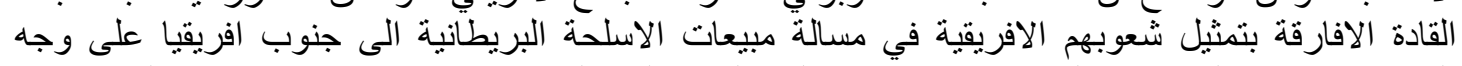

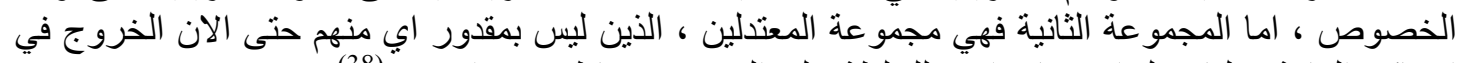

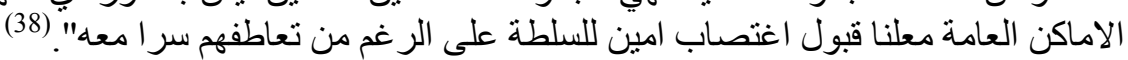

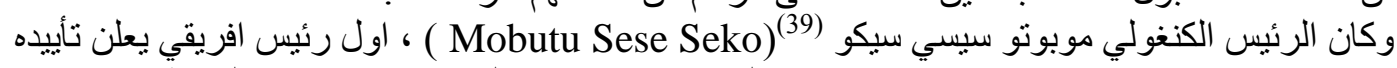



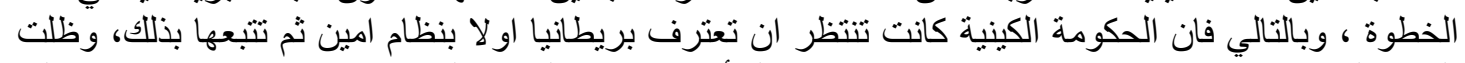

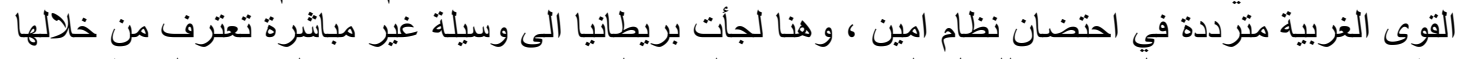

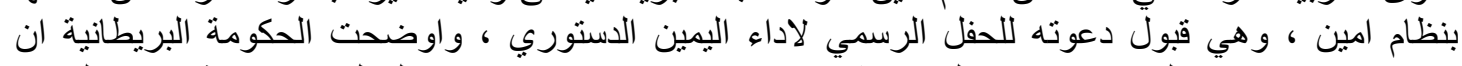

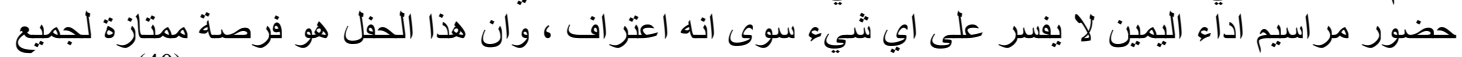

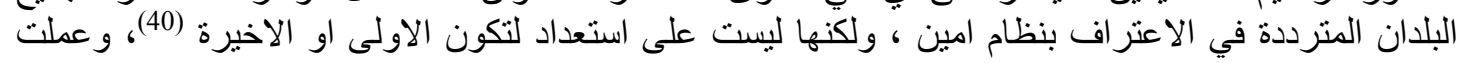

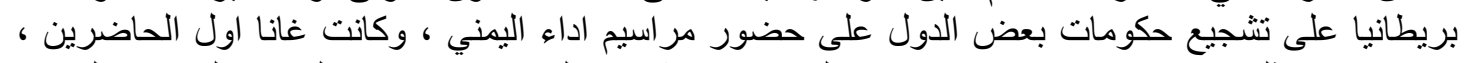

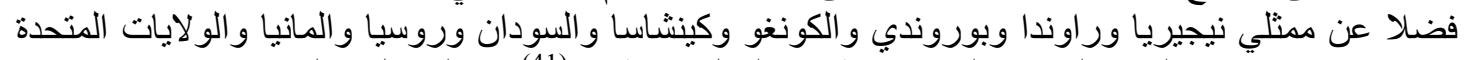

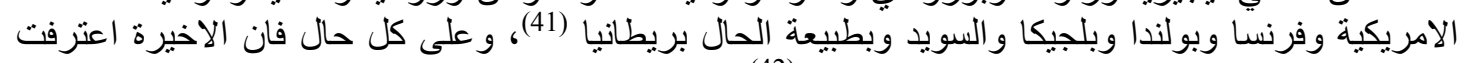

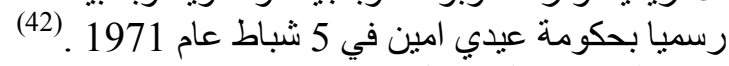

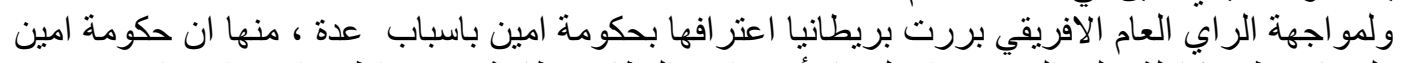

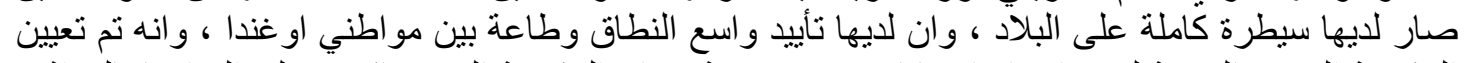

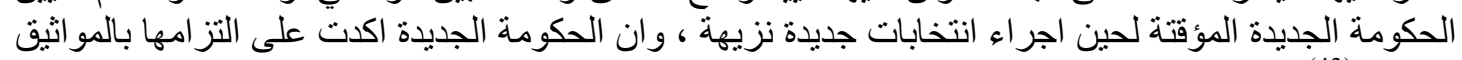

الدولية .43) 


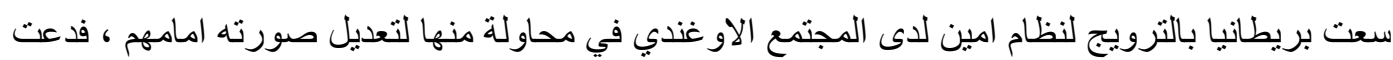

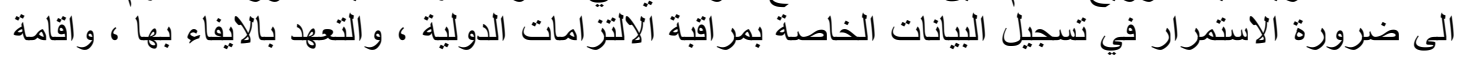

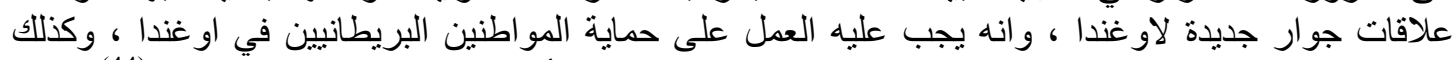

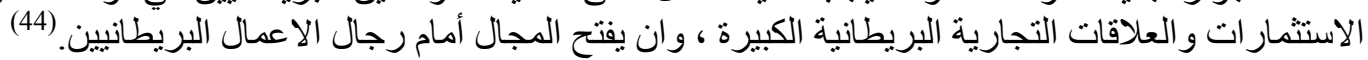

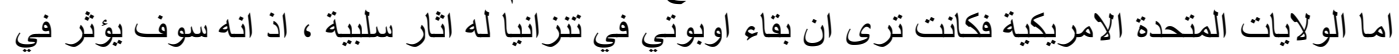

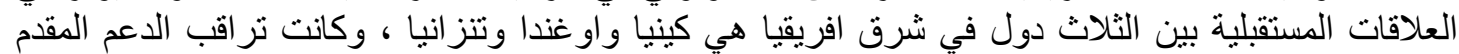

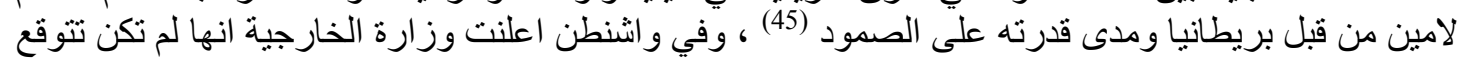

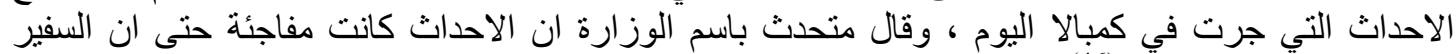

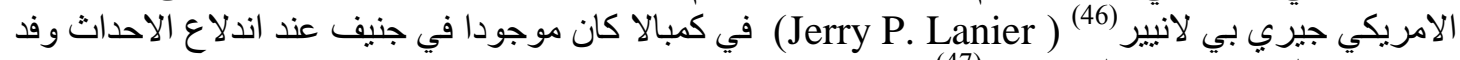

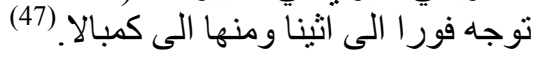

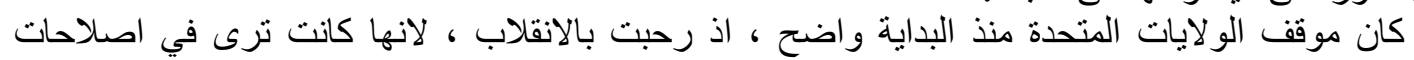

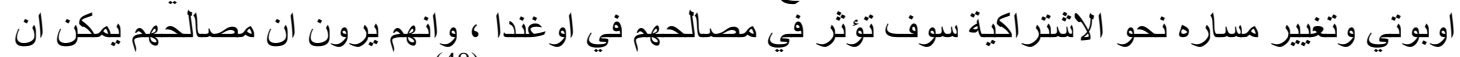

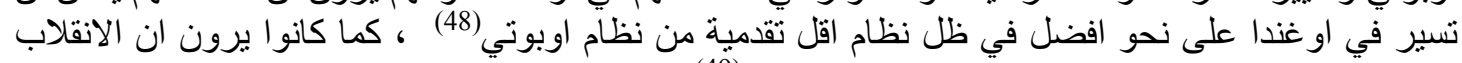

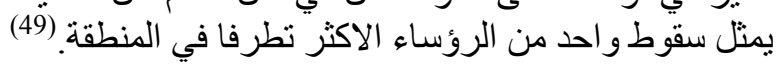

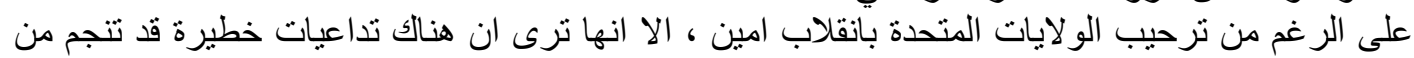

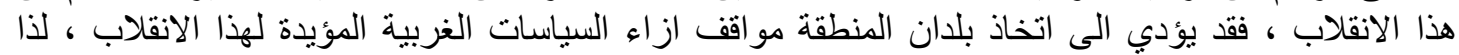

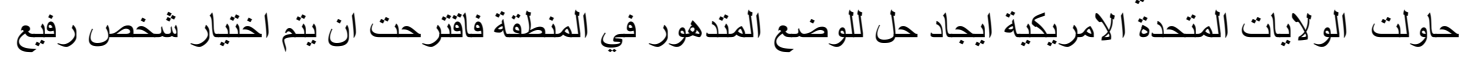

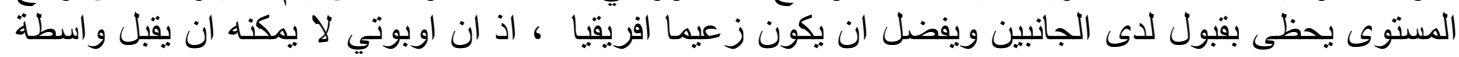

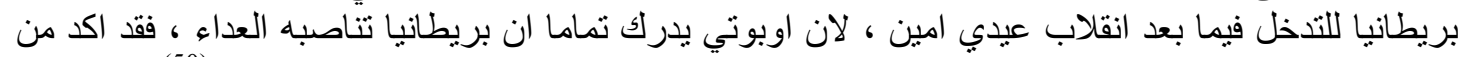

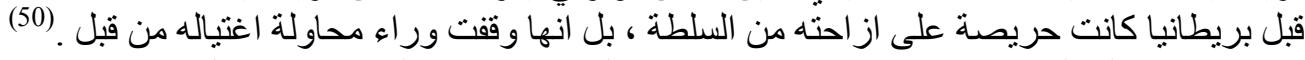

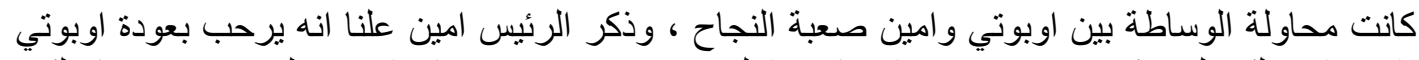

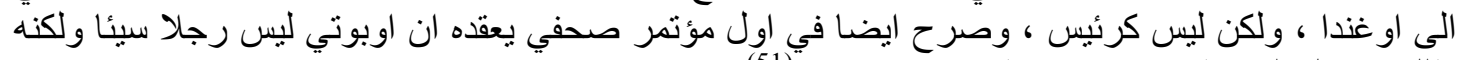

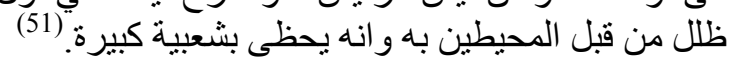

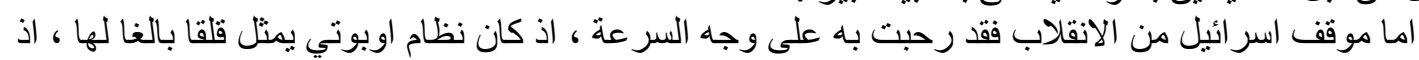

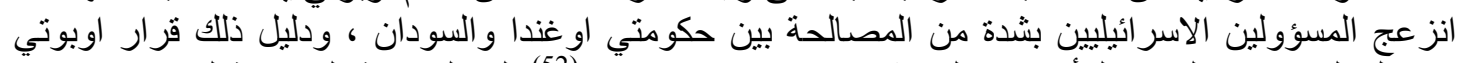

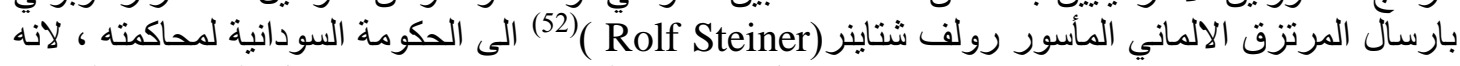

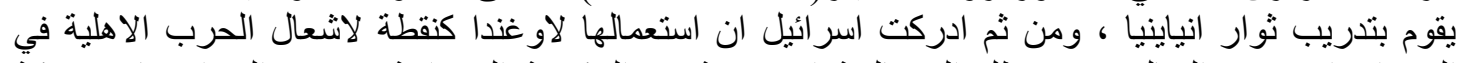

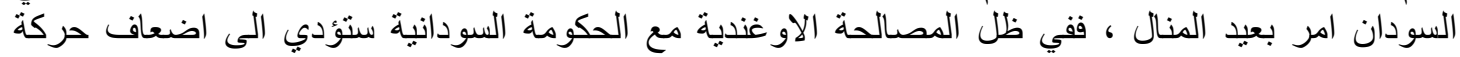

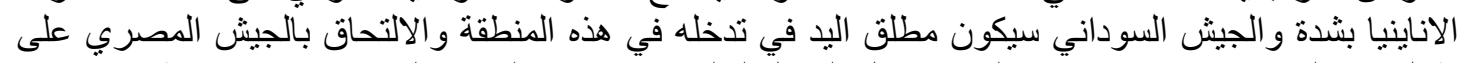

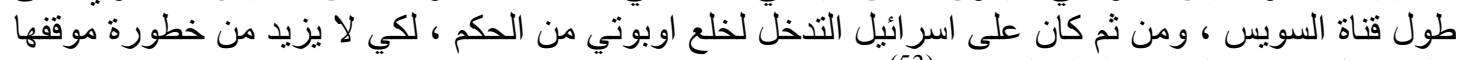

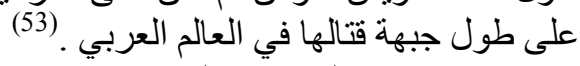

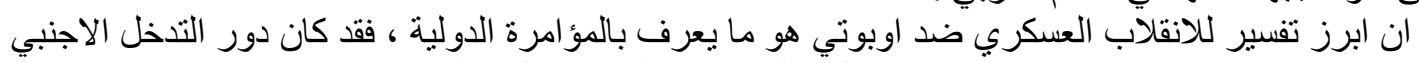

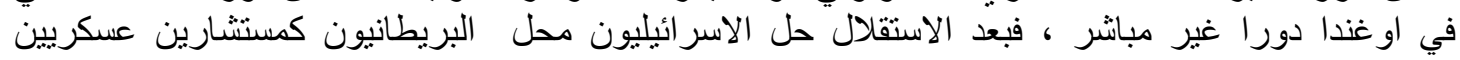

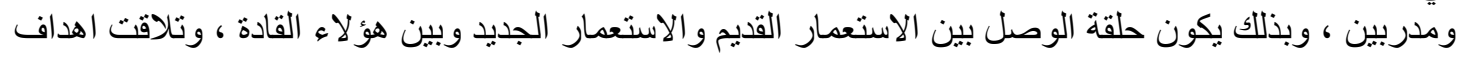

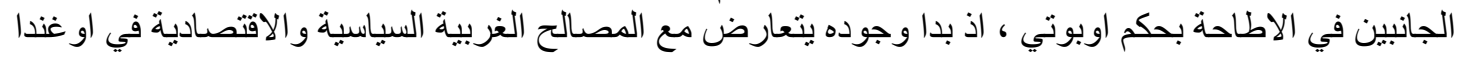

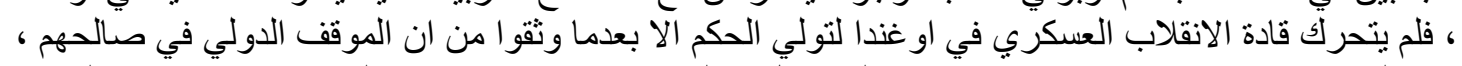

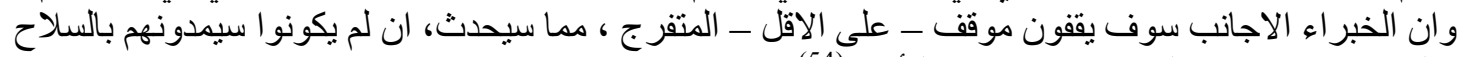

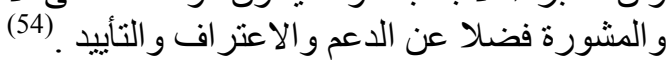

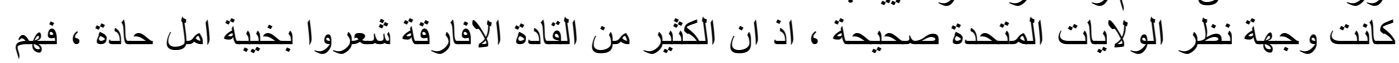

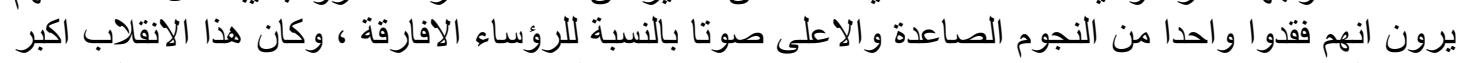

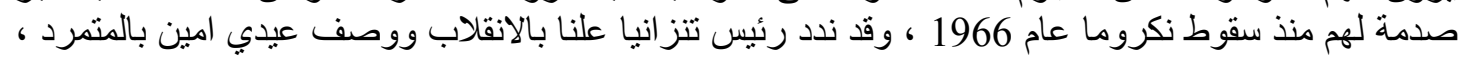

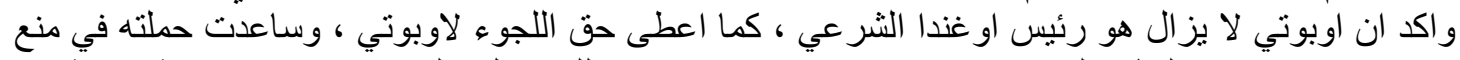

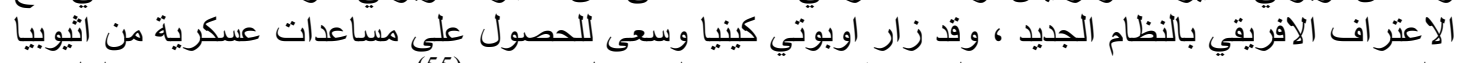

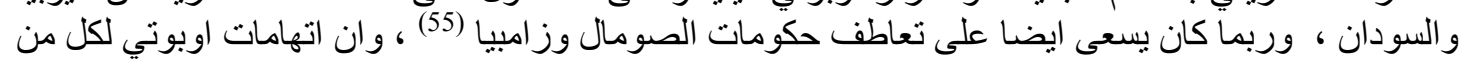




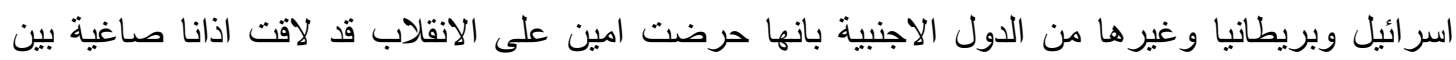

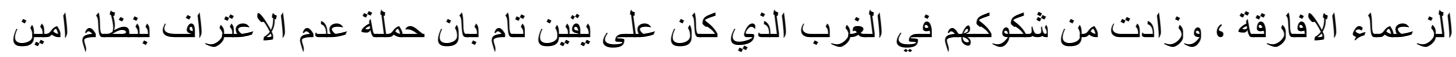

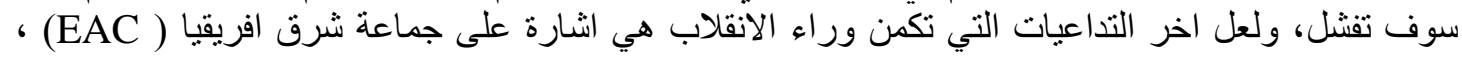

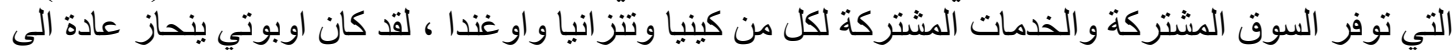

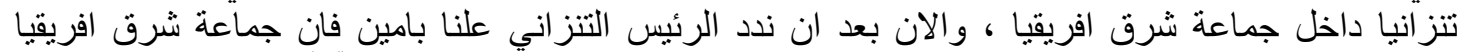

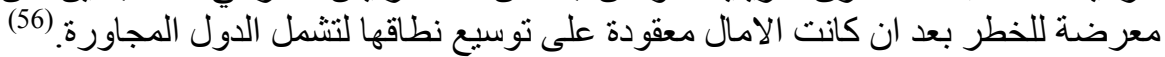

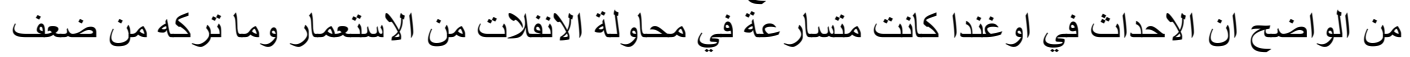

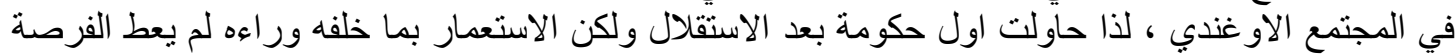

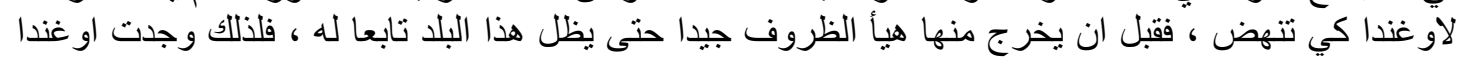

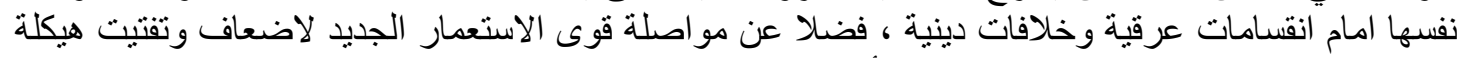

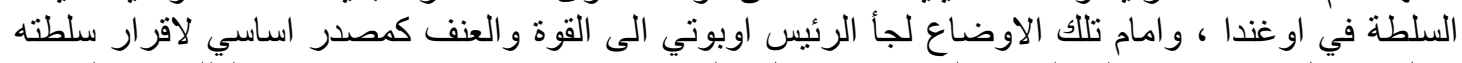

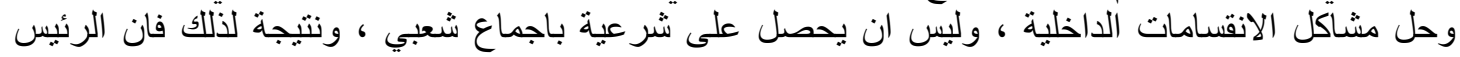

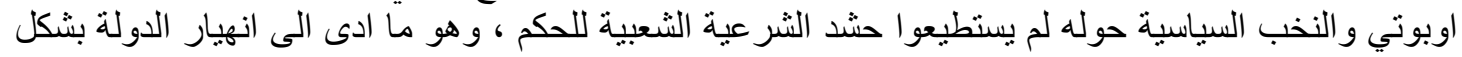
واضح في عهد عيدي امين بعد ذلك.

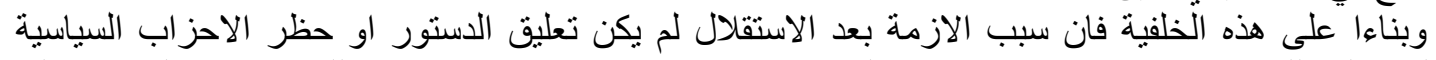

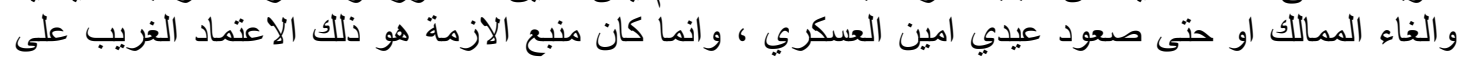

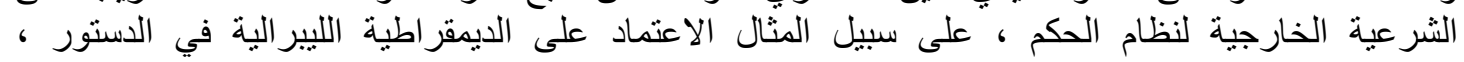

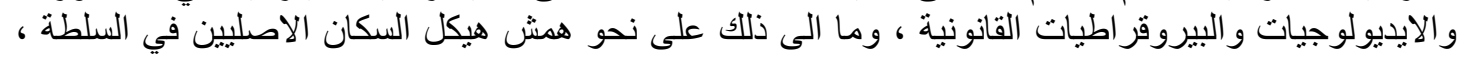

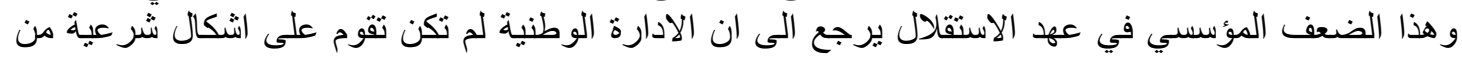

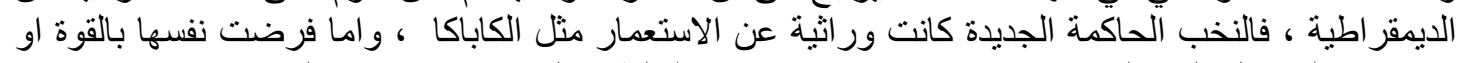

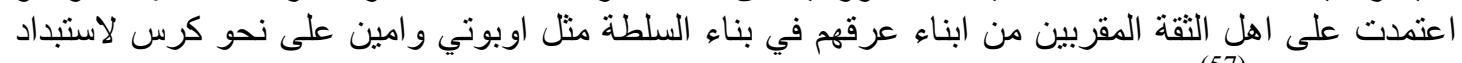

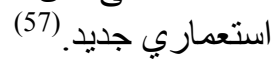

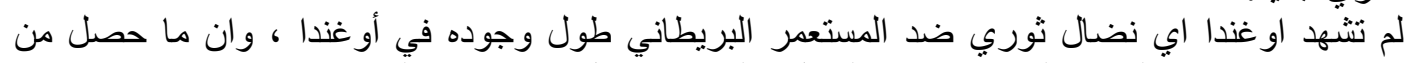

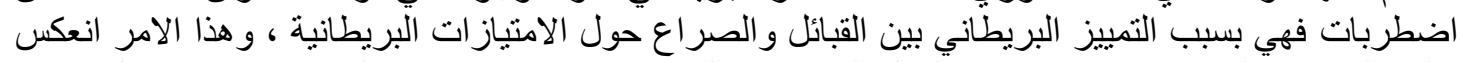

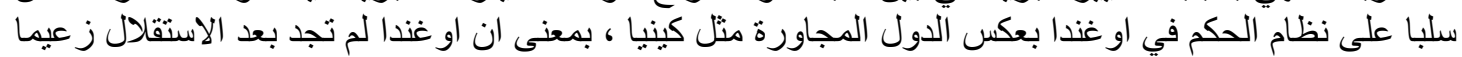

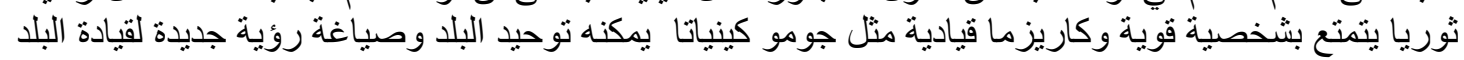

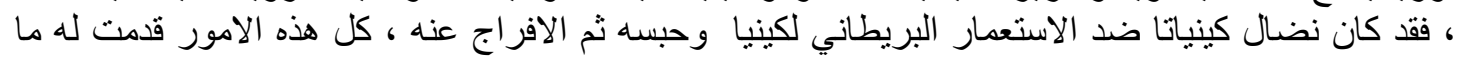

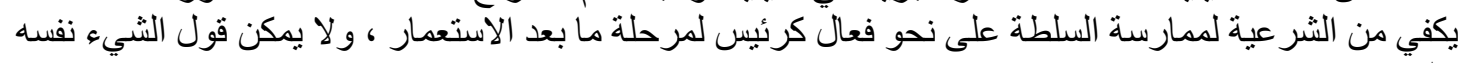

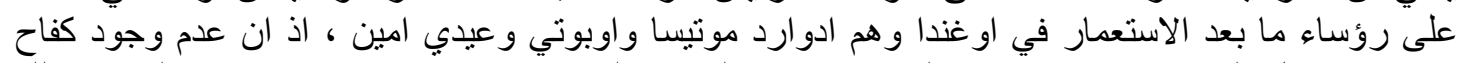

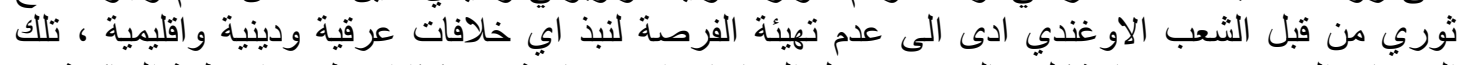

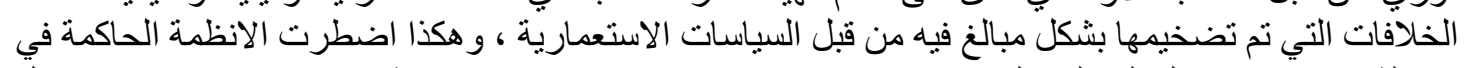

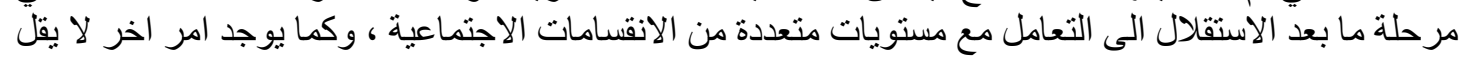

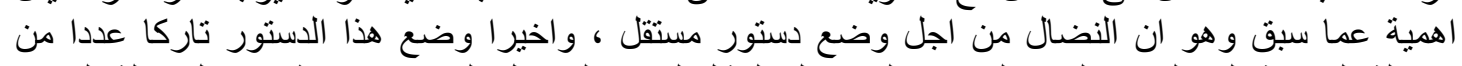

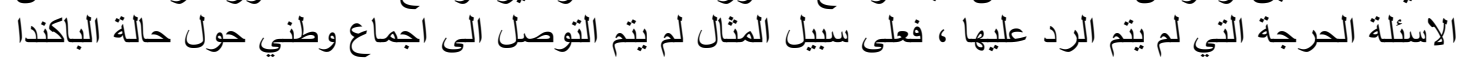

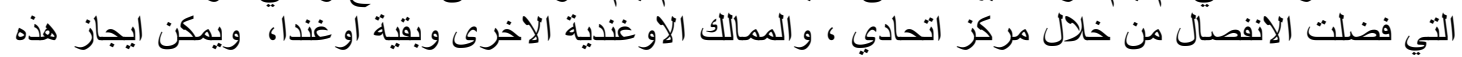

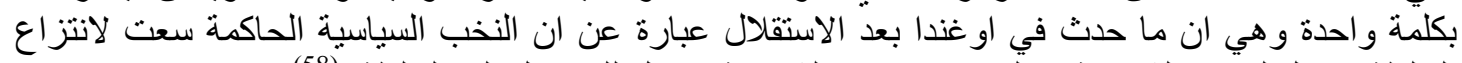

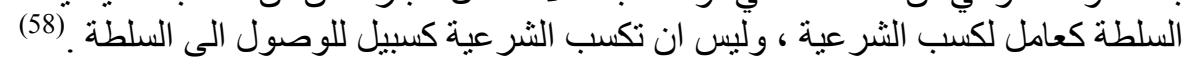

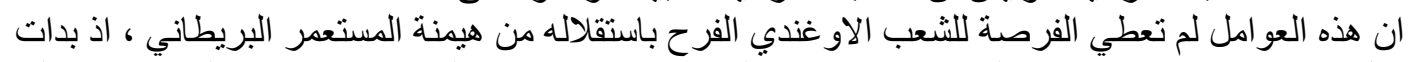

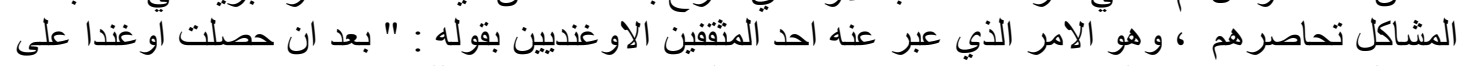

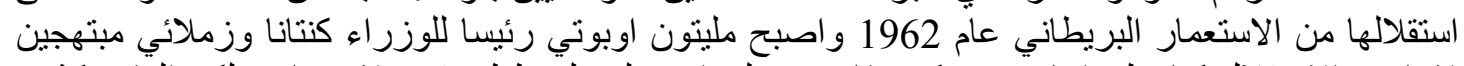

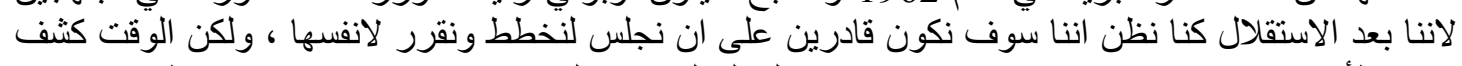

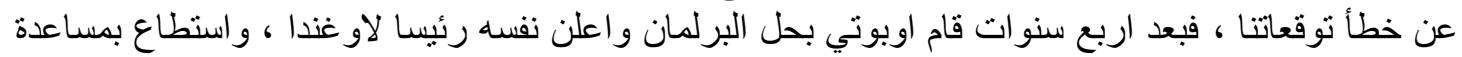

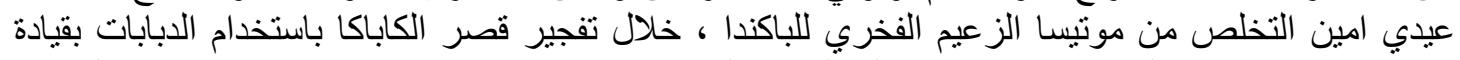

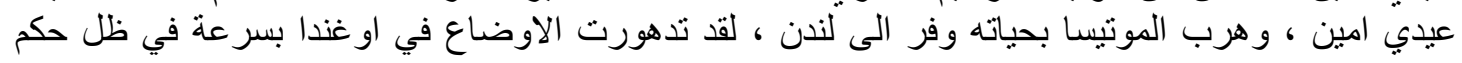


العدد (16) أكتوبر 2020

Volume (16) October 2020

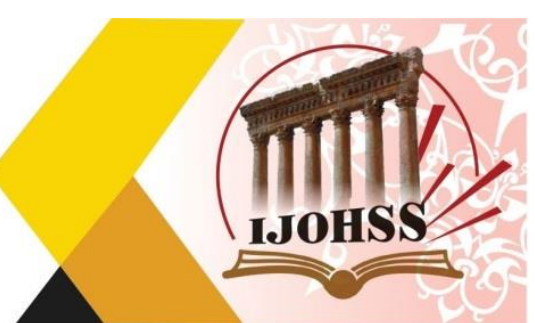

اوبوتي ، حيث حاول عقد جبهات ونوازنات سياسية ، فتخلى عن التزامها بالديمقر اطية ولجأ المئى اسلوب الاستبداد

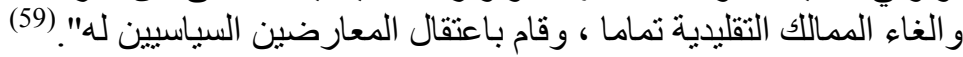

\section{المبحث الثاني : مرحلة الوفاق البريطاني - الاوغندي (كانون الثاني1971 -نهاية تموز}

بعد وصول عيدي امين للحكم بدعم ومساندة بريطانيا ، التي كانت تخطط لبدء صفحة جديدة لها في او غندا ،

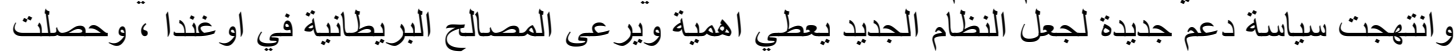

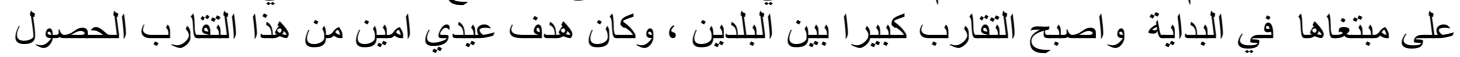

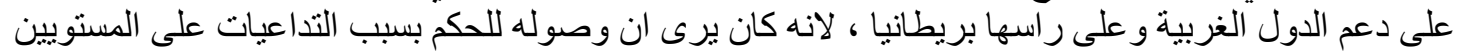

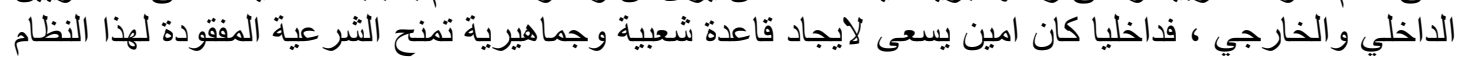

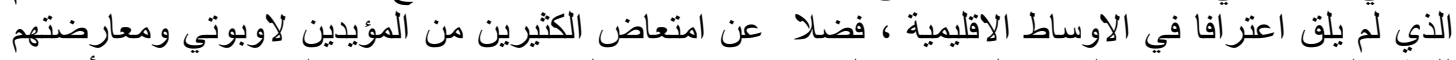

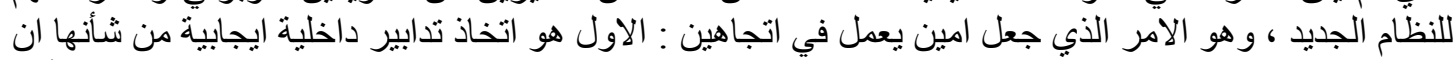

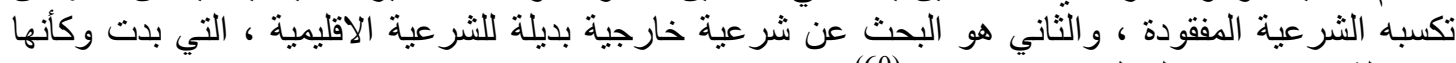

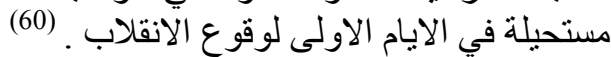

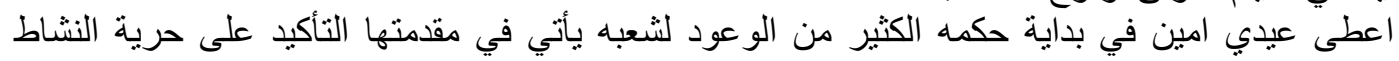

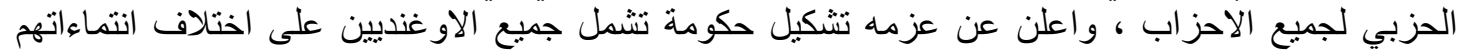

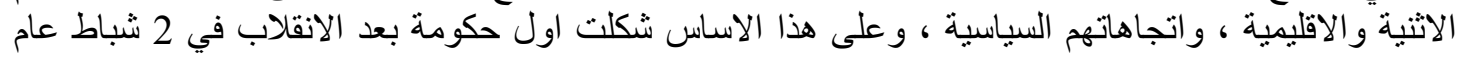

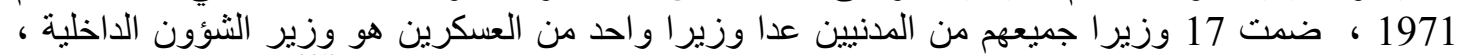

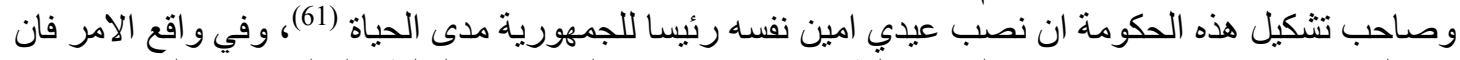

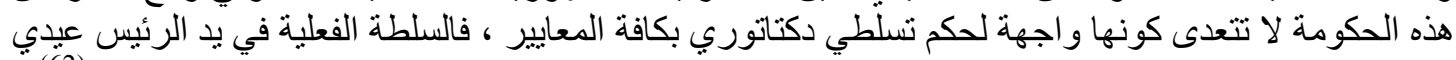

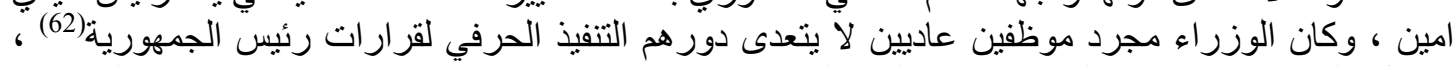

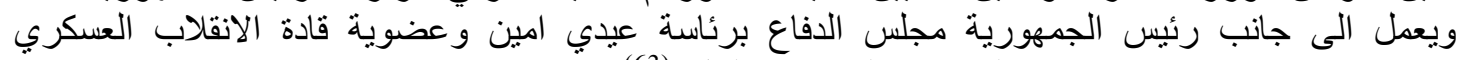

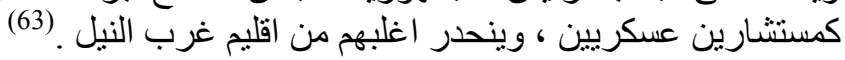

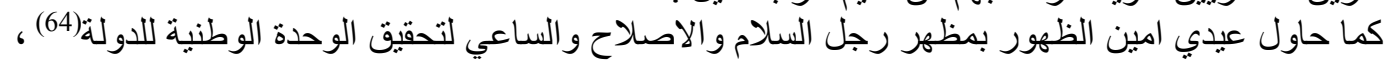

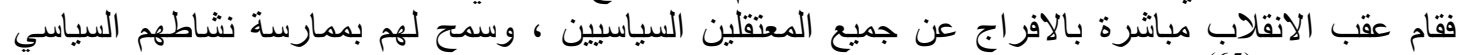

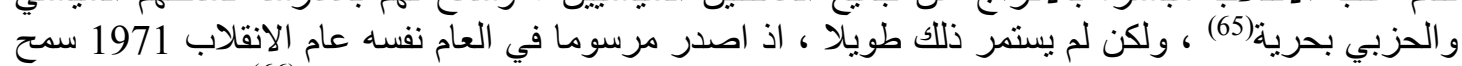

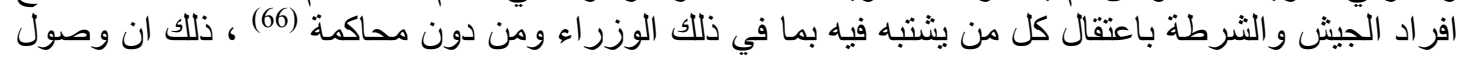

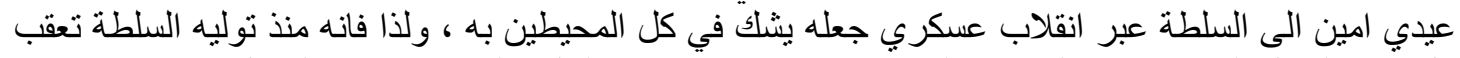

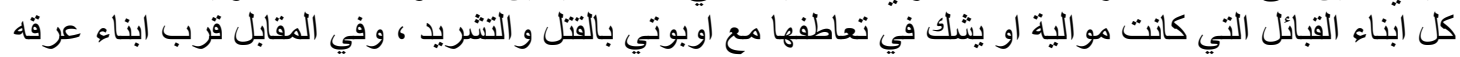

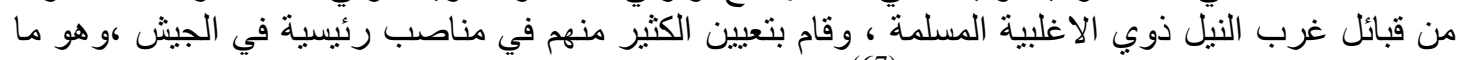

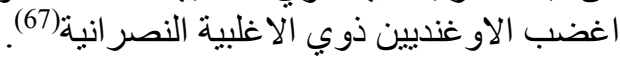

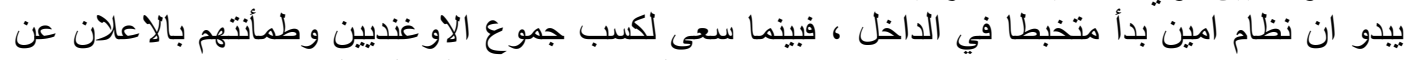

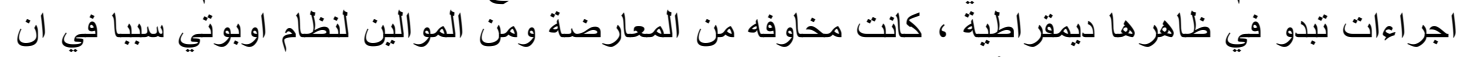

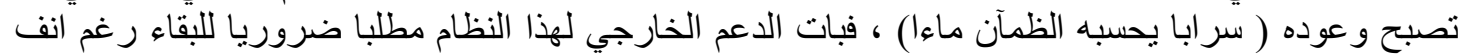

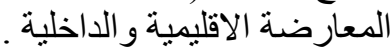

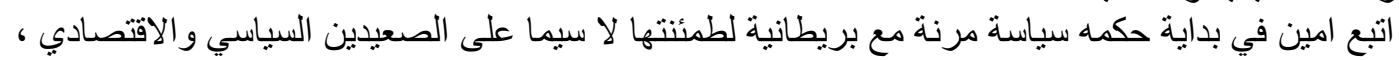

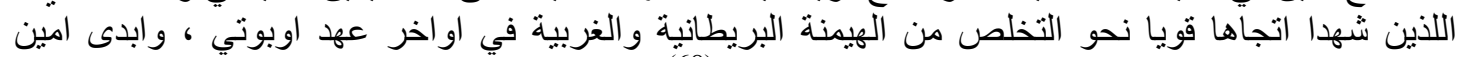

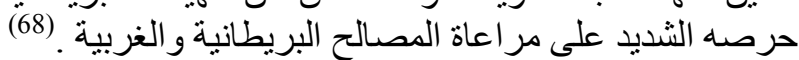

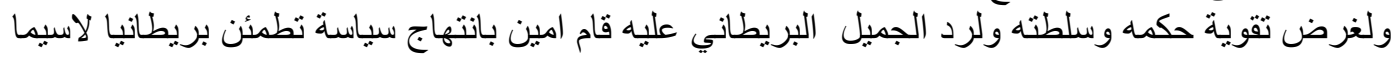

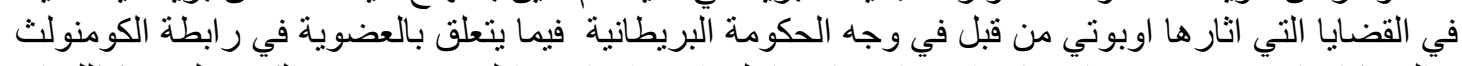

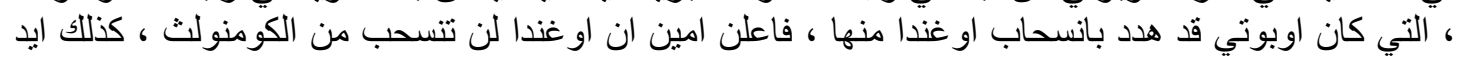

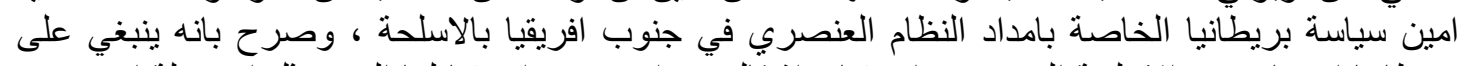

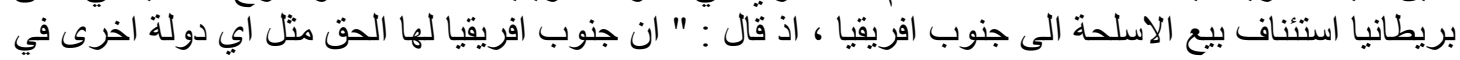


تأمين نفسها وبالتالي من حقها شر اء الاسلحة من بريطانيا"(69) ، وفيما يبدو ان عيدي امين كان يسعى لان ان تمده

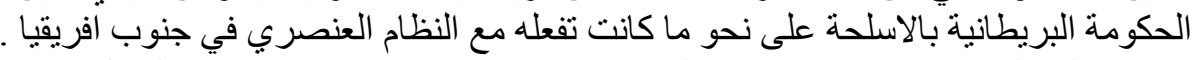

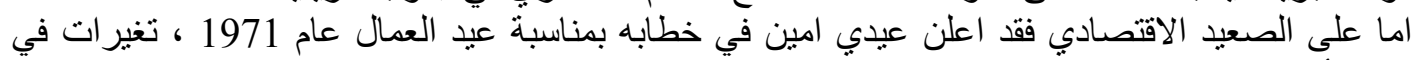

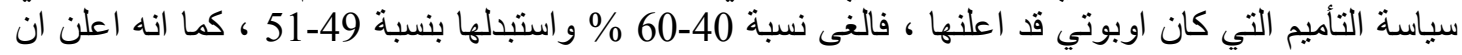

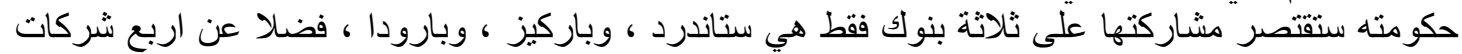

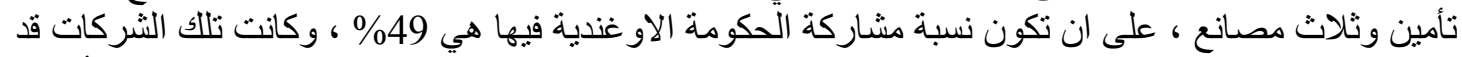

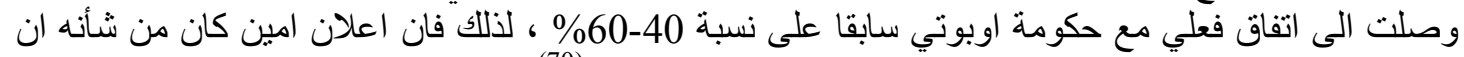

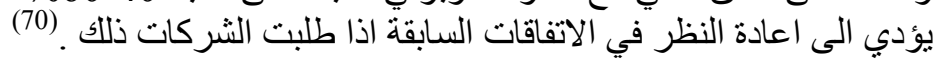

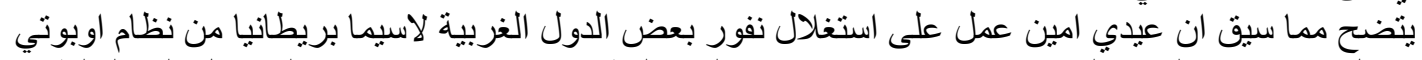

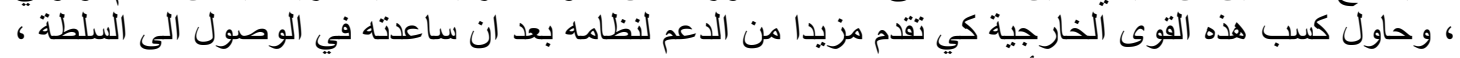

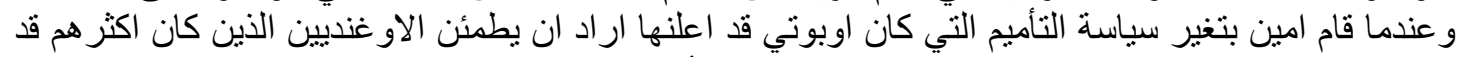

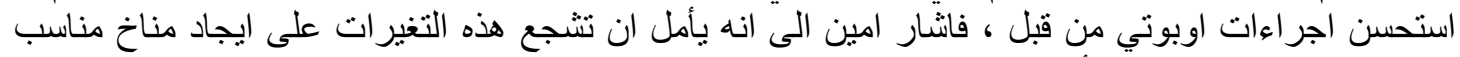

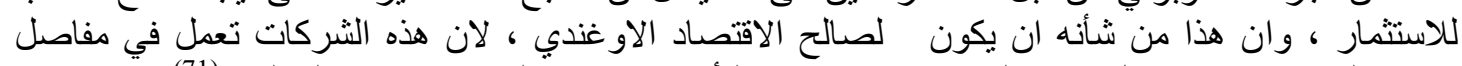

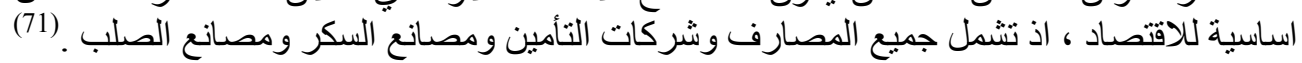

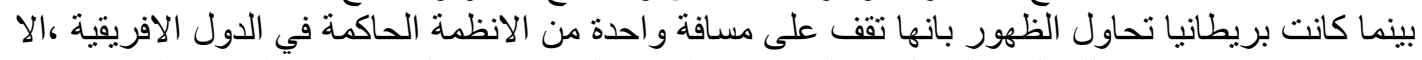

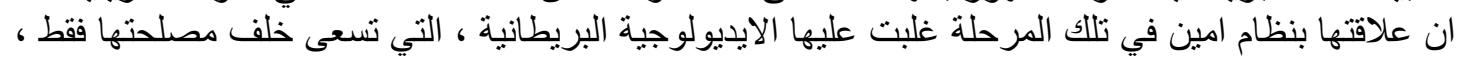

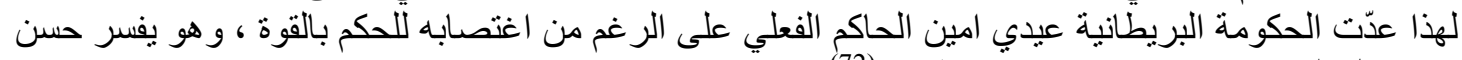

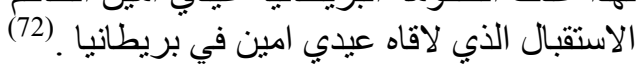

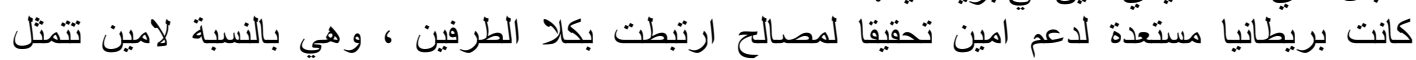

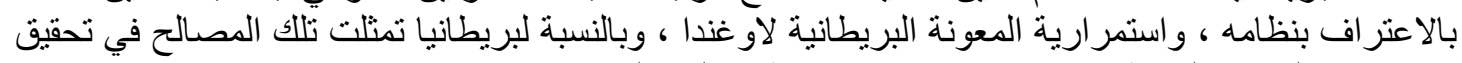

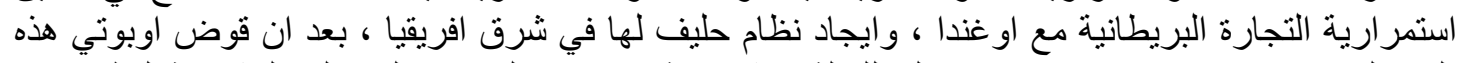

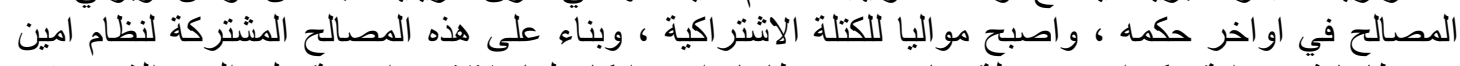

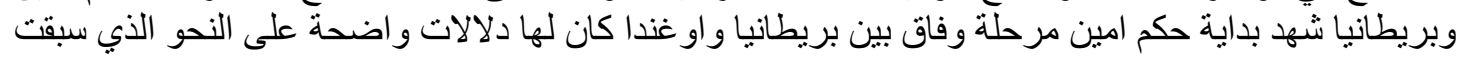

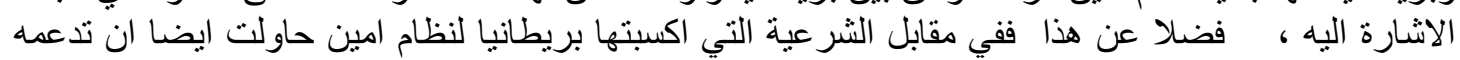

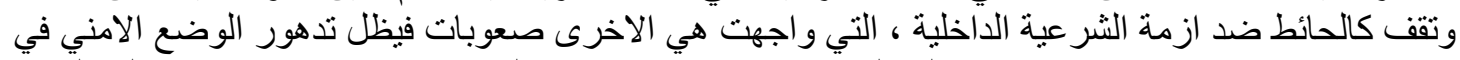

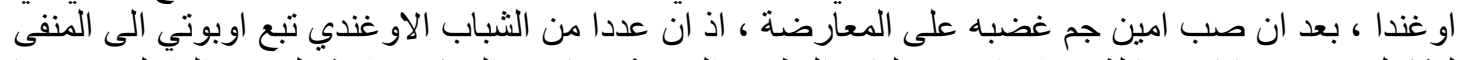

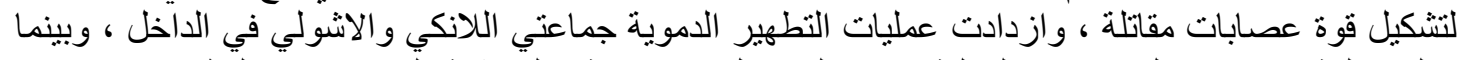

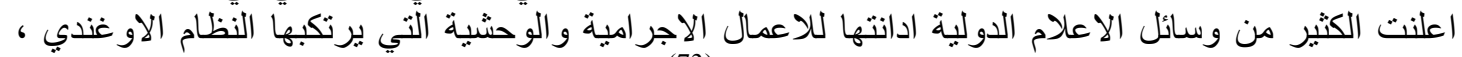

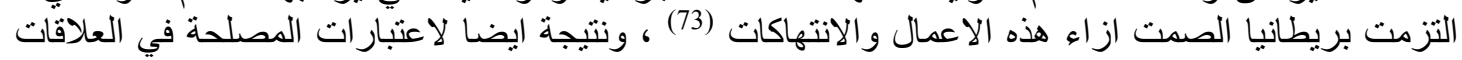

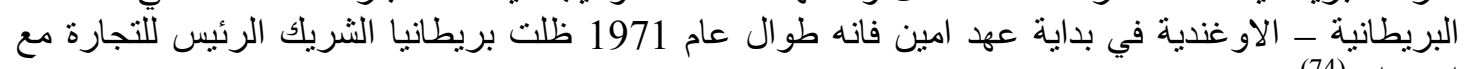

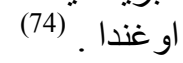

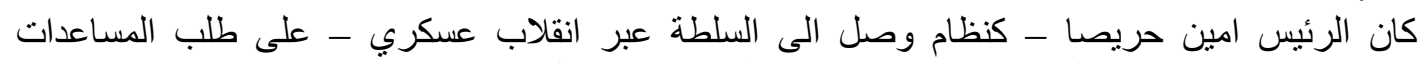

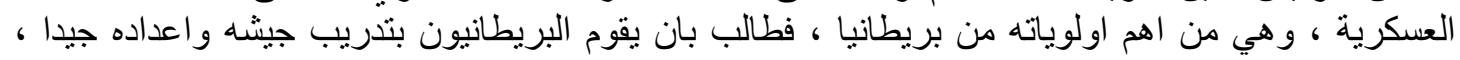

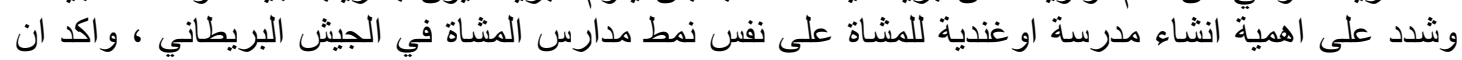

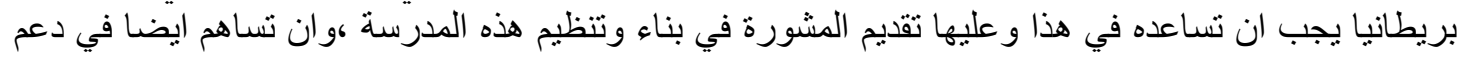

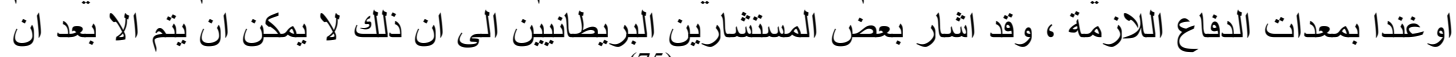

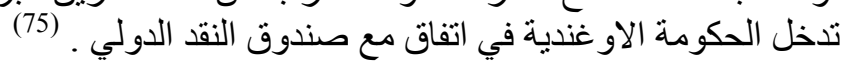

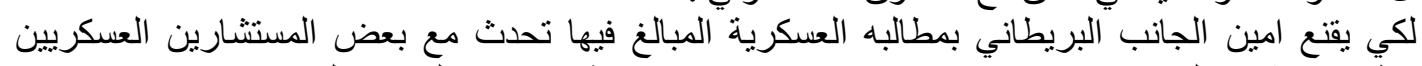

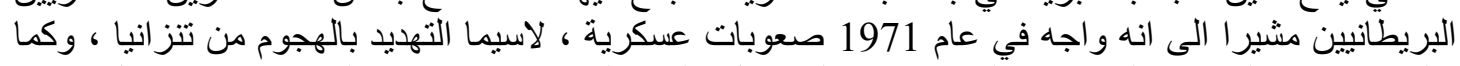

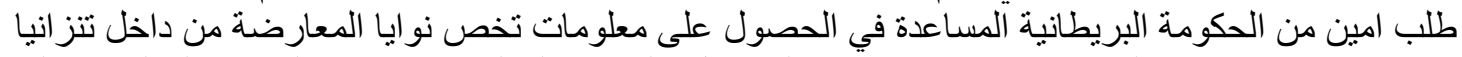

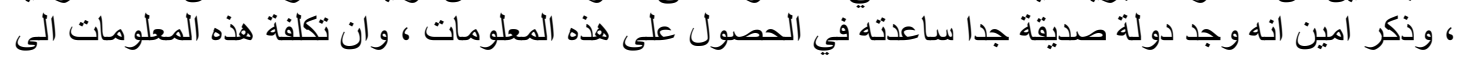

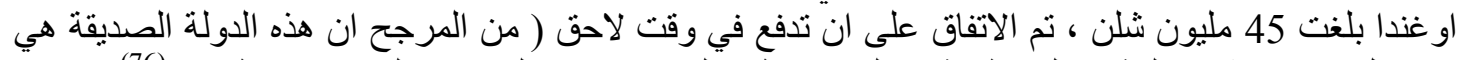

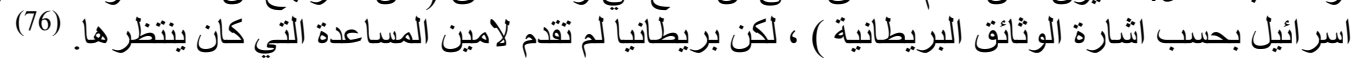


اذا كانت بريطانيا لم تقدم الدعم العسكري اللازم على النحو الذي اراده امين من حيث امداده بالاسلحة

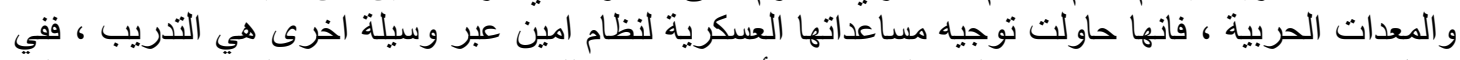

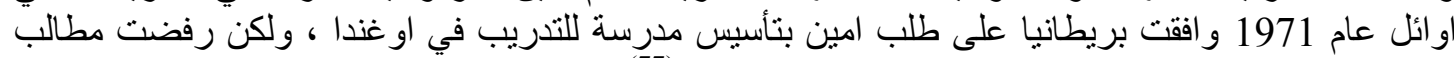

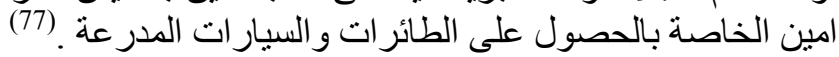

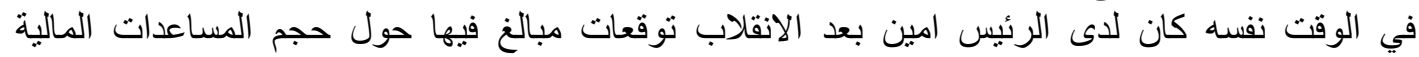

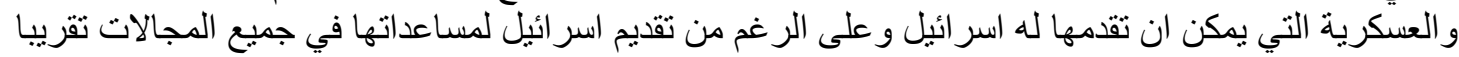

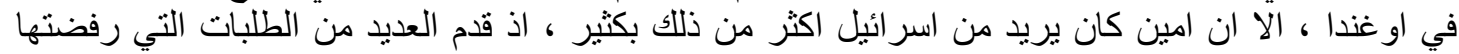

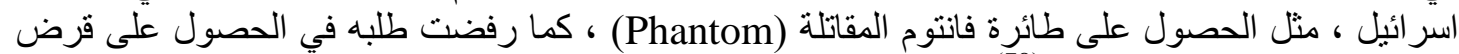

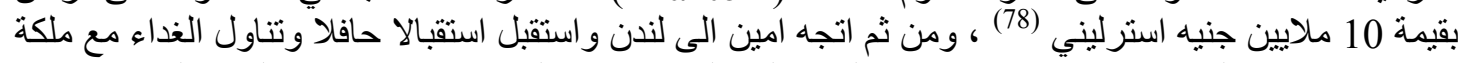

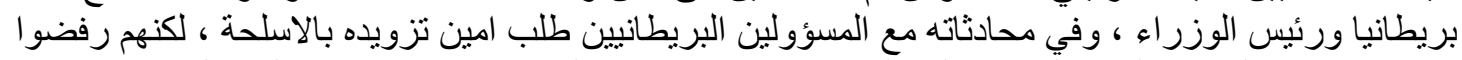

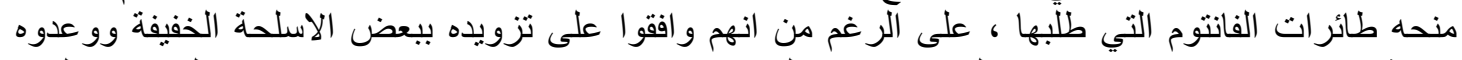

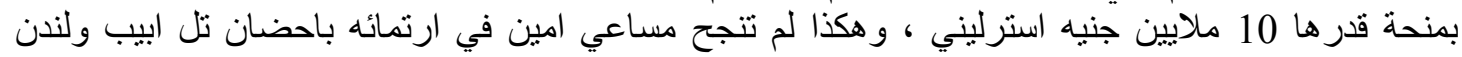

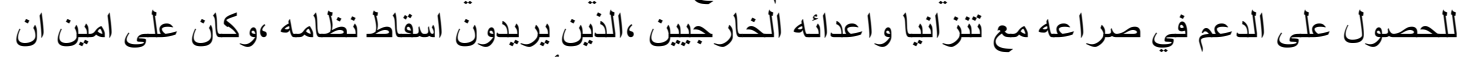

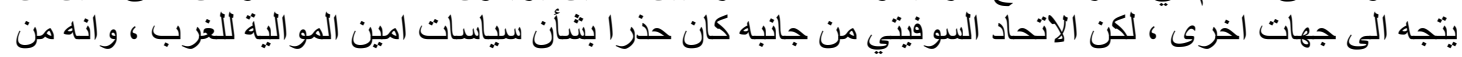

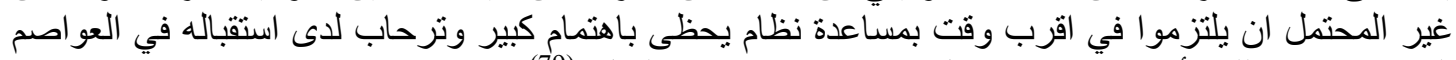

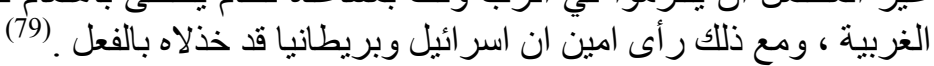

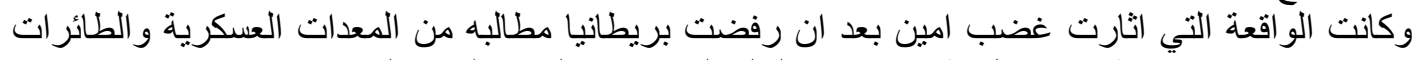

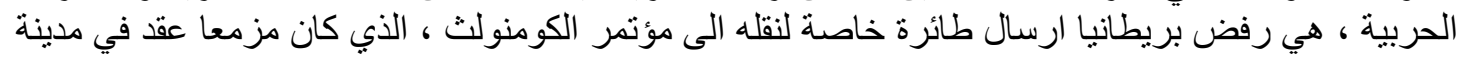

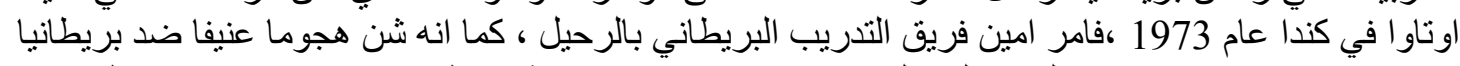

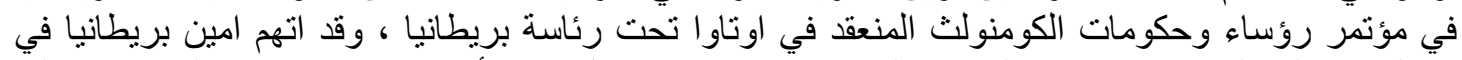

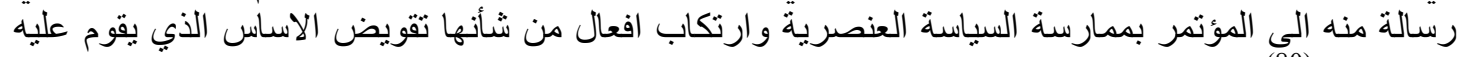

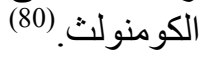

وفضلا عن هذا طالبت بريطانيا عيدي امين بالحد من الانفاق العسكري بدلا من امداده بالمساعدات العسكرية

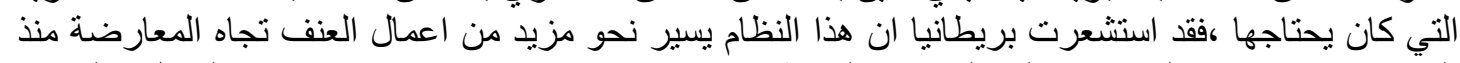

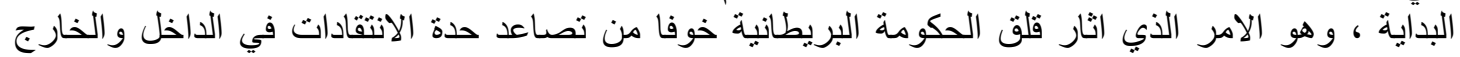

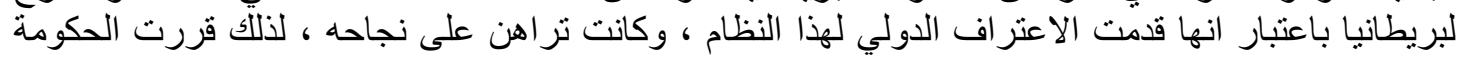

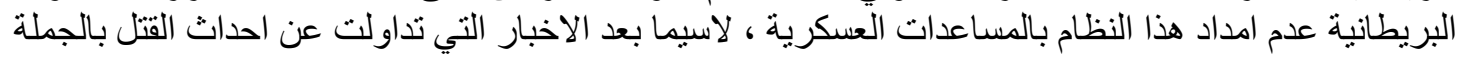

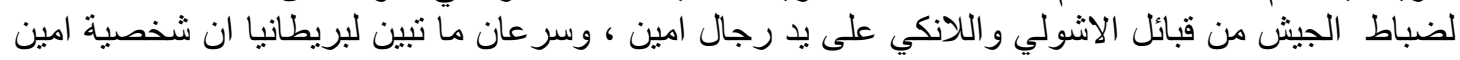

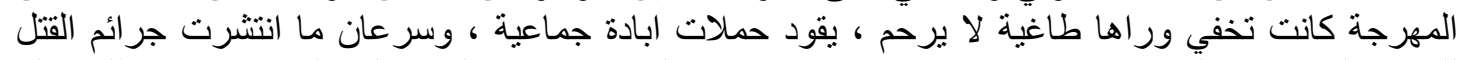

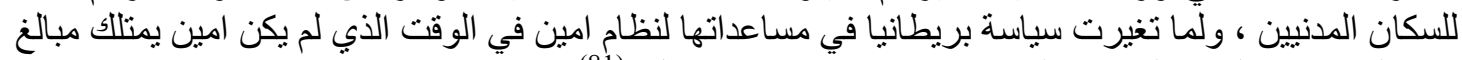

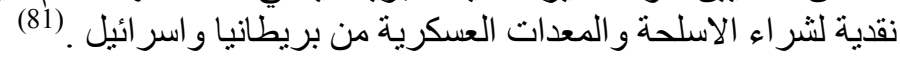

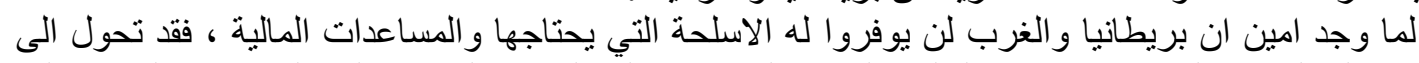

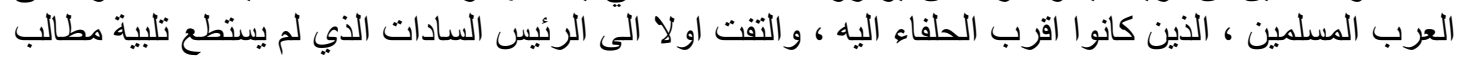

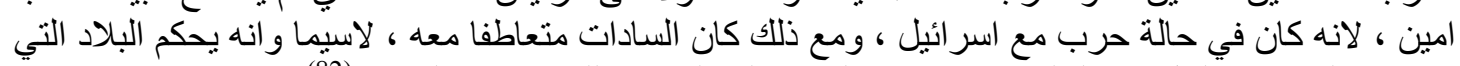

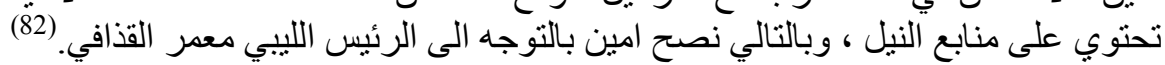

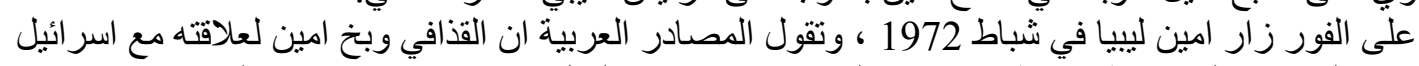

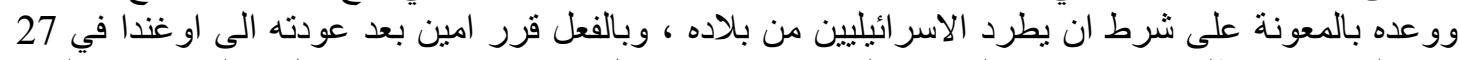

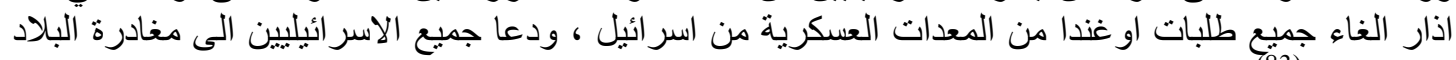
على الفور . (83) على هذا برى الباحث ان المساعدة الدفاعية لها دور كبير ومؤثر في علاقة عيدي امين ببريطانيا ، فيينما كان النهان

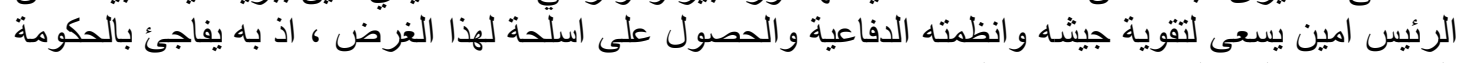

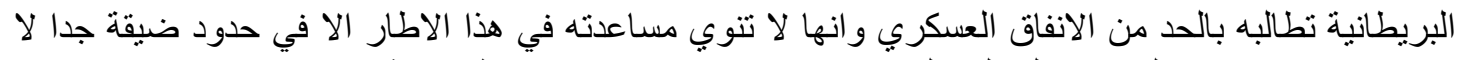

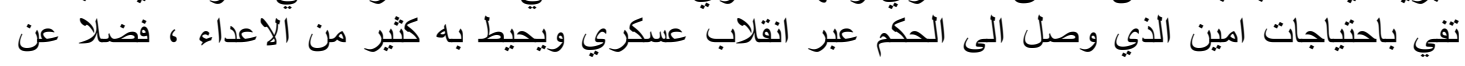




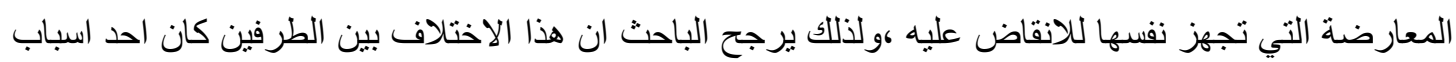

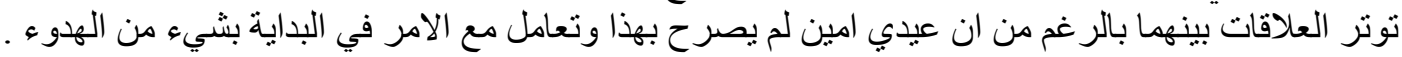

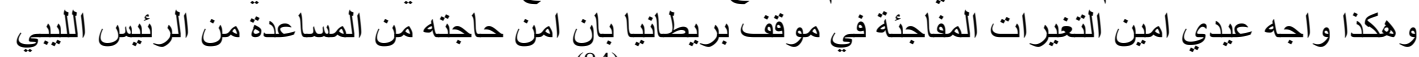

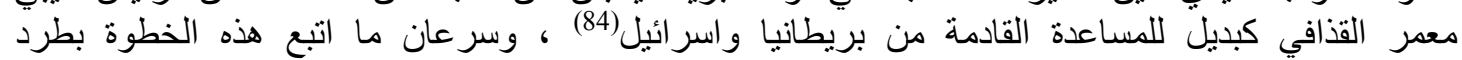

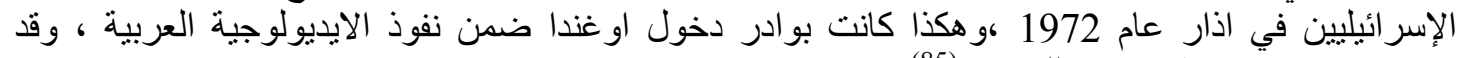

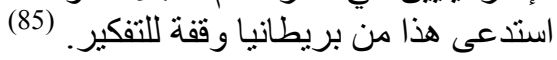

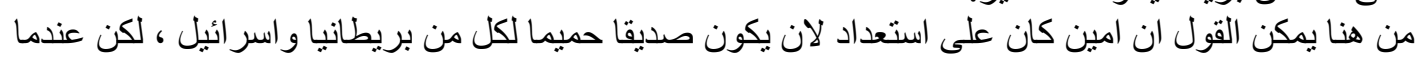

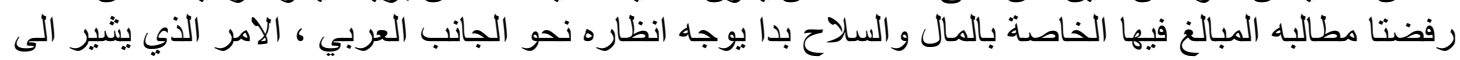

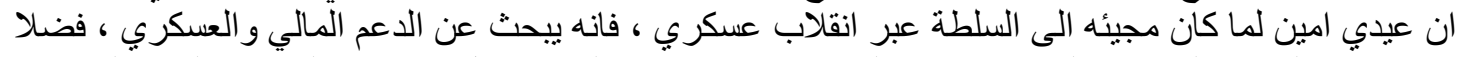

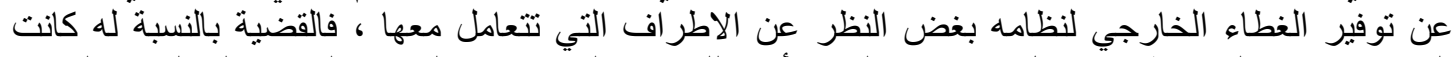

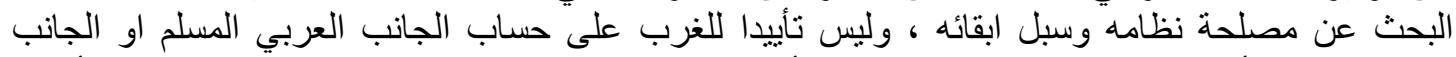

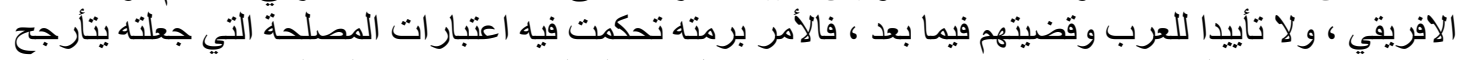

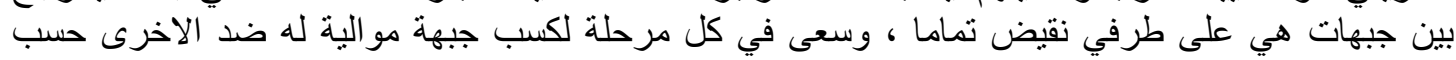

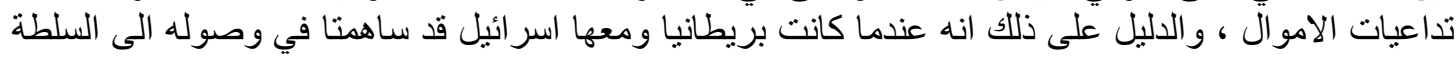

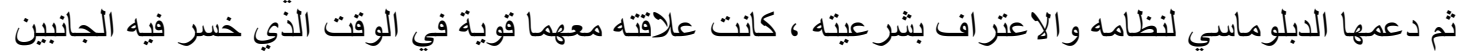

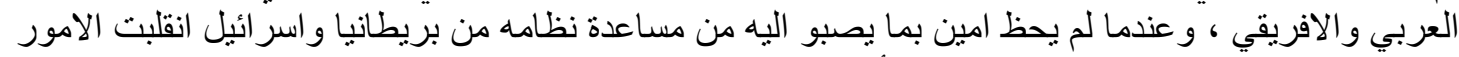

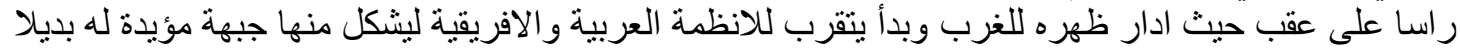

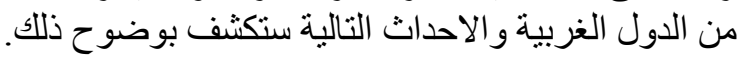

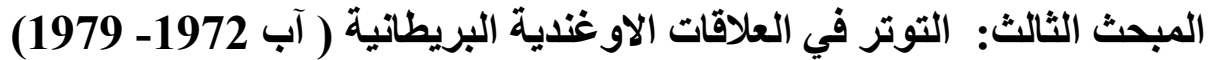

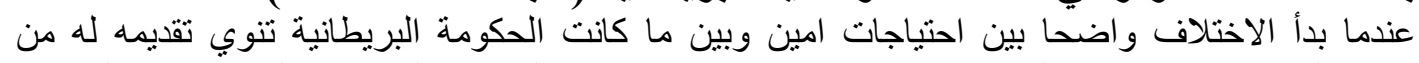

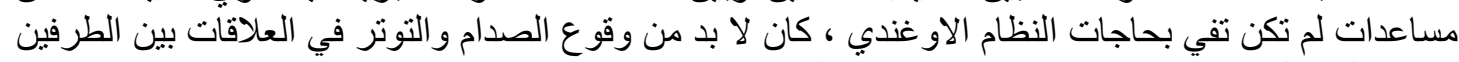

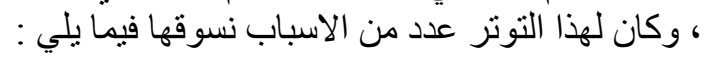

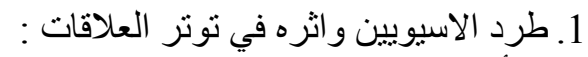

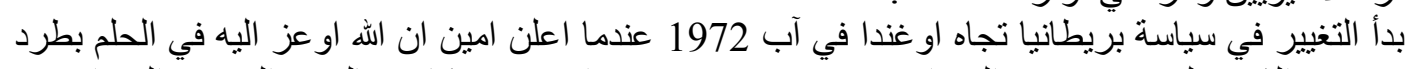

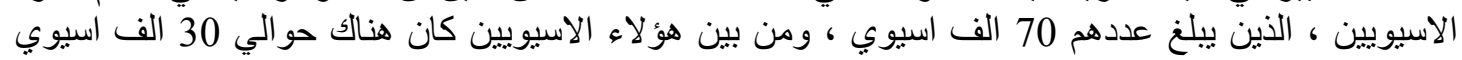

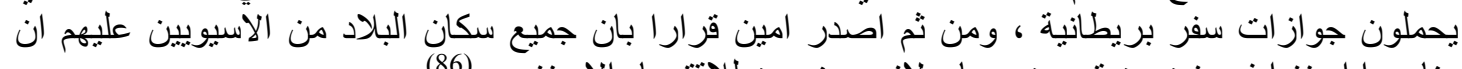

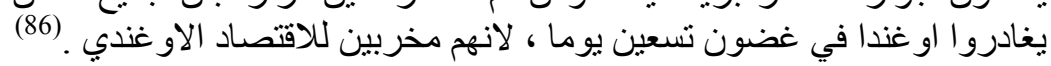

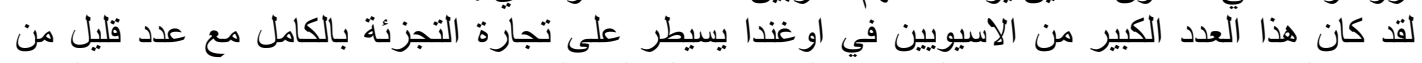

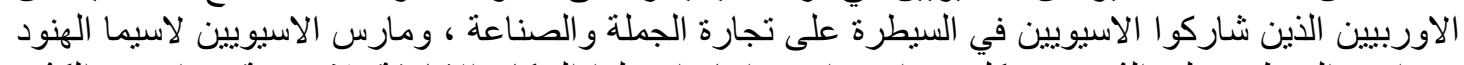

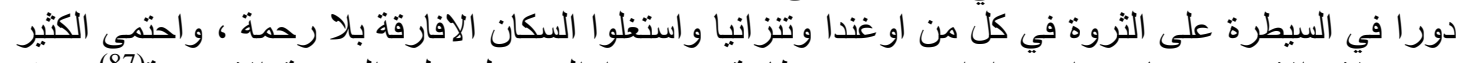

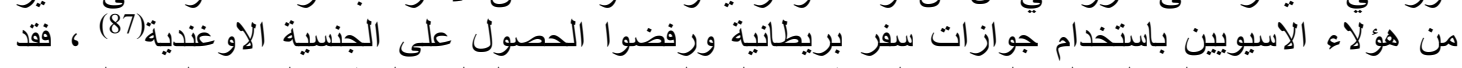

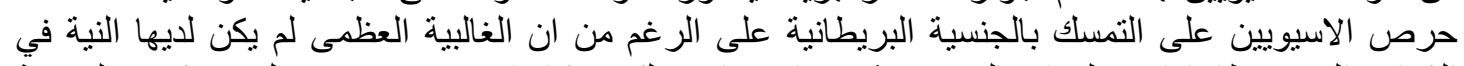

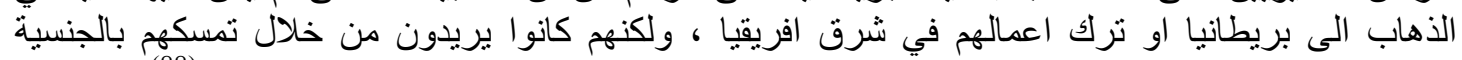

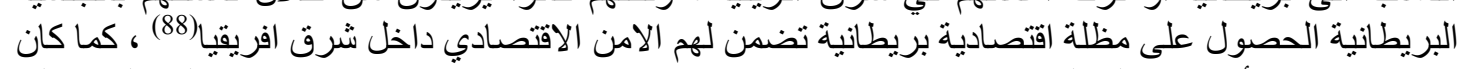

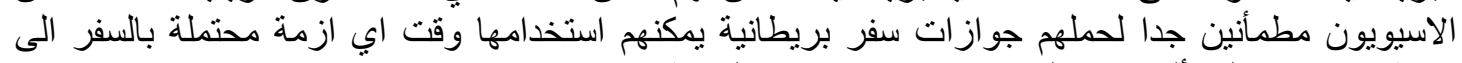

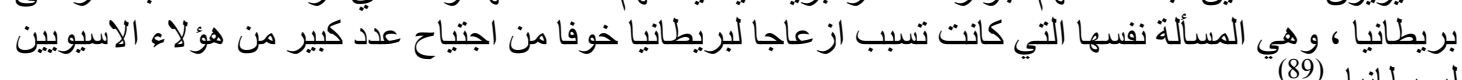

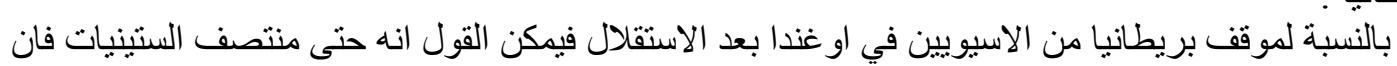

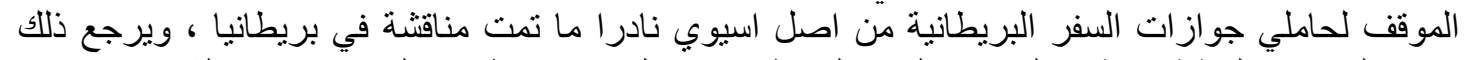

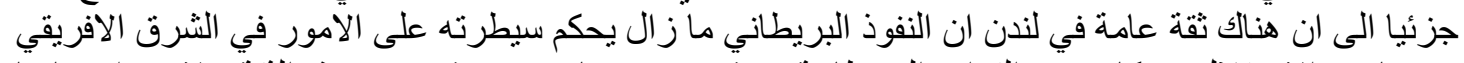

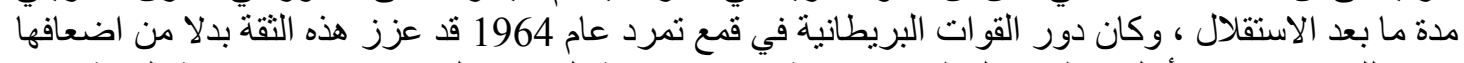

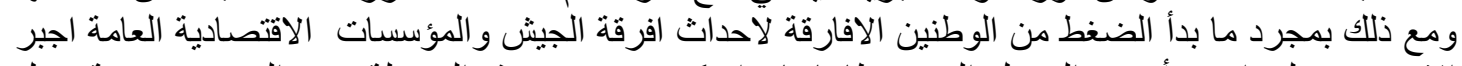

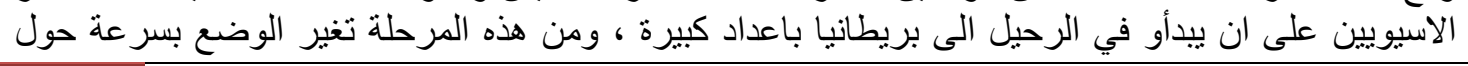


النقاش في بريطانيا ، و اصبحت هجرة الملونين هي النقطة المحورية لنقاش الاحز اب و السياسيين في بريطانيا ،

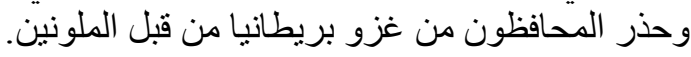

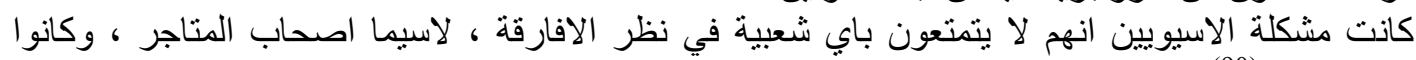

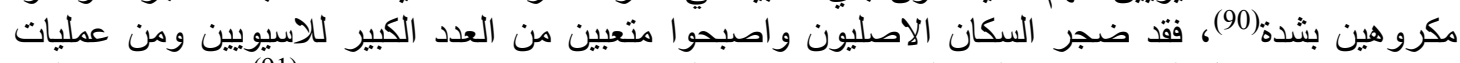

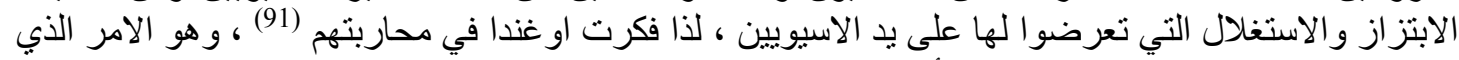

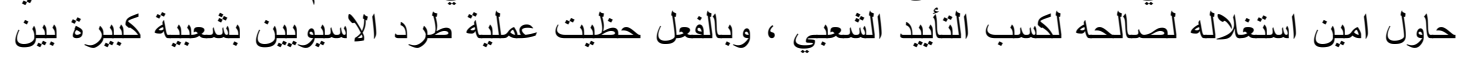

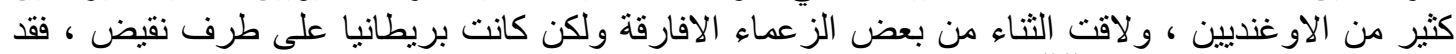

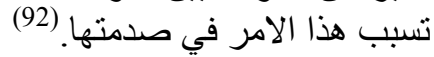

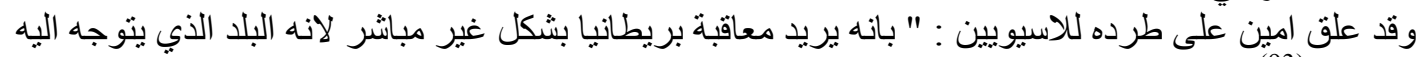

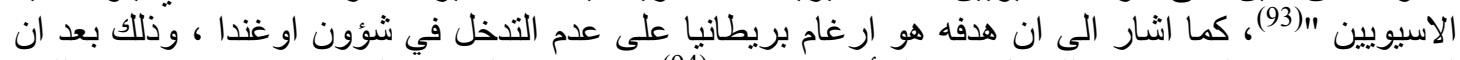

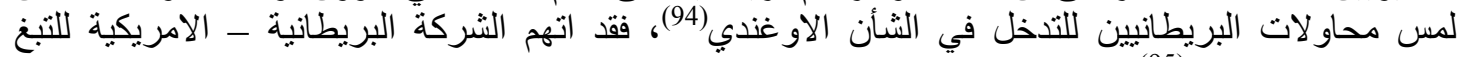

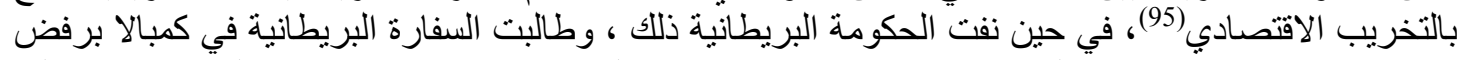

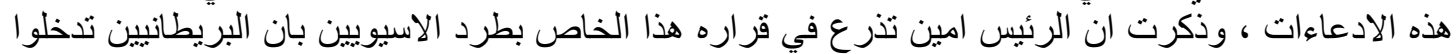

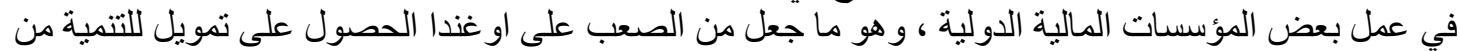

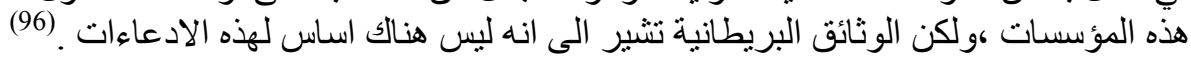

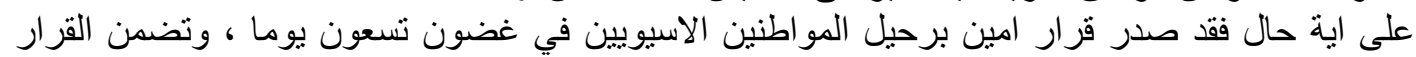

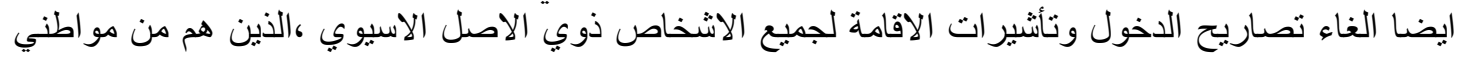

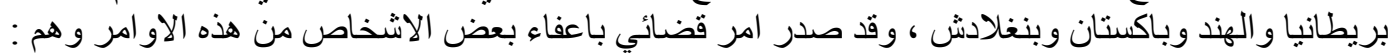

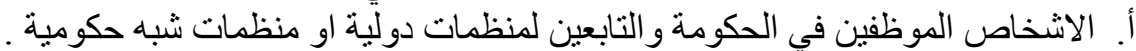

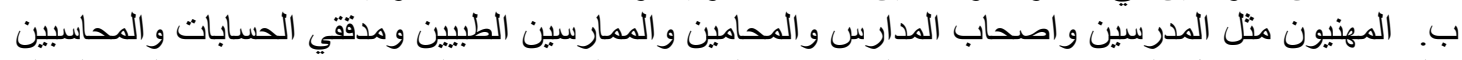

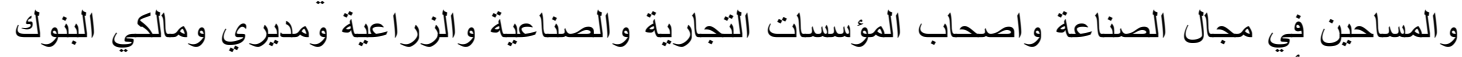
وشركات التأمين.

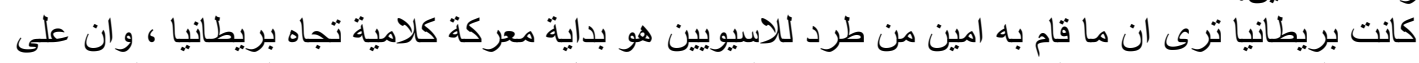

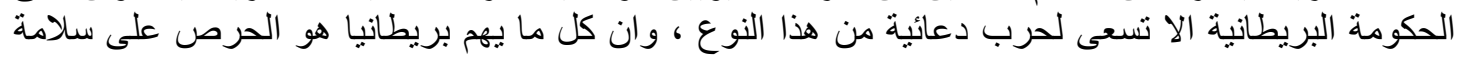

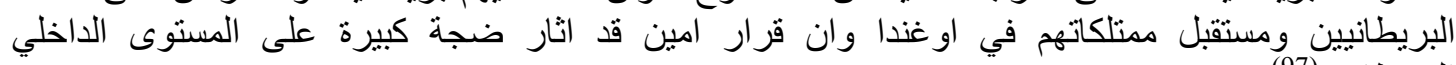
البريطاني. (97)

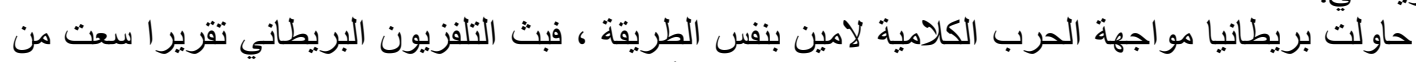

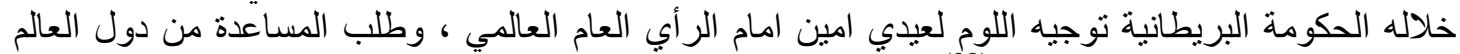
للمساهمة في اعادة توطين البربطانية توجيه الاسيوبين(98).

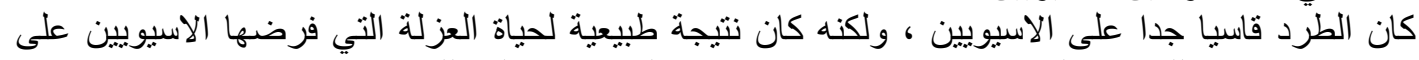

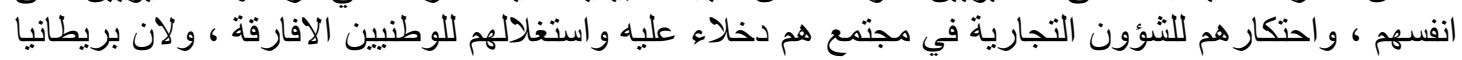

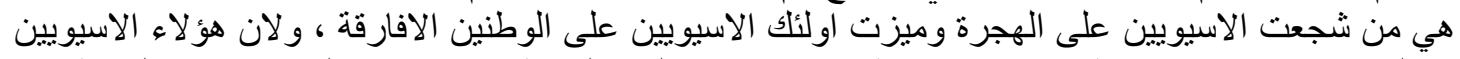

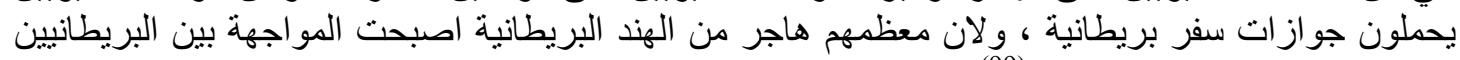

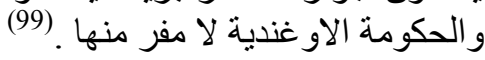

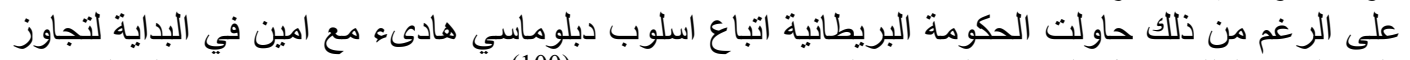

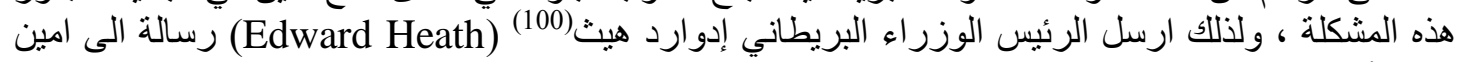

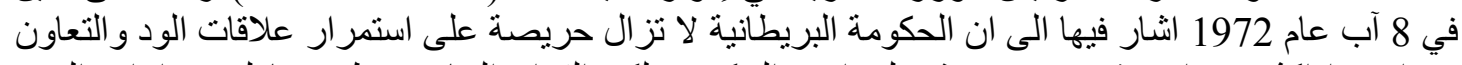

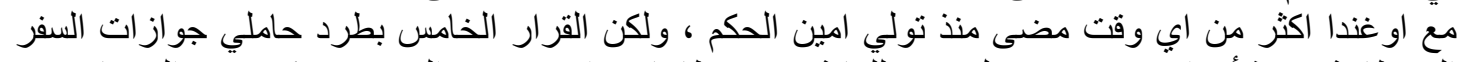

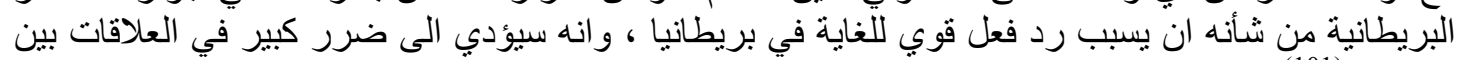

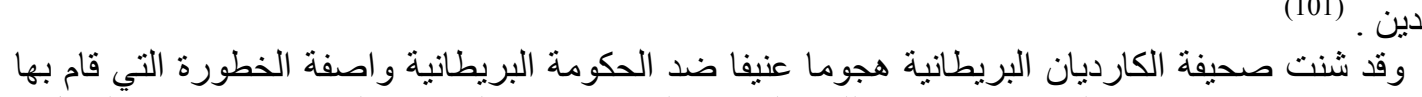

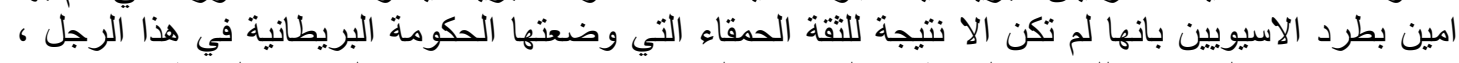

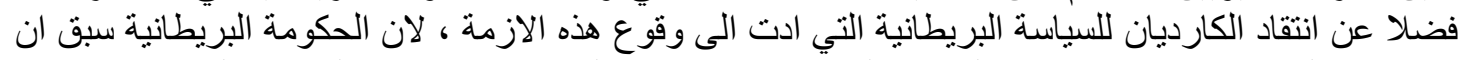

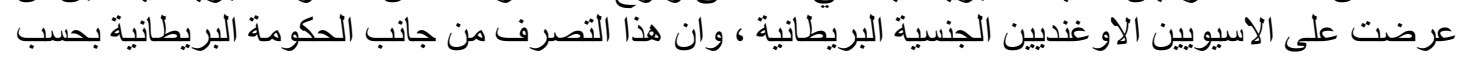




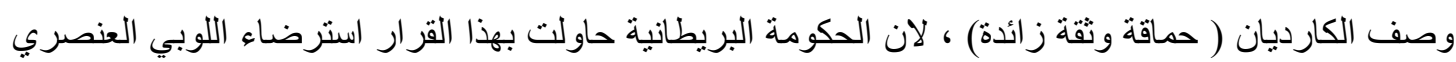

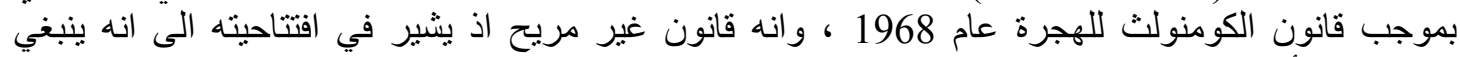

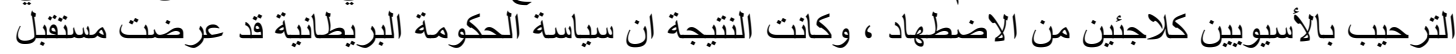

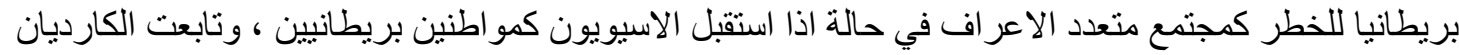

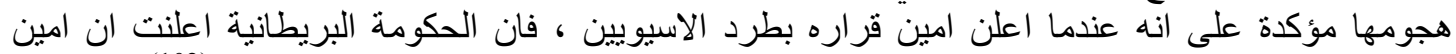

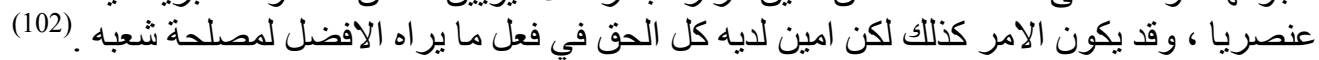

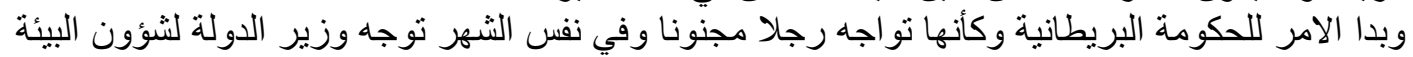

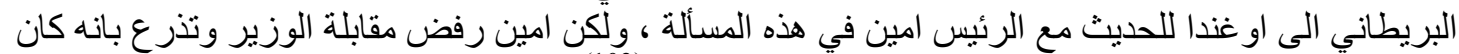

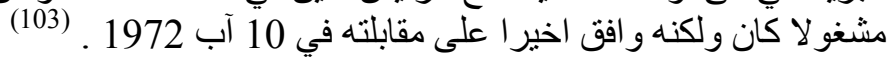

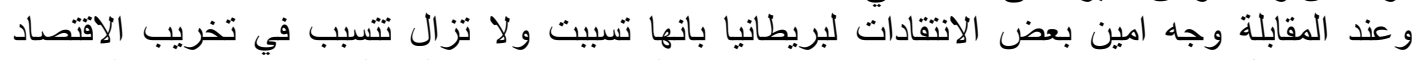

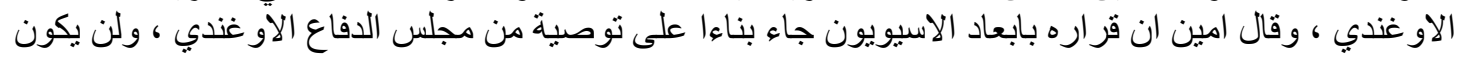

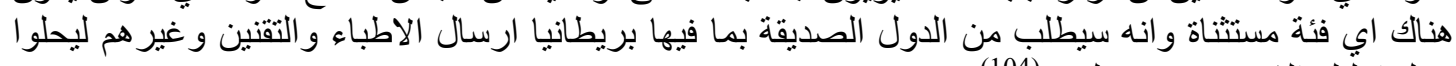

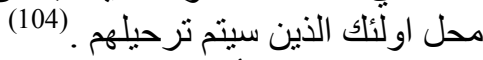

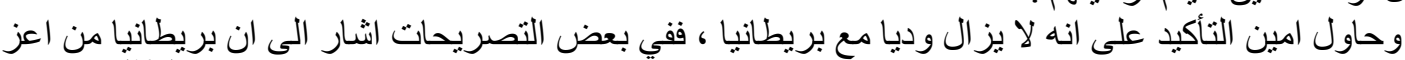

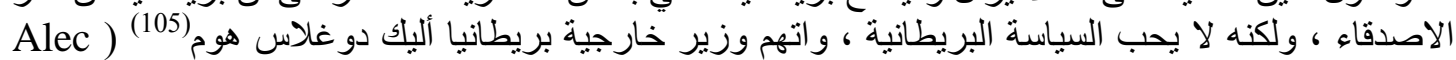

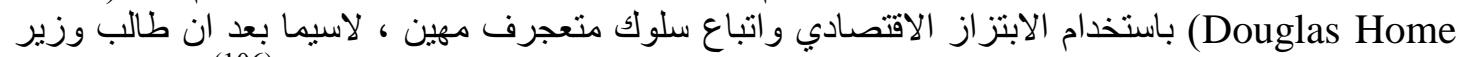

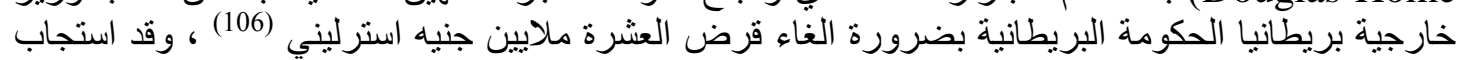

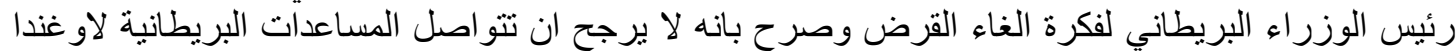

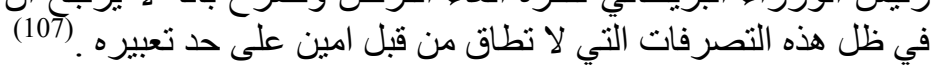

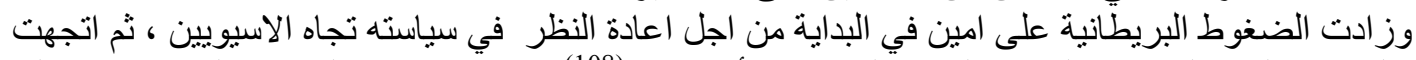

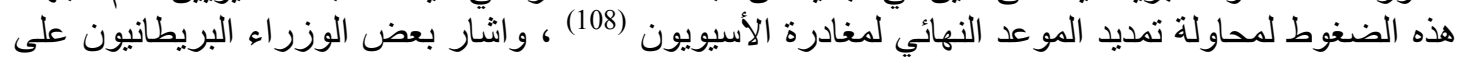

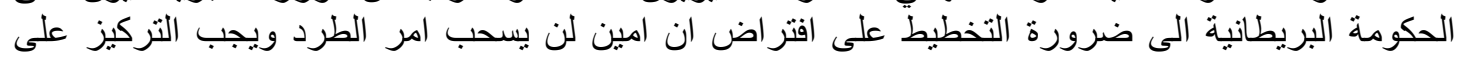

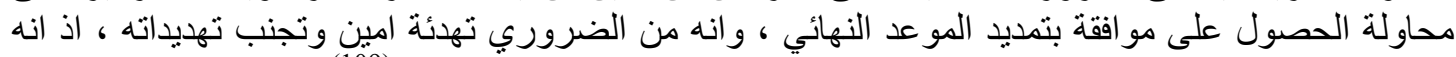

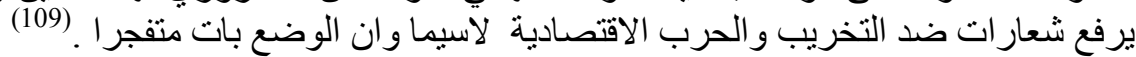

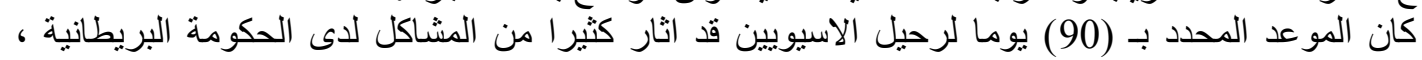

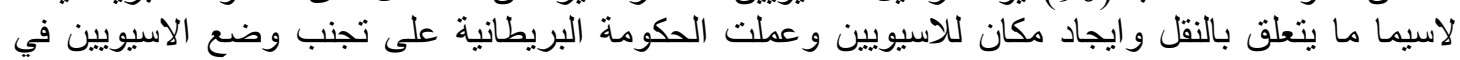

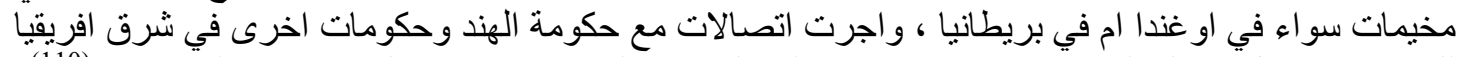

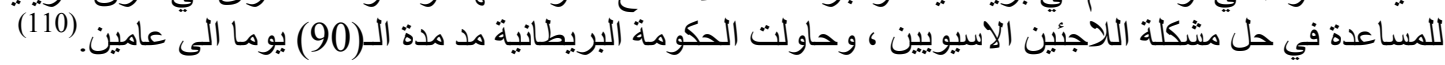

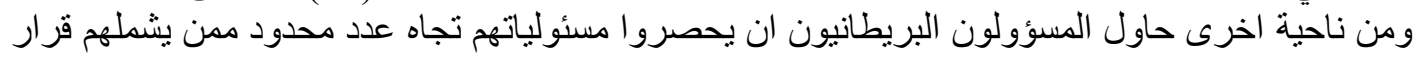

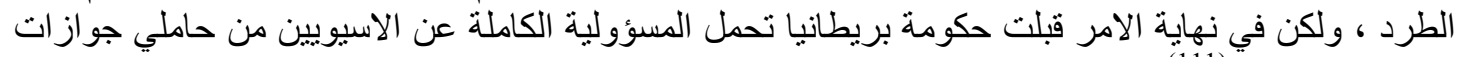

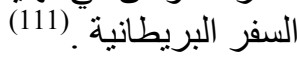

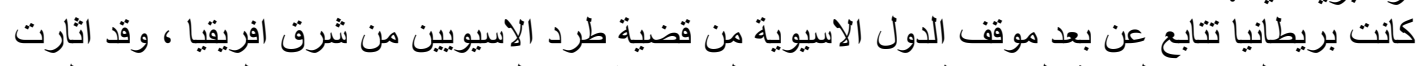

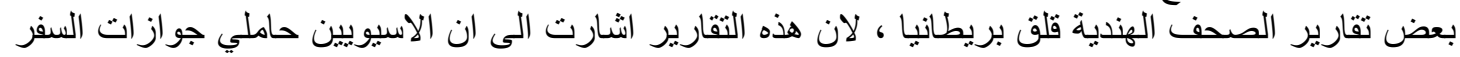

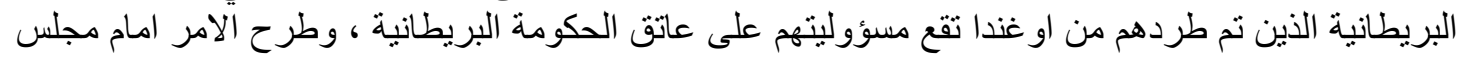

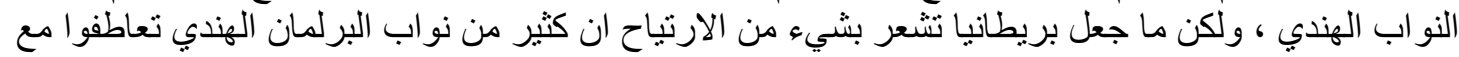

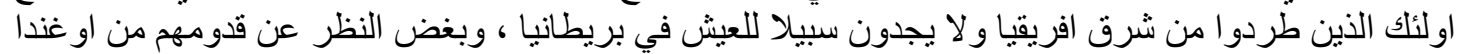

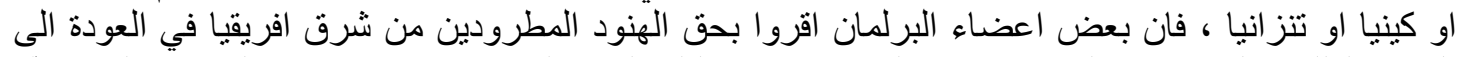

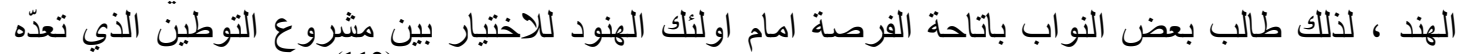

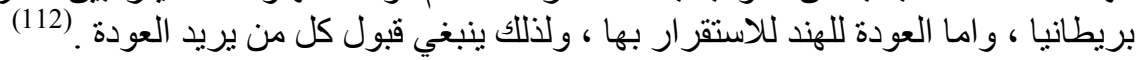

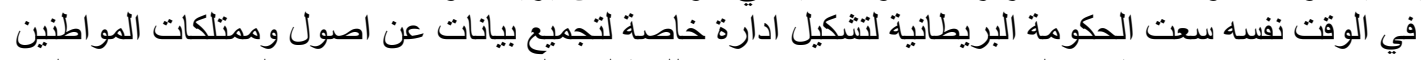

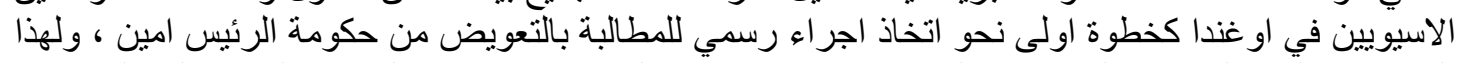

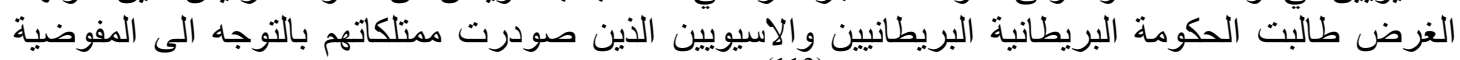

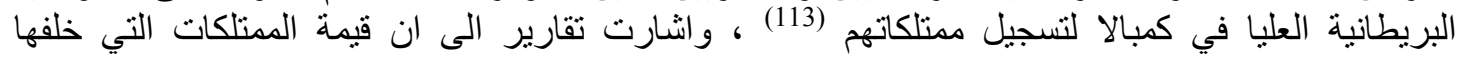


المواطنون البريطانيون الذين طردوا من او غندا غير معروفة على وجه الدقة ، ولكن تفاوتت التقديرات ما بين

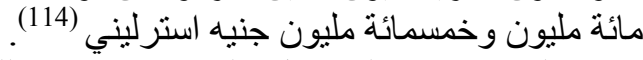

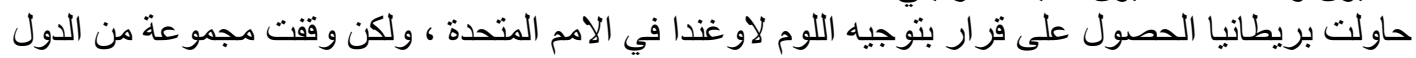

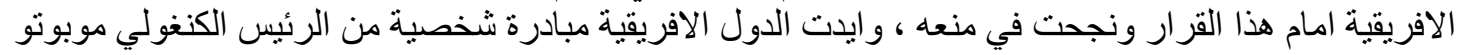

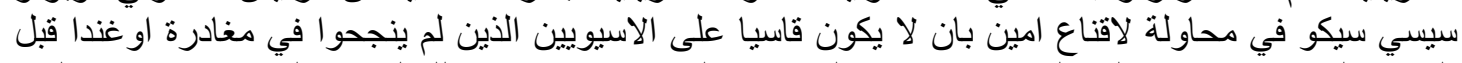

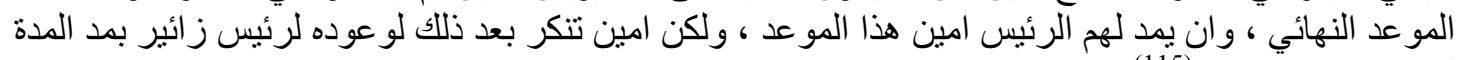

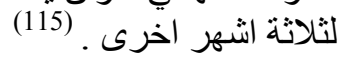

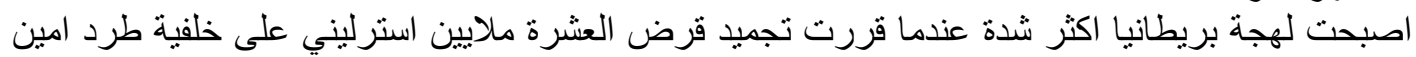

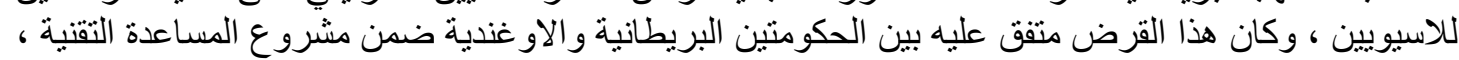

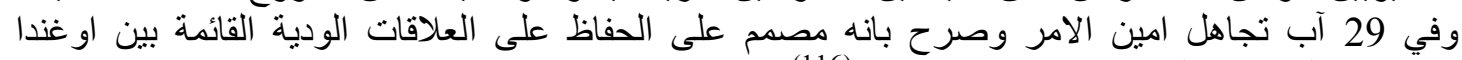

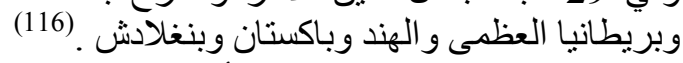

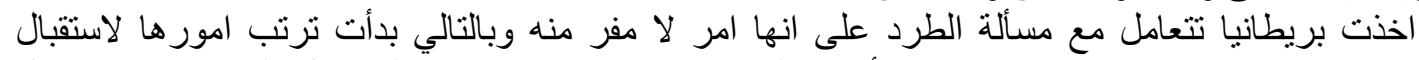

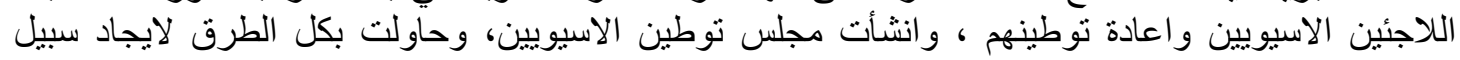

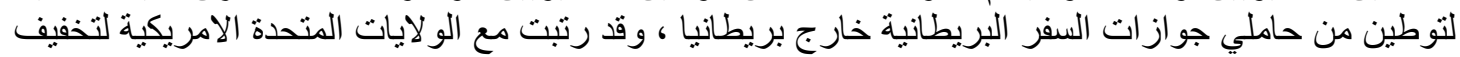

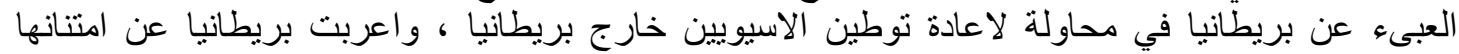

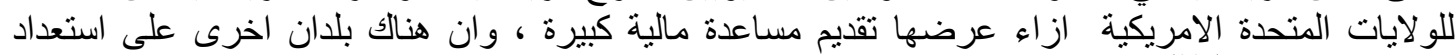
لالمساعدة المالية . (117)

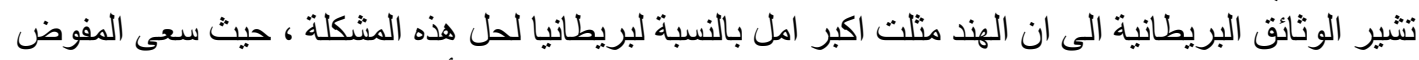

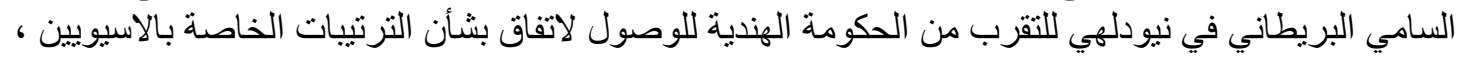

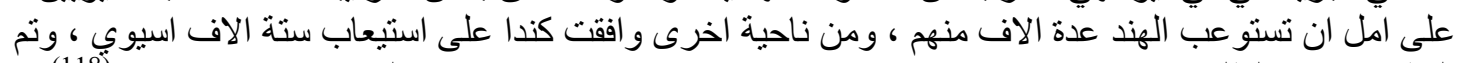

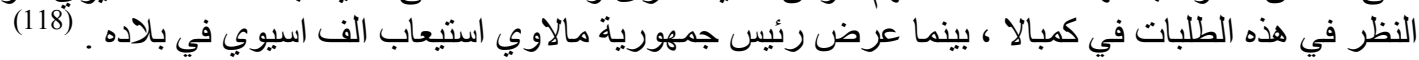

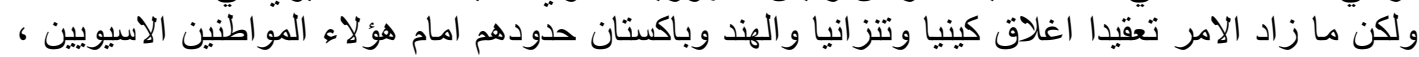

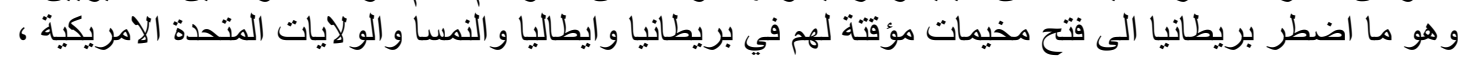

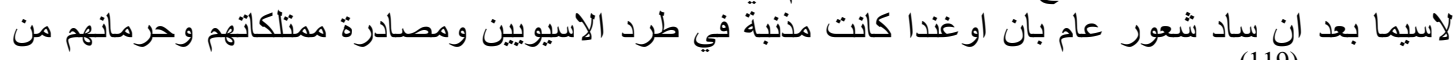
استخدامها . (119)

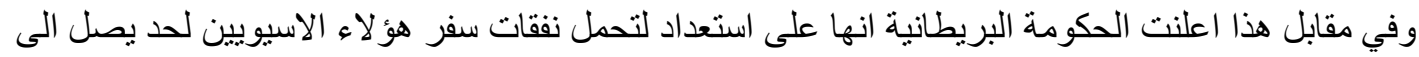

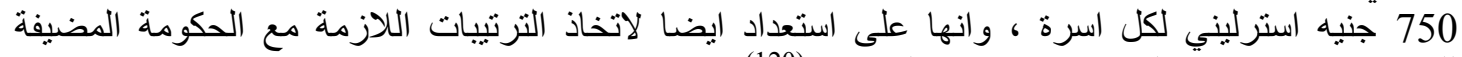

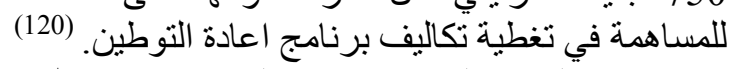

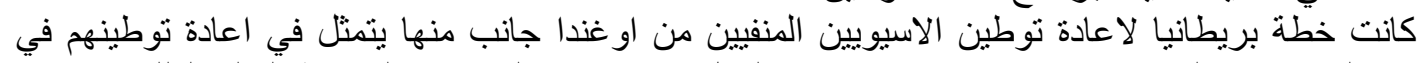

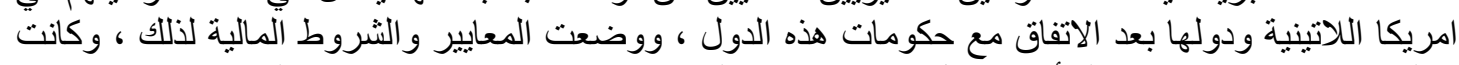

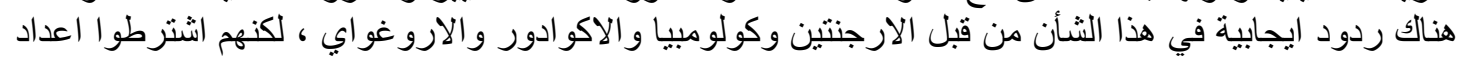

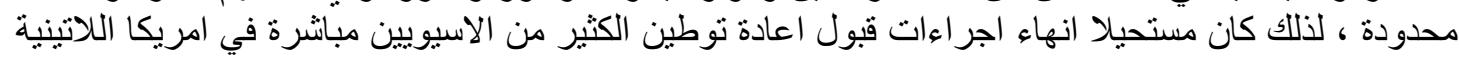

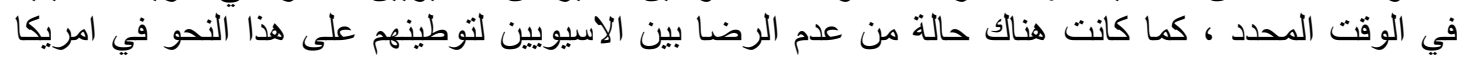

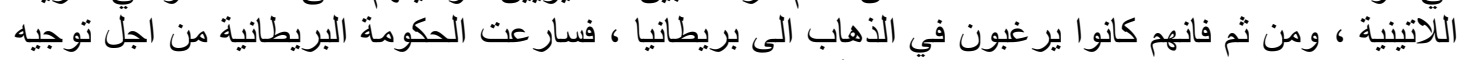

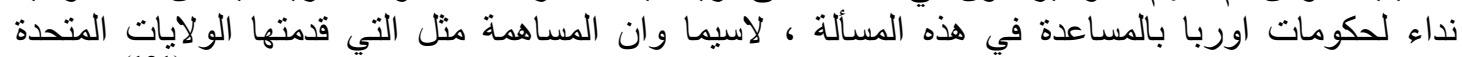

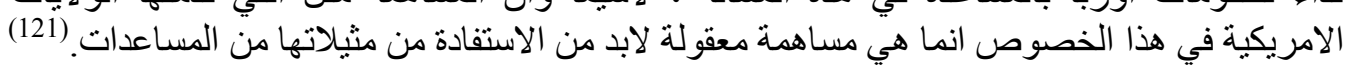

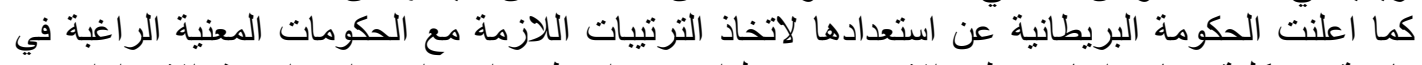

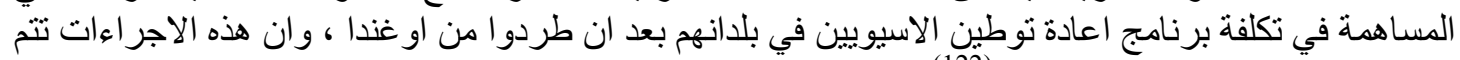

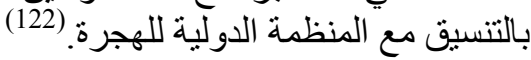

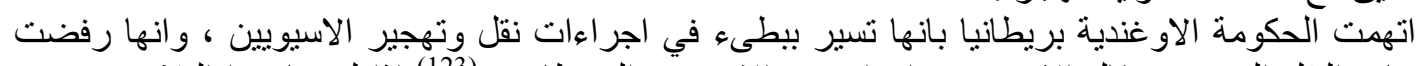

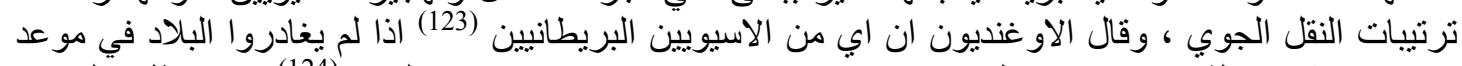

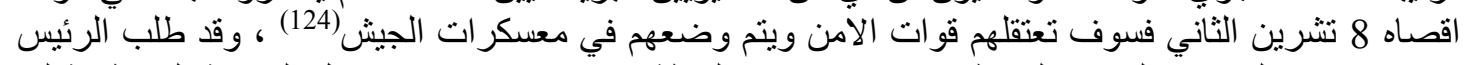

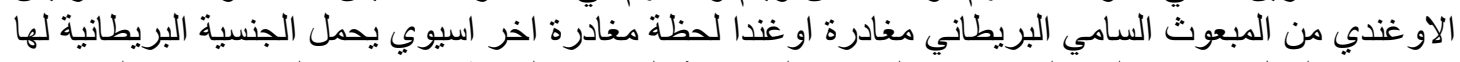

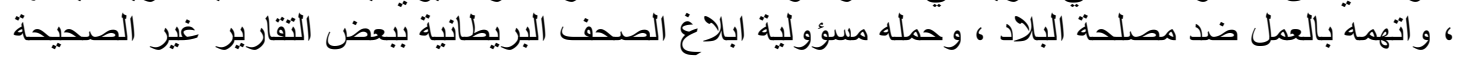


(125) ، ويبدو ان هذه المحاولة من قبل او غندا كانت لاجبار بريطانيا على قبول المقترحات المالية الاوغندية لنقل

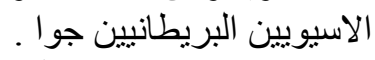

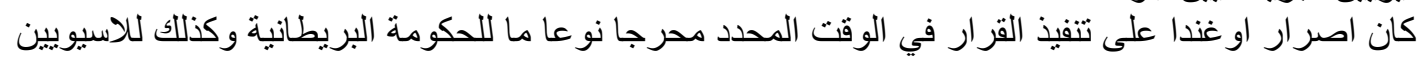

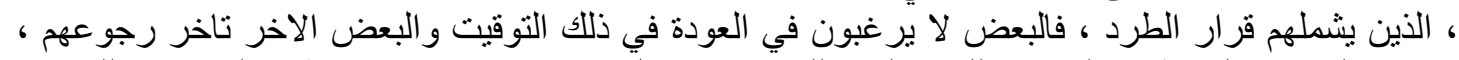

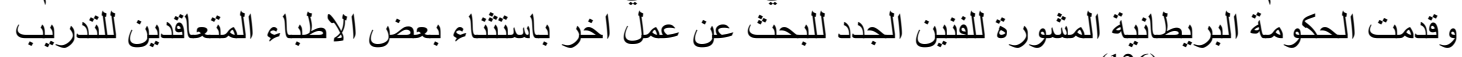

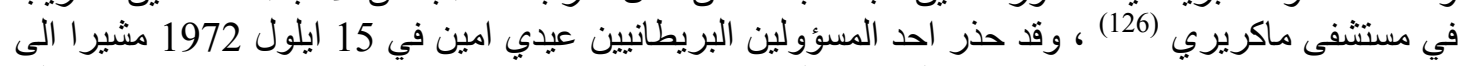

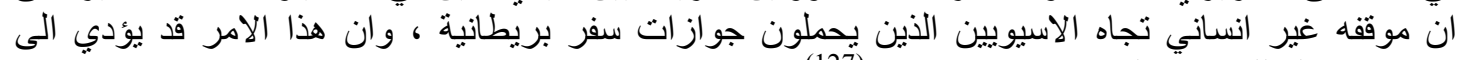

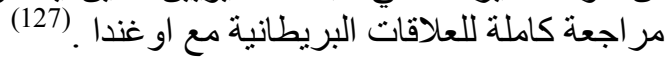

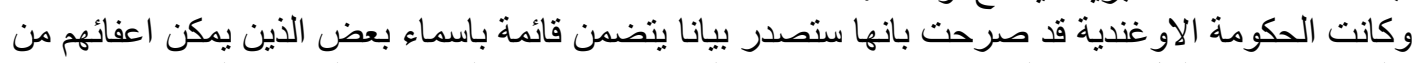

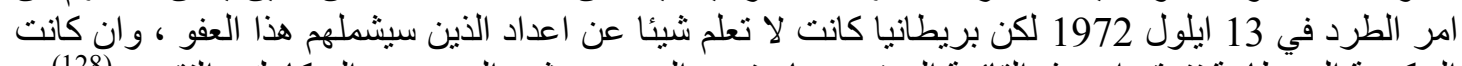

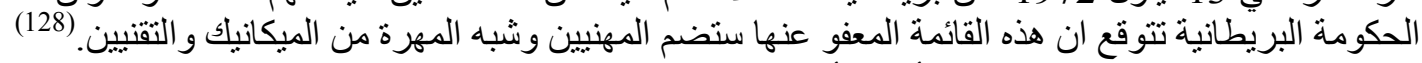

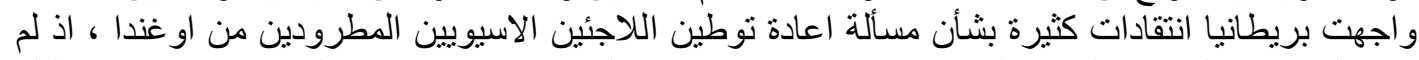

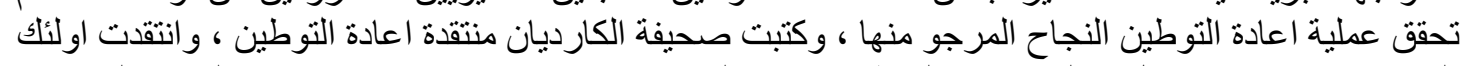

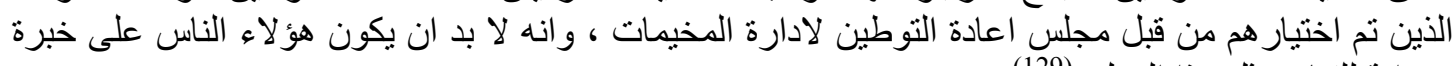

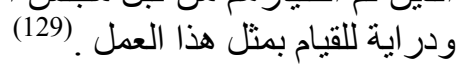

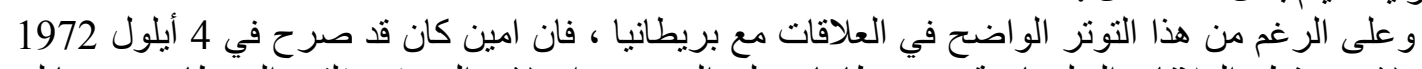

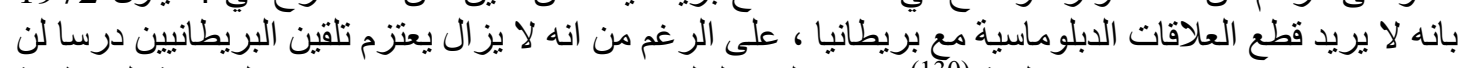

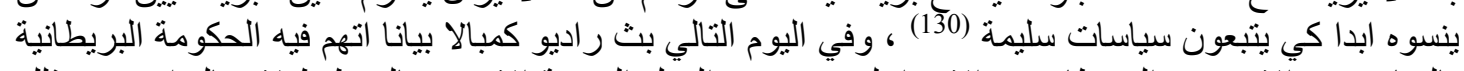

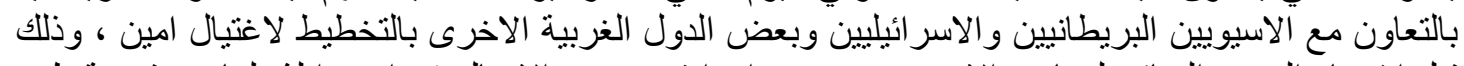

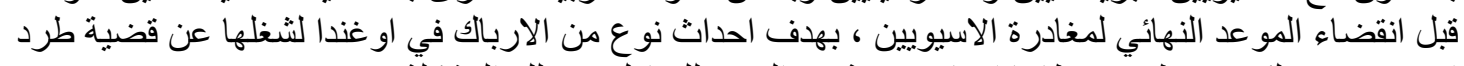

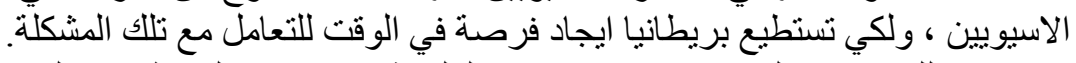

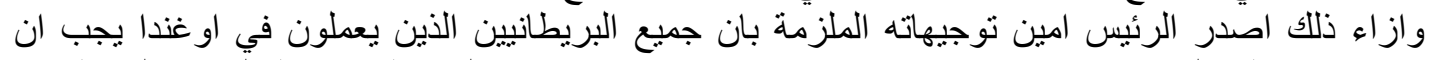

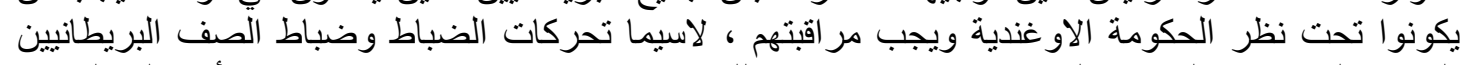

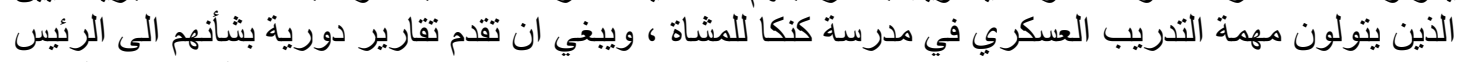

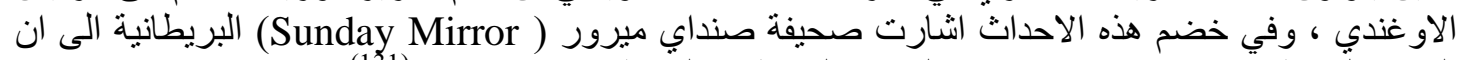

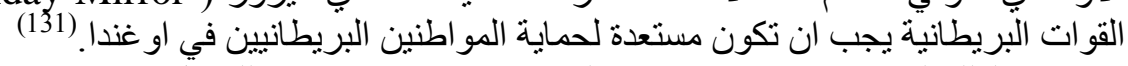

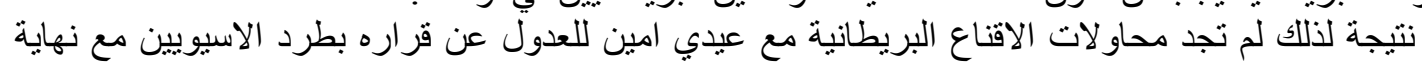

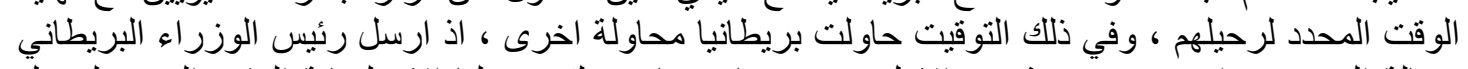

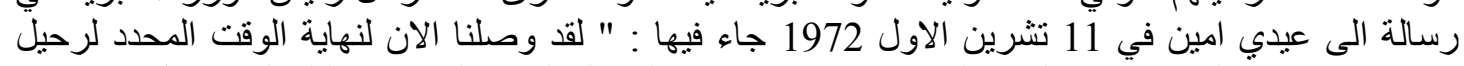

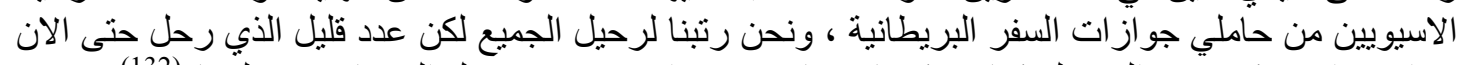

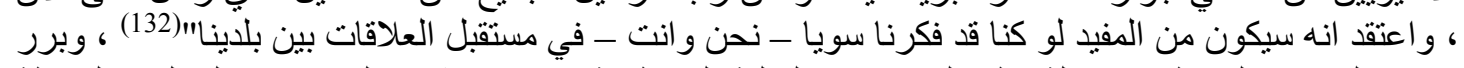

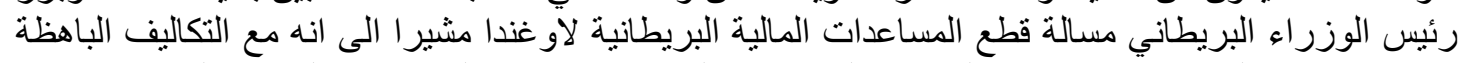

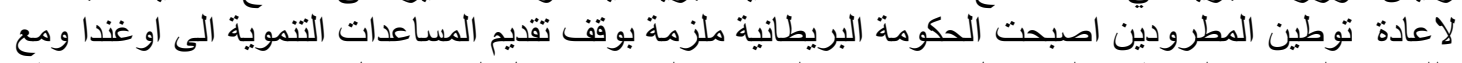

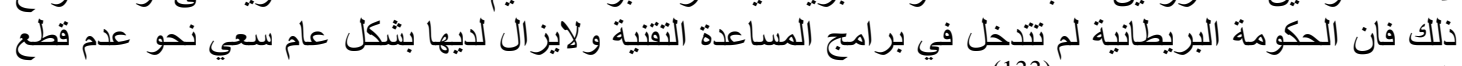

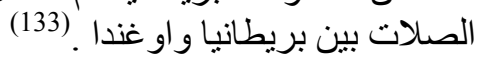

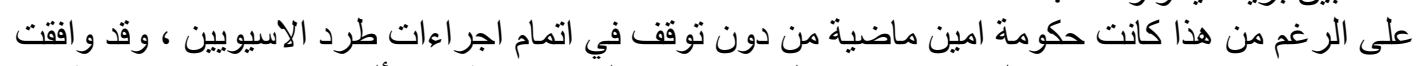

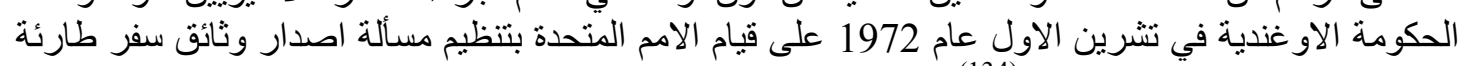

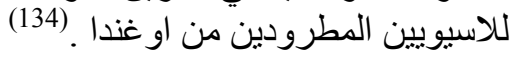

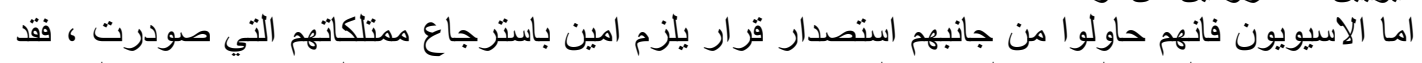

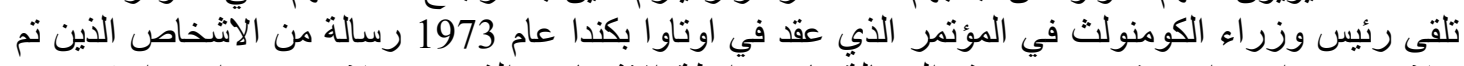

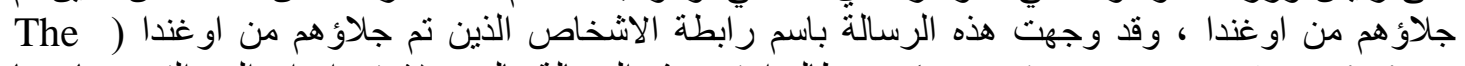

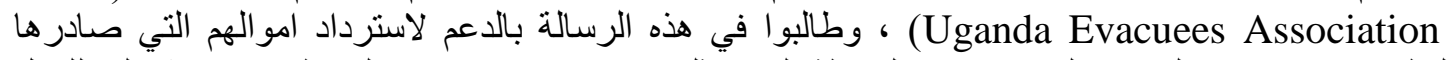

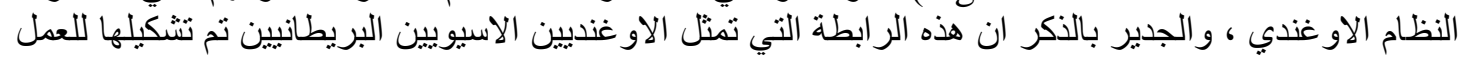


من اجل استرداد الاموال المفقودة والضغط الدولي الدبلوماسي على الحكومة الاوغندية ، و اقترحت الرسالة

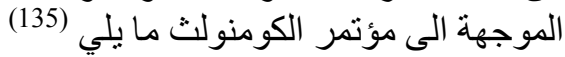
1. ان اموال الحكومة الاوغندية وشركاتها في اي بلد من بلدان الكومنولث ينبغي ان يتم حضرها حتى تقوم

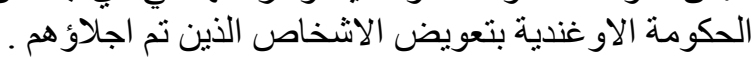

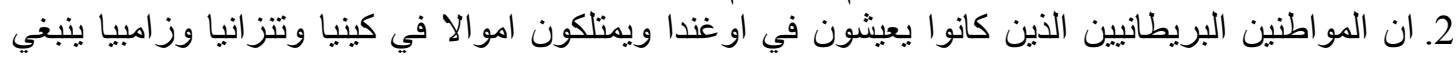

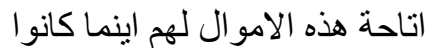

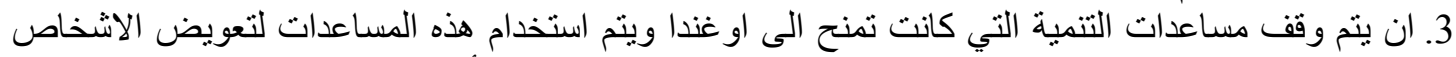

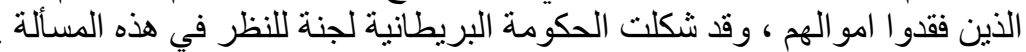

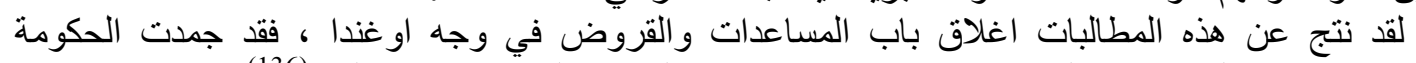

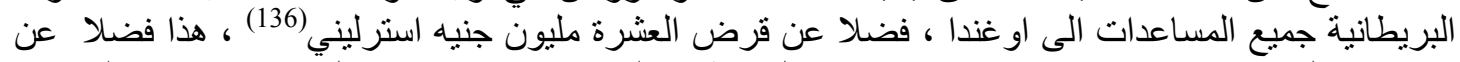

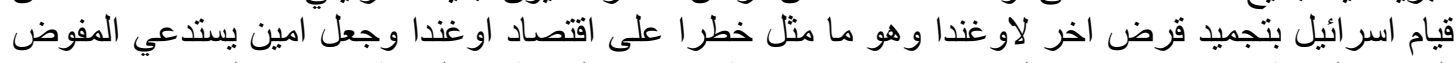

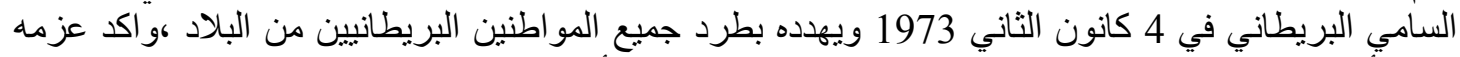

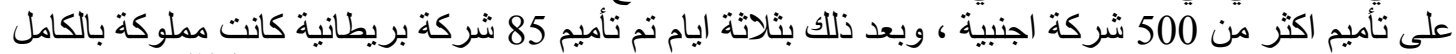

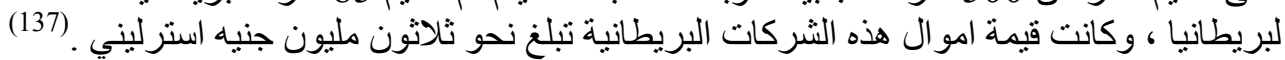

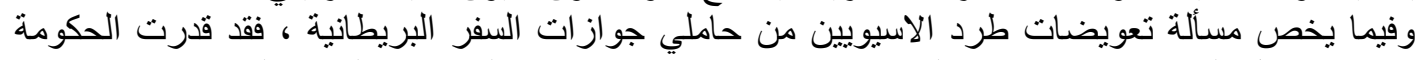

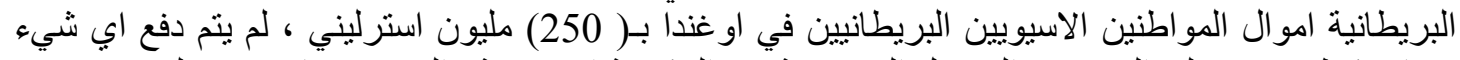

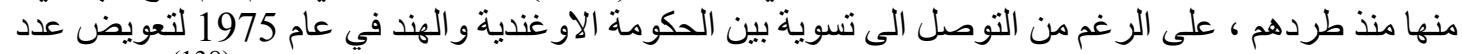

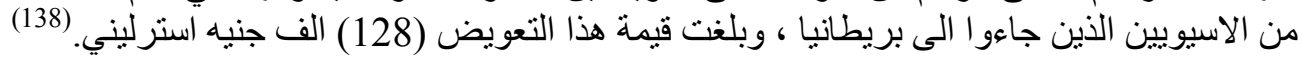

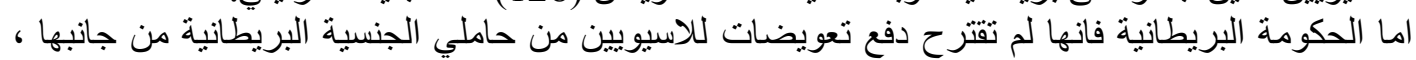

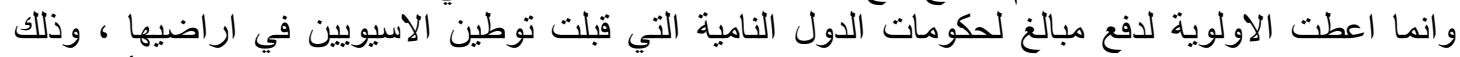

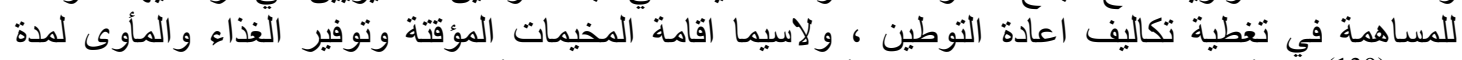

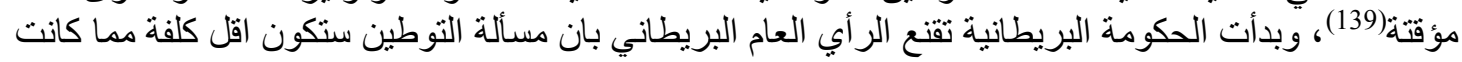

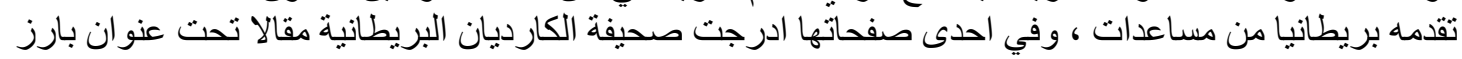

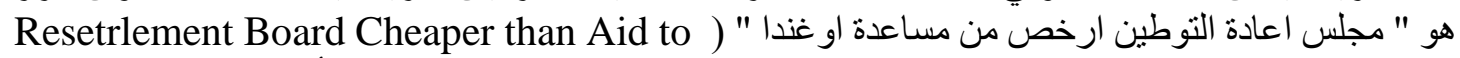
(Uganda

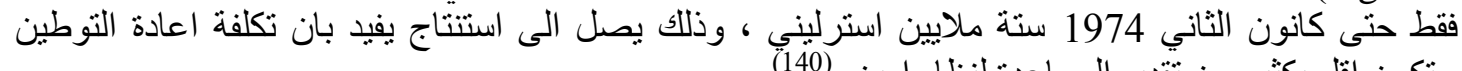

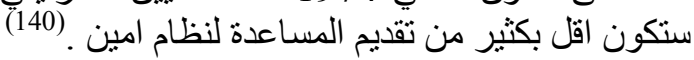
وقد توزع الاسيويون الذين تم طردهم على عدئ عدد من البلدان ، وكان لبريطانيا النصيب الاكبر ، اذ استقبلت

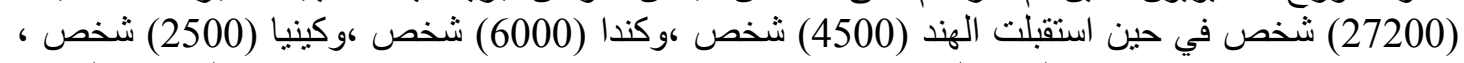

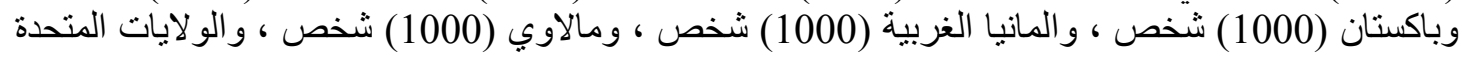

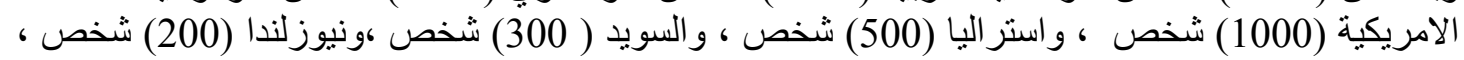

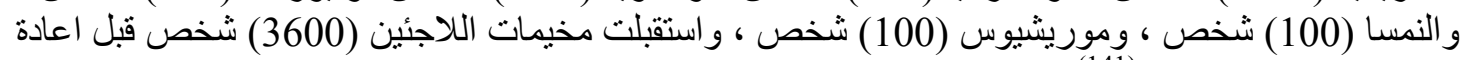

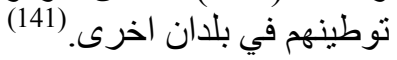

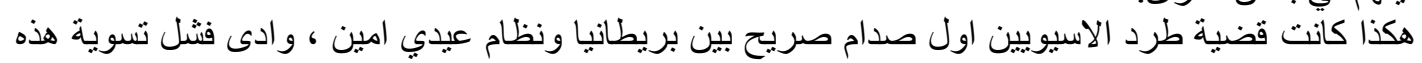

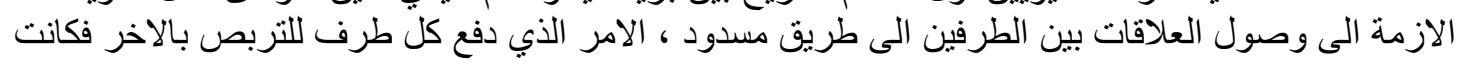

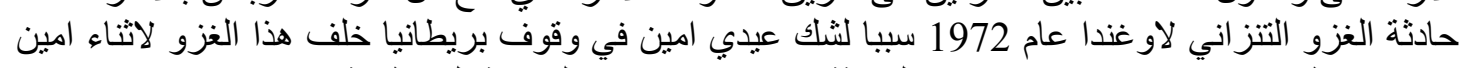

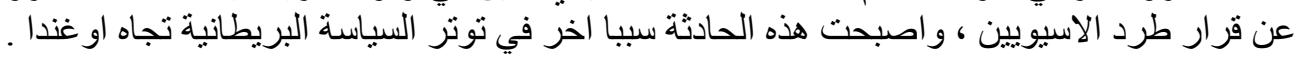

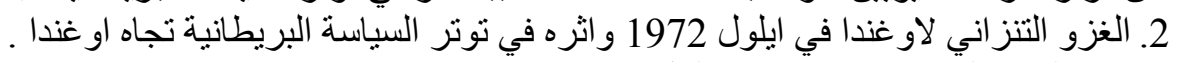

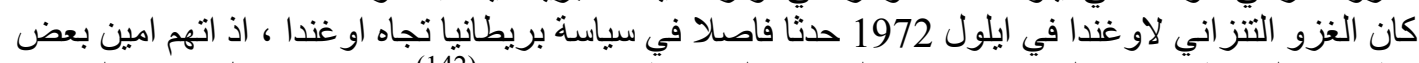

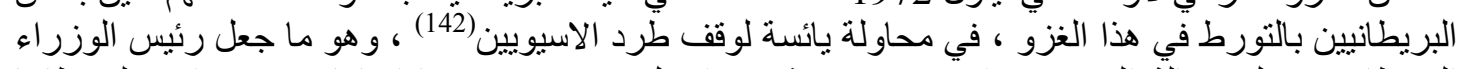

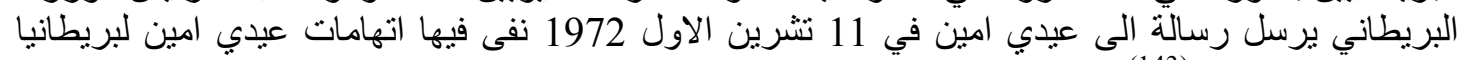

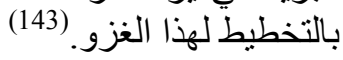

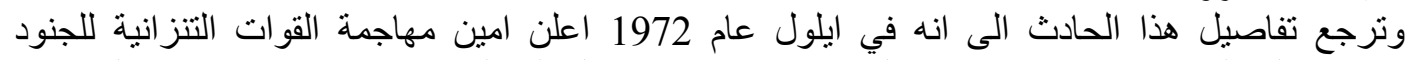

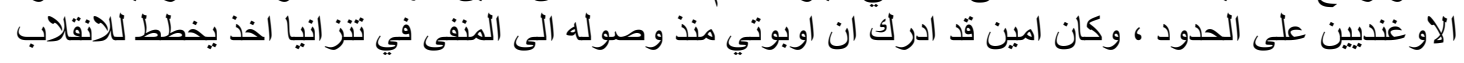


ضده ، وبالفعل شنت قوة غازية من المنفيين في تنز انيا ، وكان نصفهم من الاعضاء السابقين في الجيش هجوما

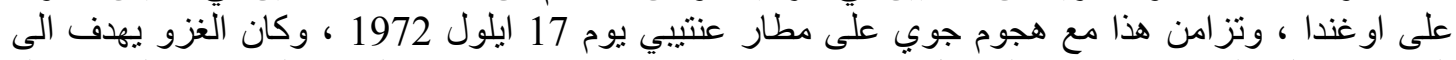

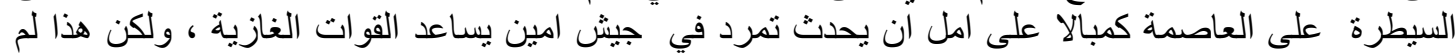

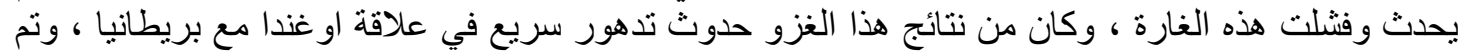

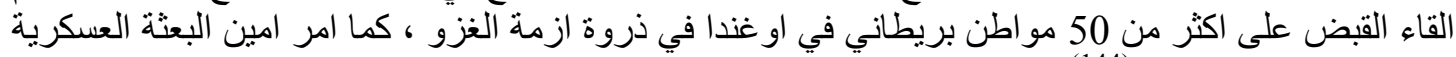

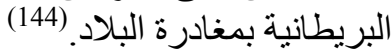
ابلغت وزيرة الدولة البريطانية للثؤون الخارجية و الكومنولث البردية مجلس اللوردات في 18 ايلول 1972 ، انوان

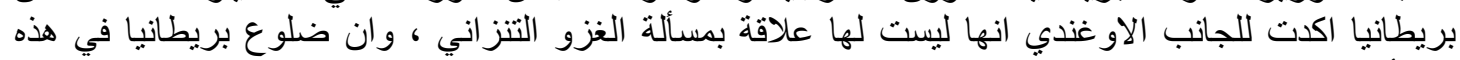

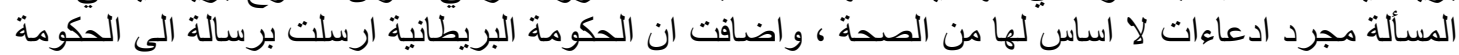

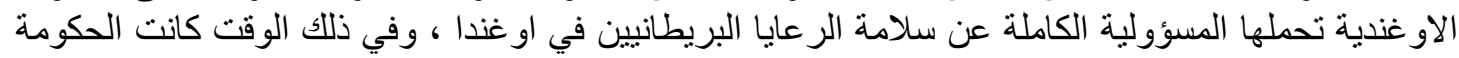

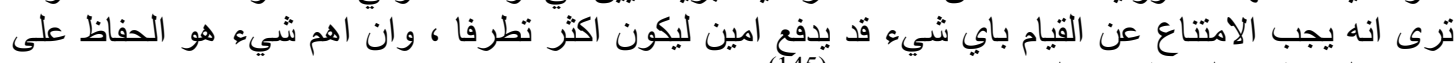

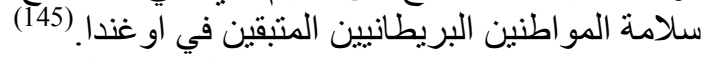

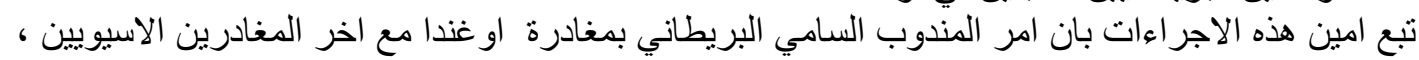

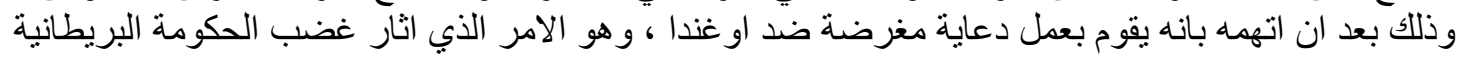

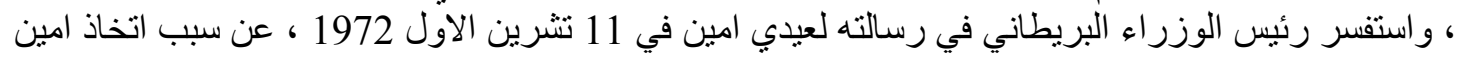

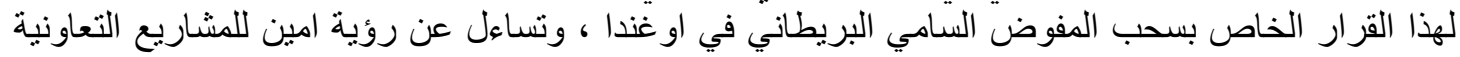

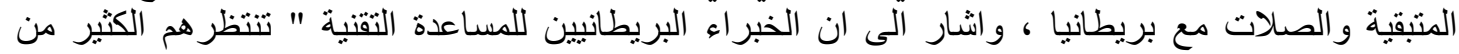

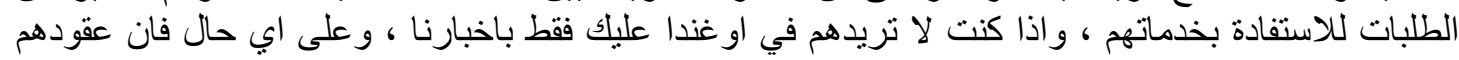

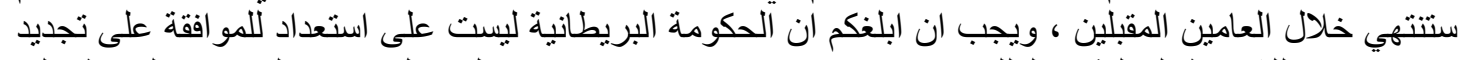

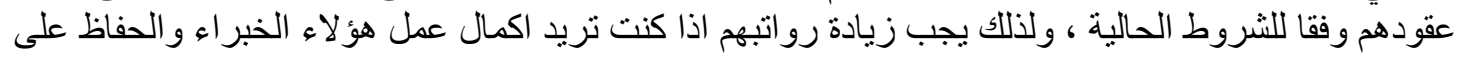

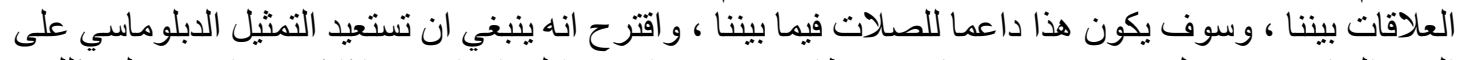

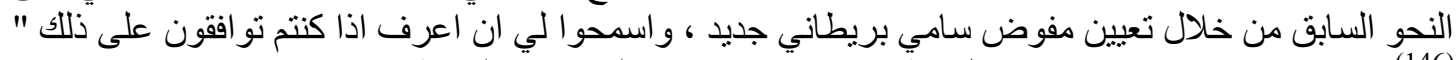

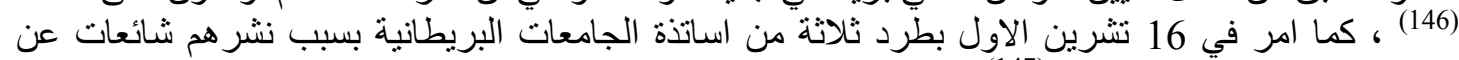
وقوع اضطر ابات أهلية وشيكة .

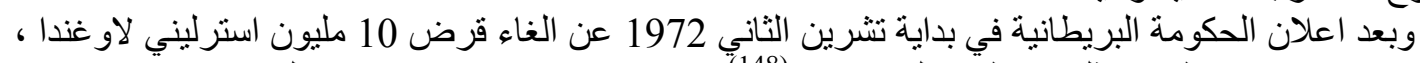

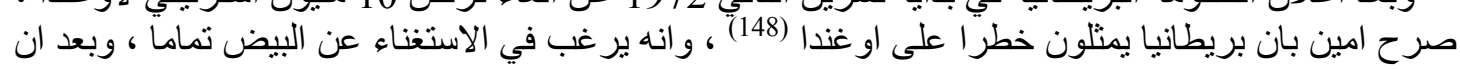

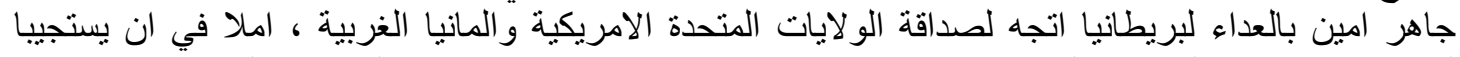

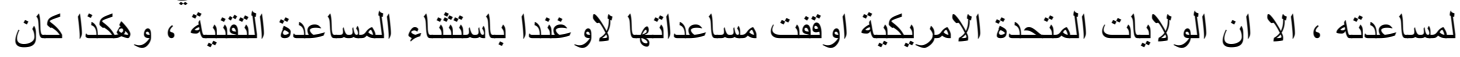

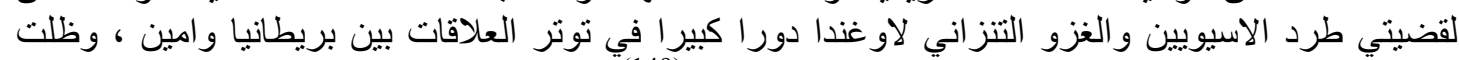

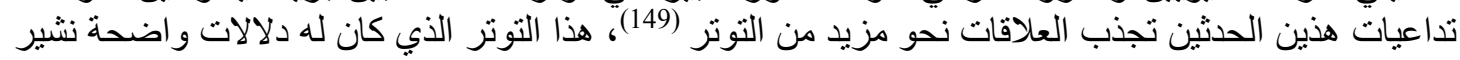

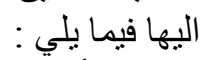

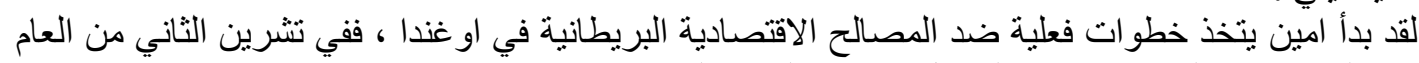

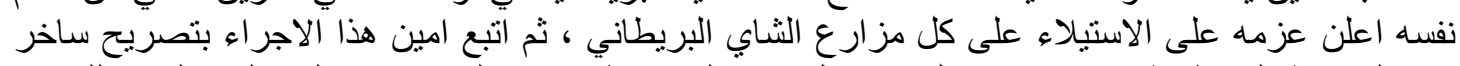

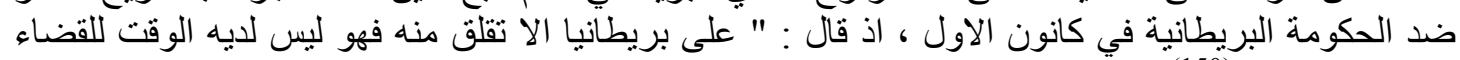

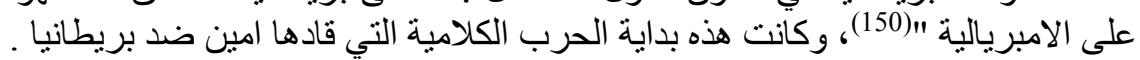

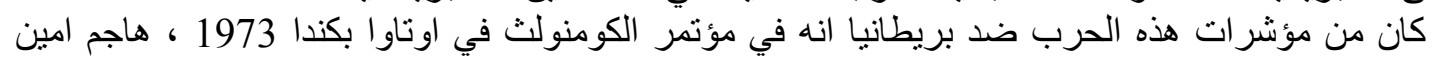

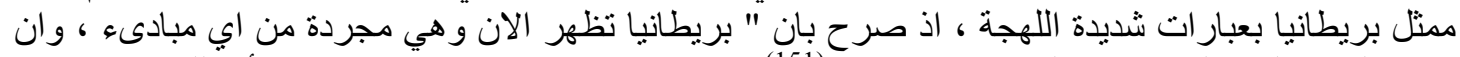

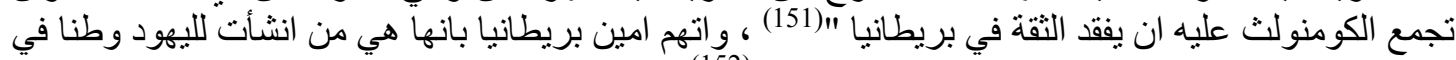

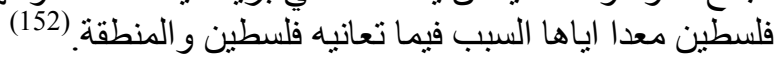

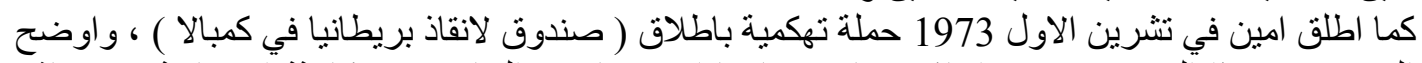

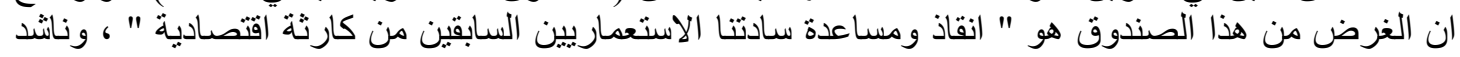

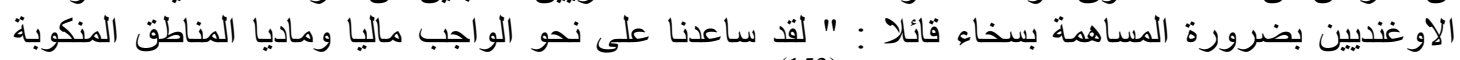
بالكو ارث في جميع الانحاء المختلفة في العالم ". (153) 
وشجع امين الاوغنديين على التبرع بالفواكه والخضروات لدعن صندوق انقاذ بريطانبا لمساعدة الحكومة

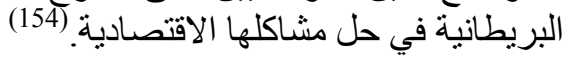

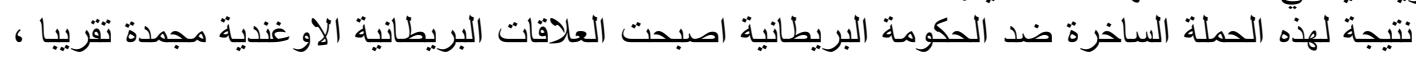

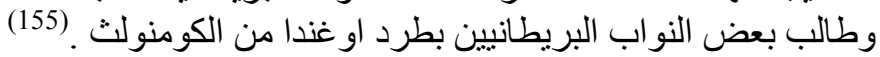

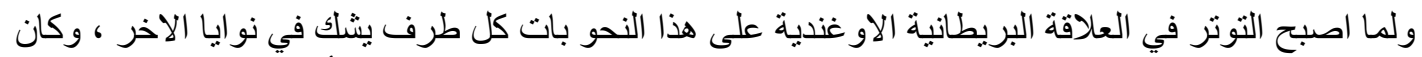

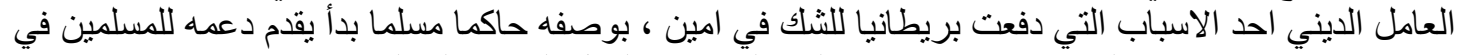

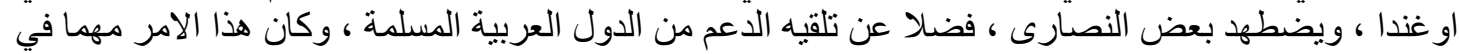

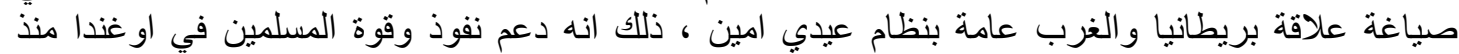

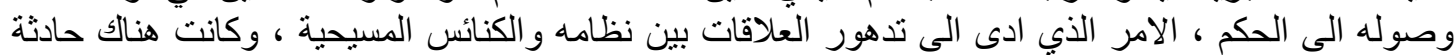

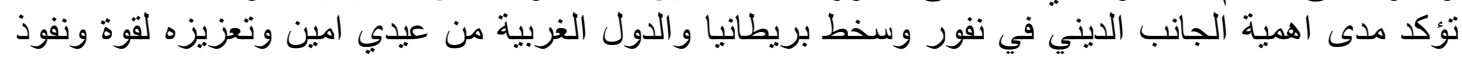

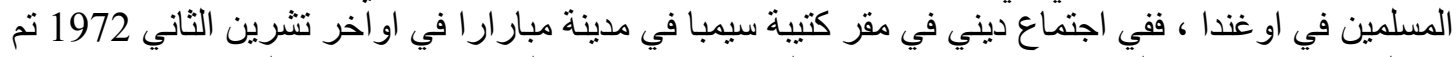

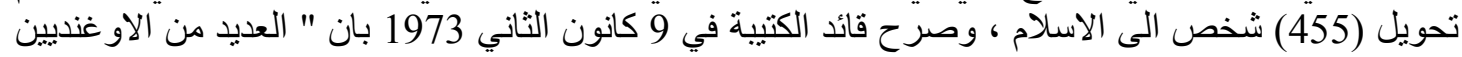

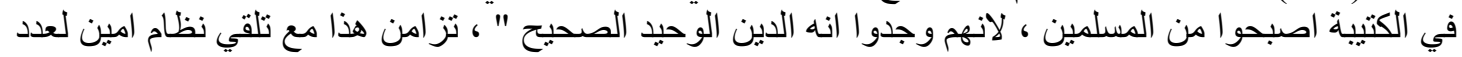

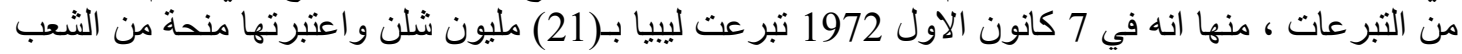

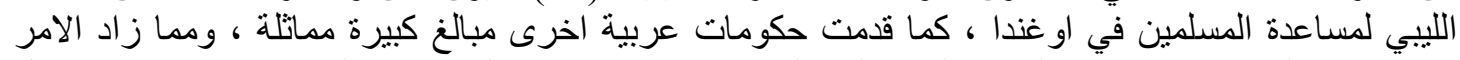

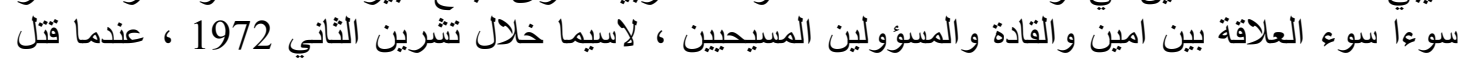

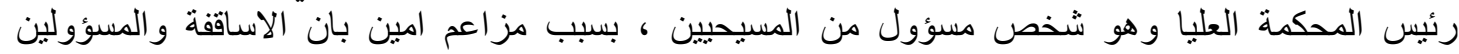

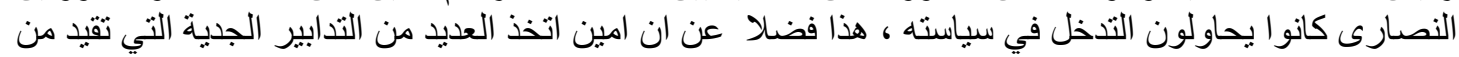

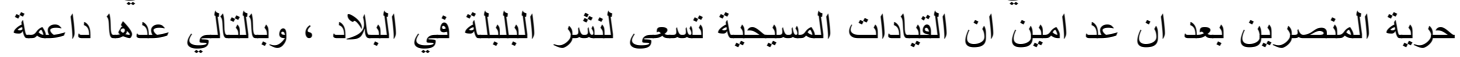

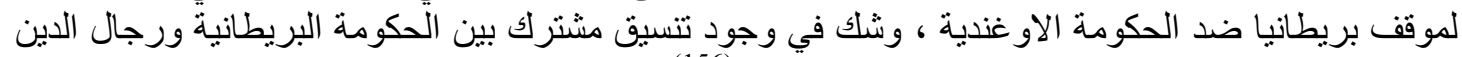

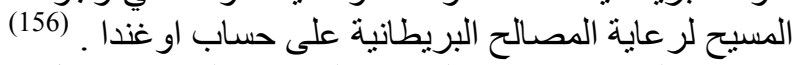

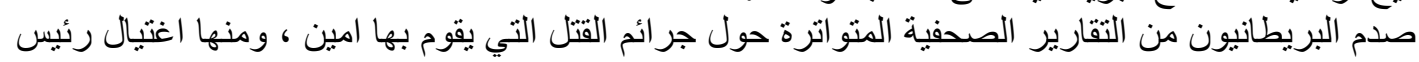

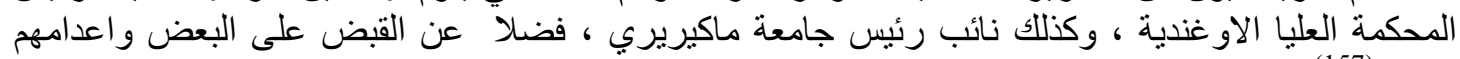

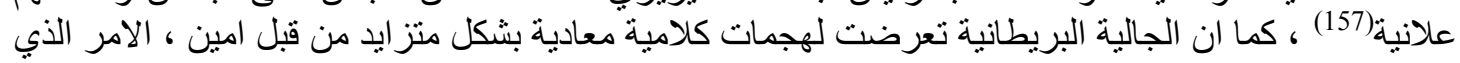

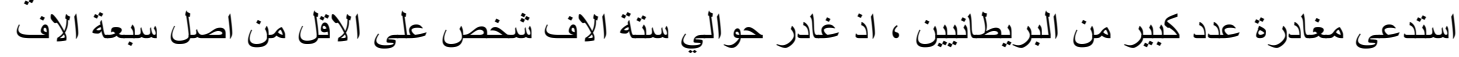

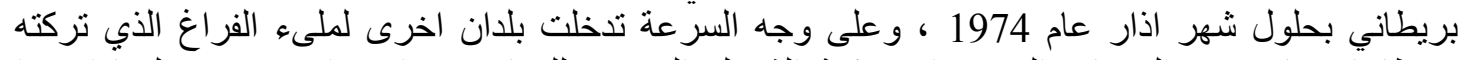

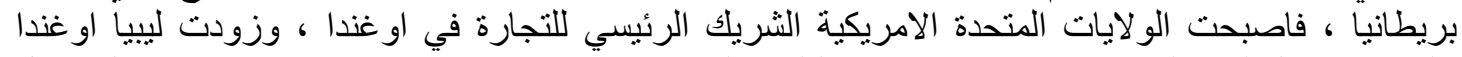

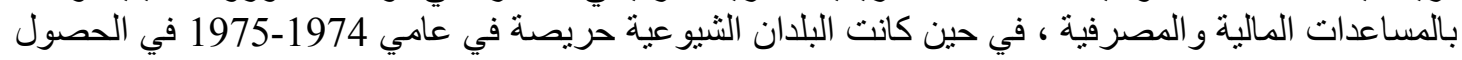

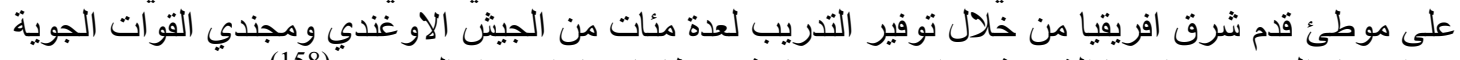

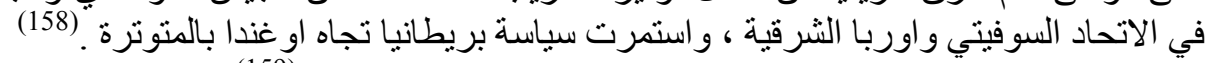

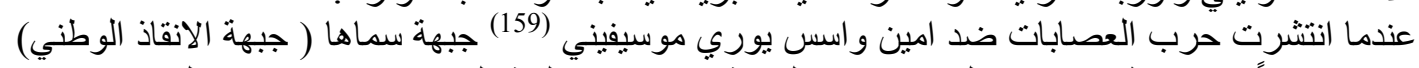

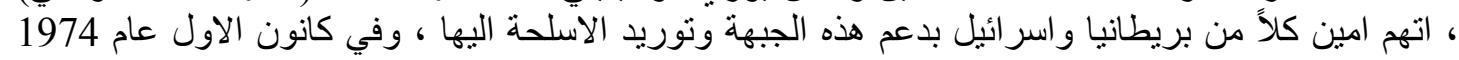

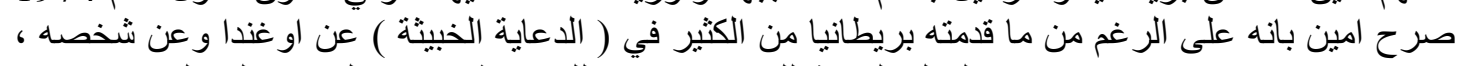

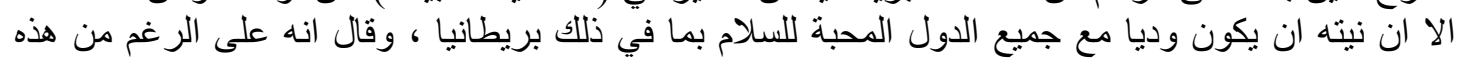

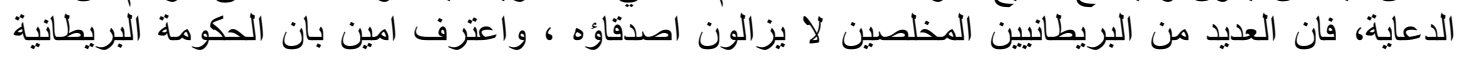

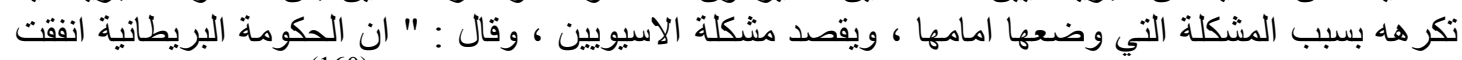

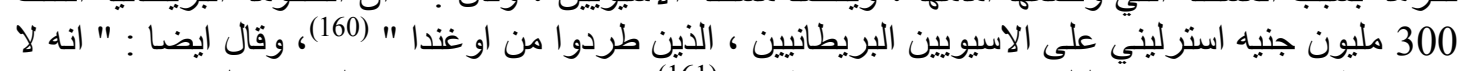

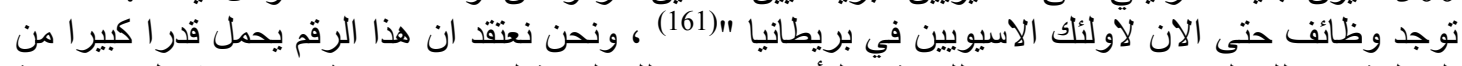

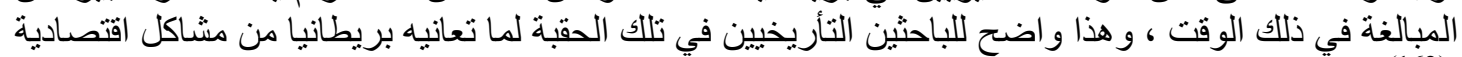

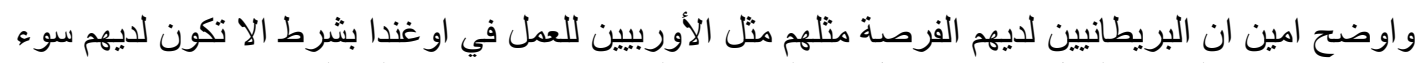

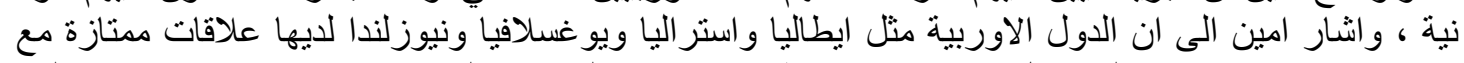

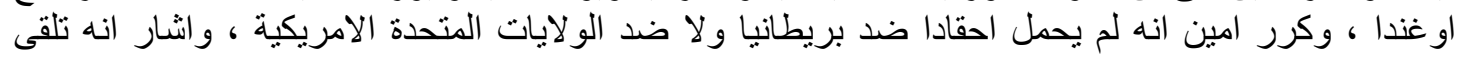


المجلة اللحولية اللملوم الآسانية والإمتصاعية International Journal of Humanities and Social Sciences website:www.ijohss.com Email:editor@ijohss.com ISSN: 2415 - 4822

\section{0 أكتوبر \\ العدد (16) \\ Volume (16) October 2020}

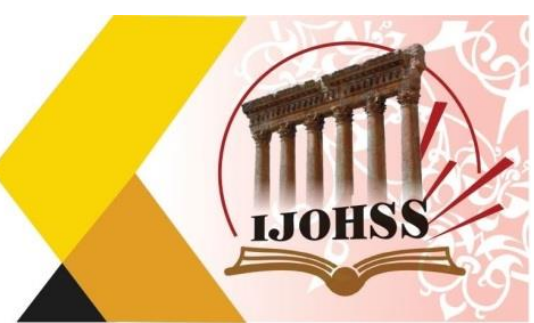

شخصيا العديد من الدورات العسكرية في بريطانيا ، وكانت اخر دورة عسكرية عام 1964 على يد المدربين في جامعة كيمبرلي . (163)

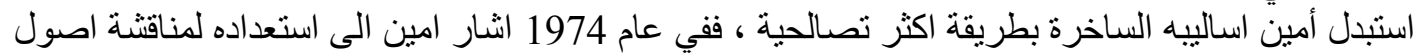

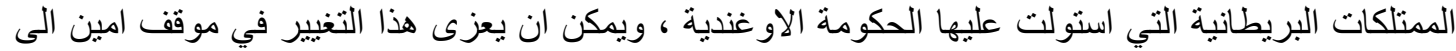

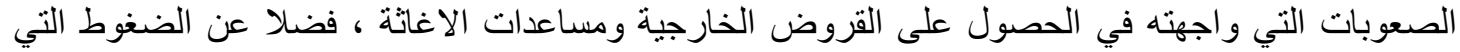

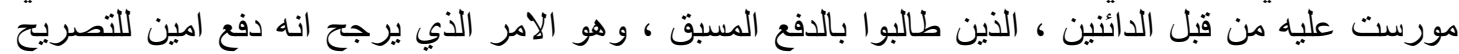

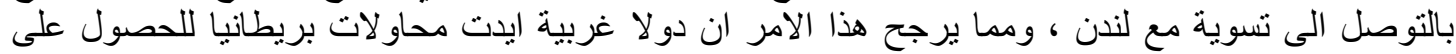

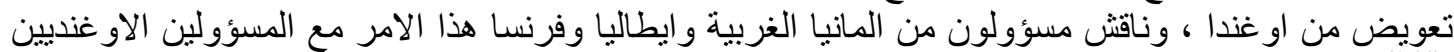

(164)

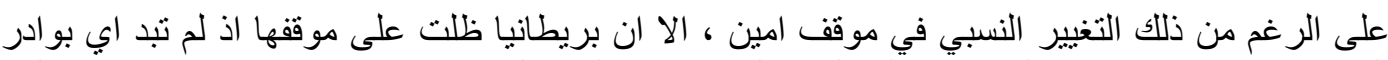

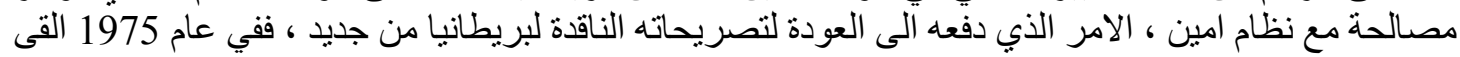

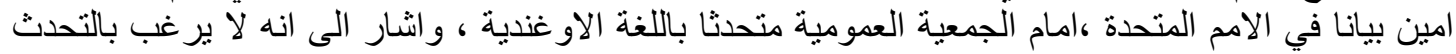

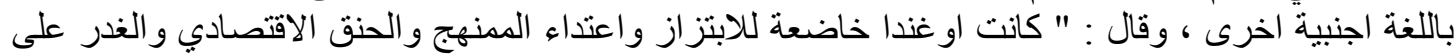

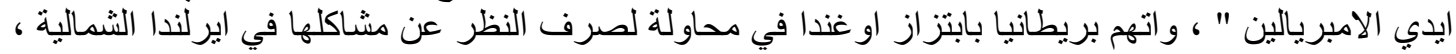

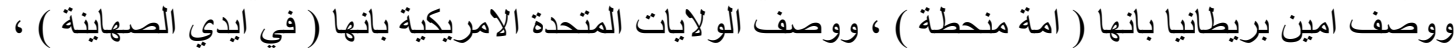

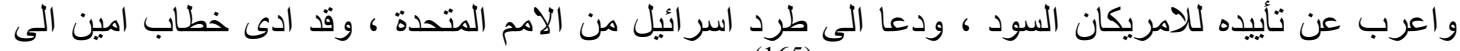

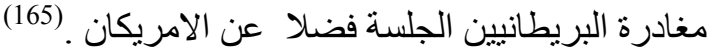

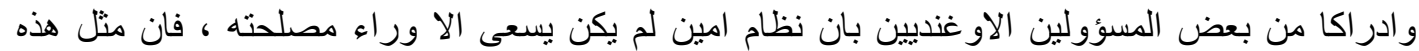

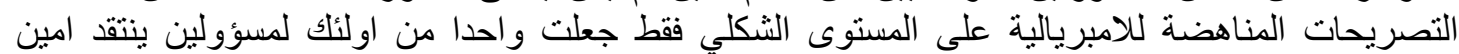

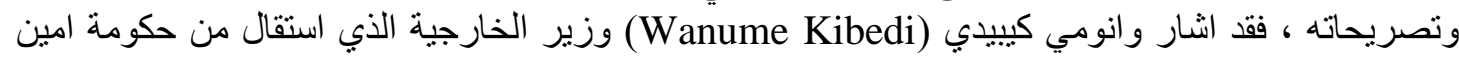

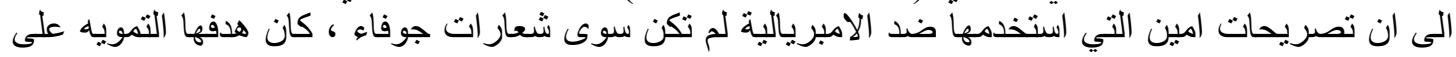

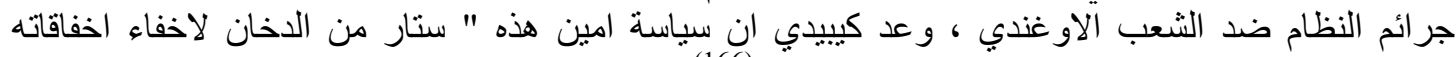

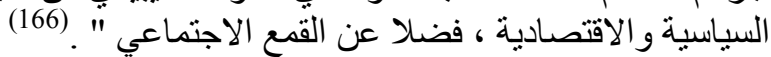

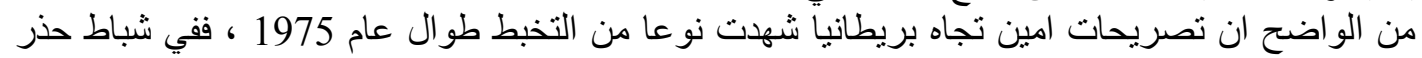

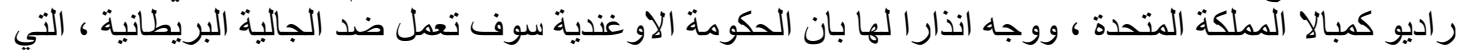

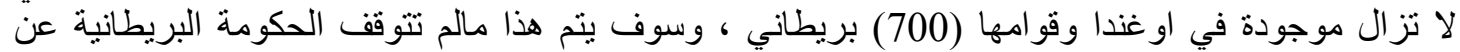

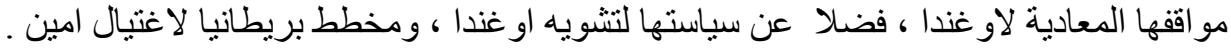

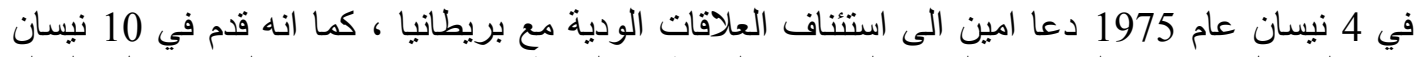

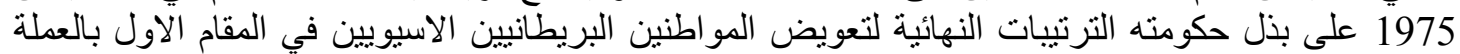

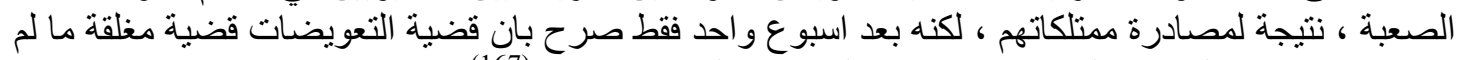

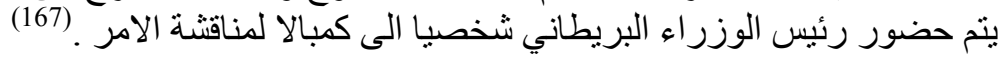

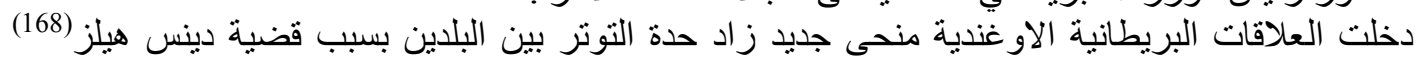

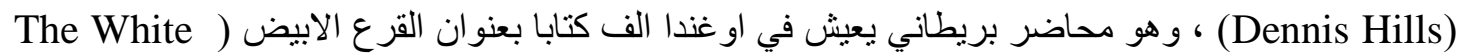

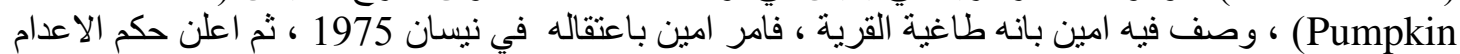

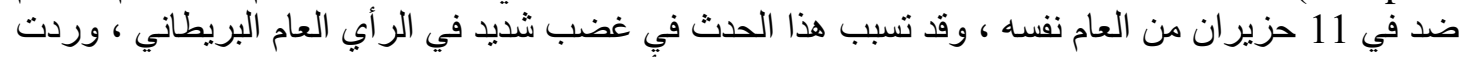

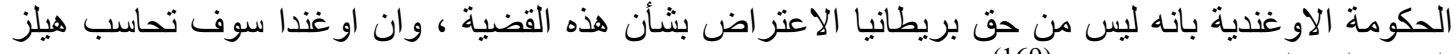

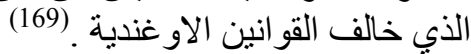

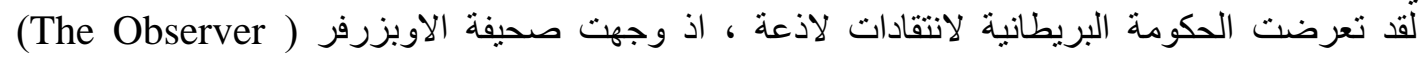

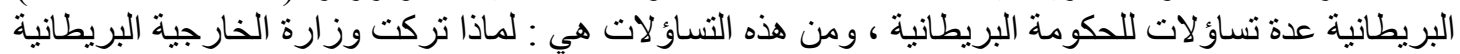

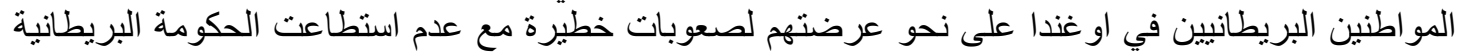

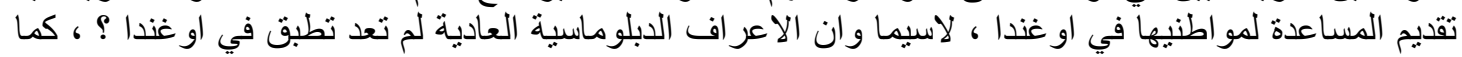

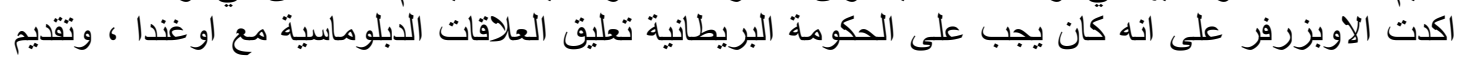

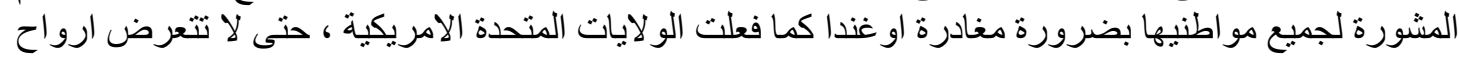

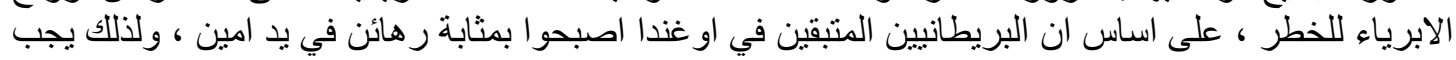


على الحكومة البريطانية انتهاز هذه الحادثة لقطع العلاقات مع نظام امين ، وينبخي ان تعيد الحكومة البريطانية

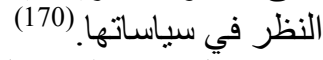

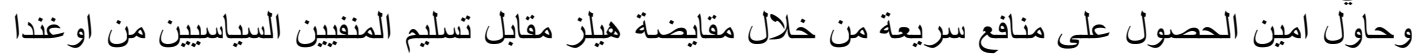

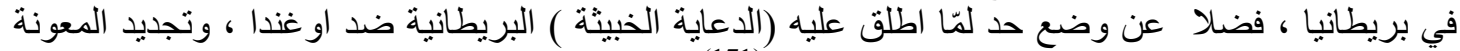

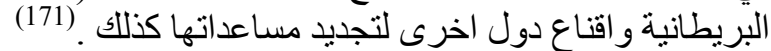

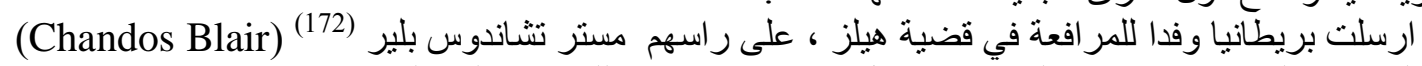

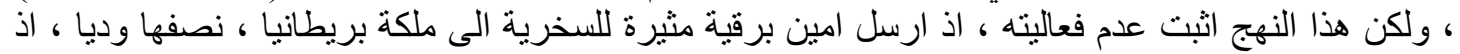

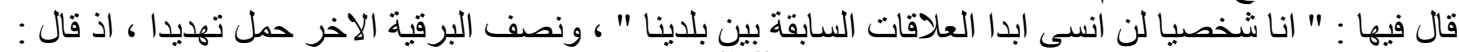

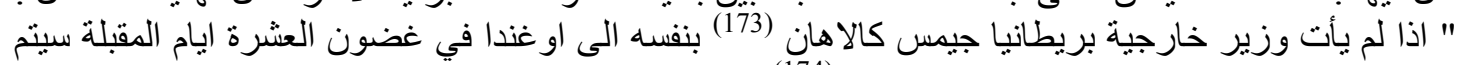

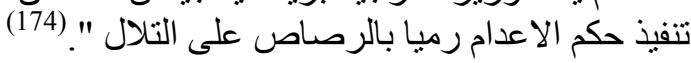

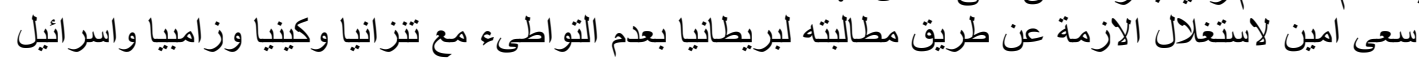

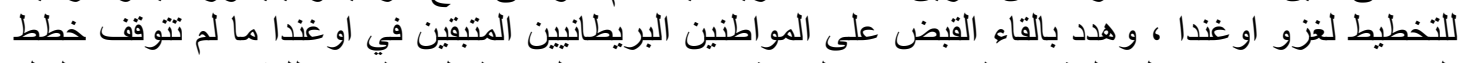

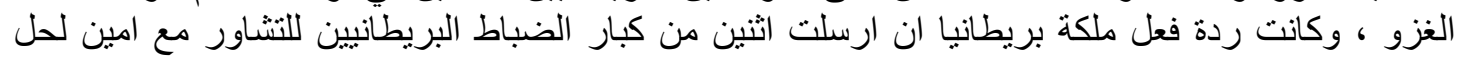

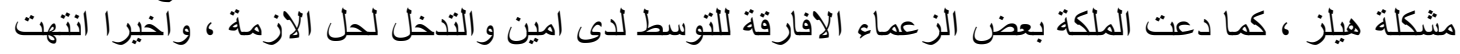

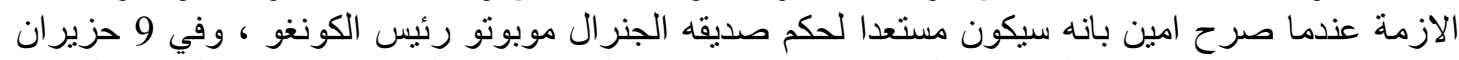

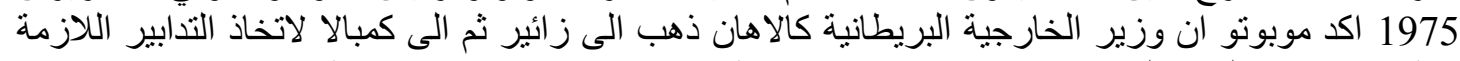

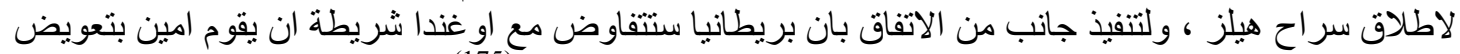

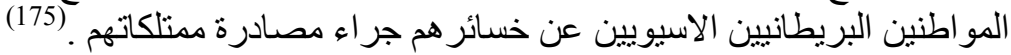

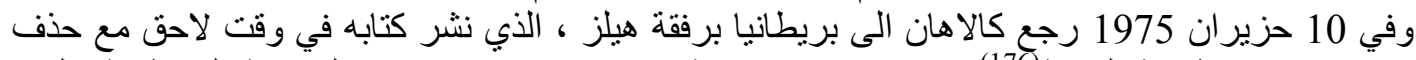

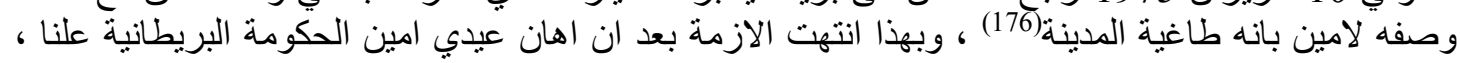

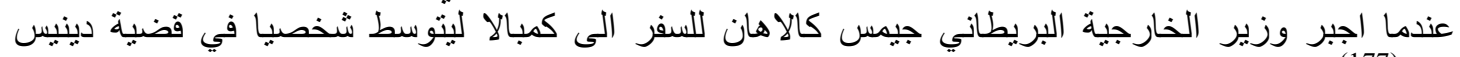

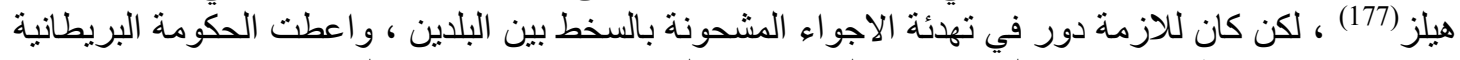

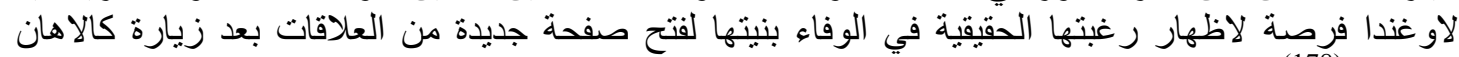

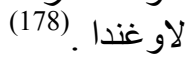

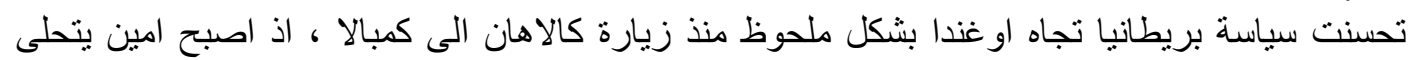

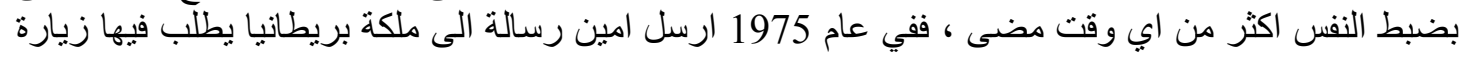

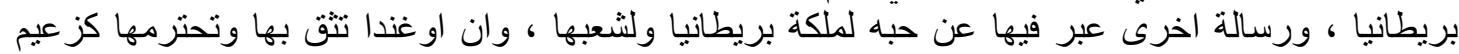

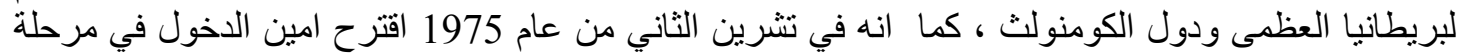

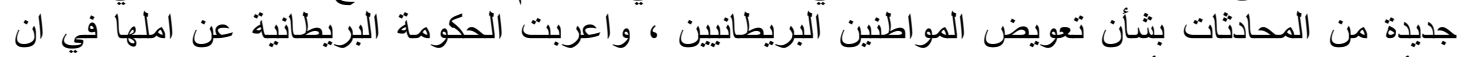

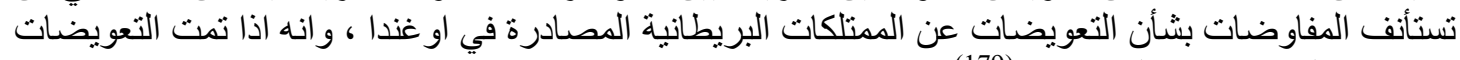

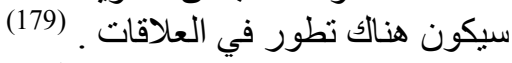

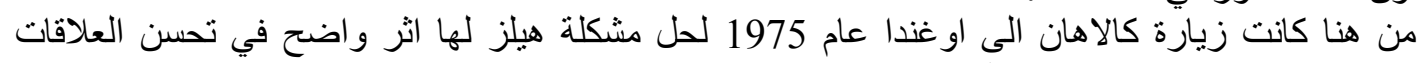

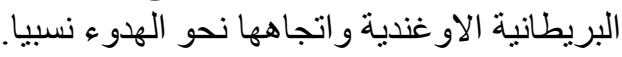

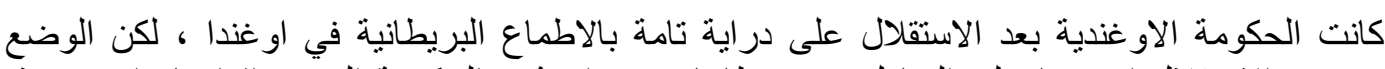

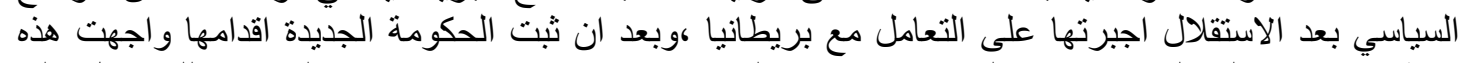

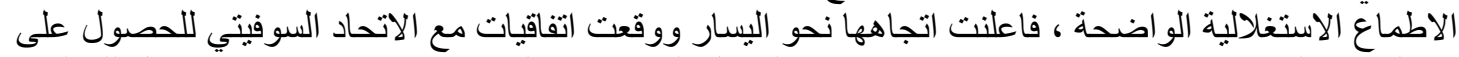

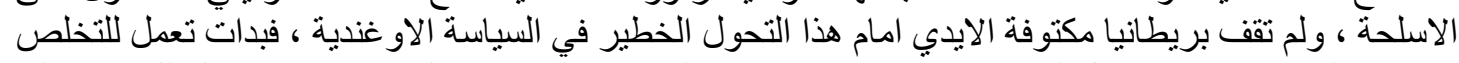

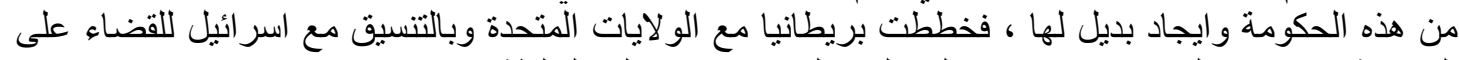

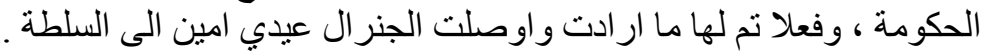

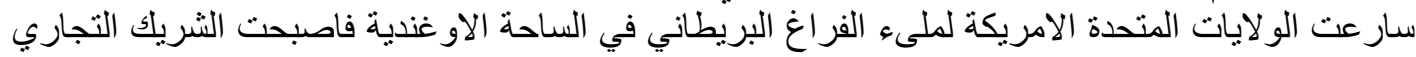

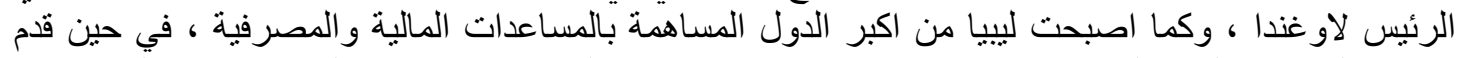

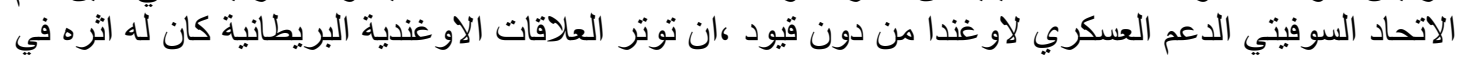




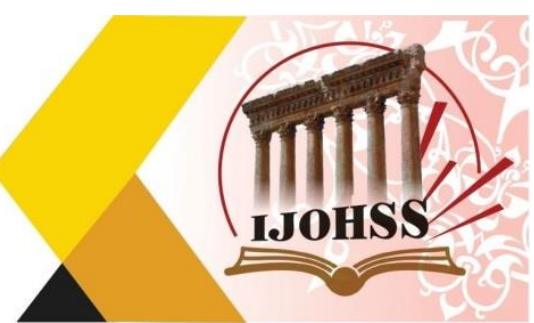

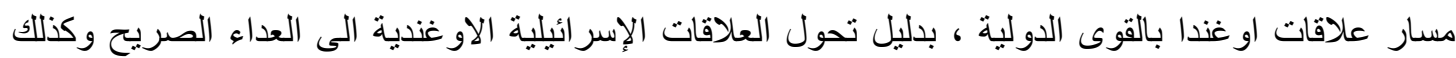

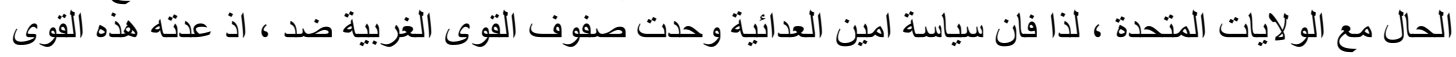

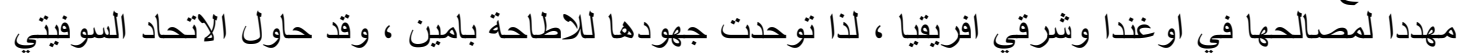

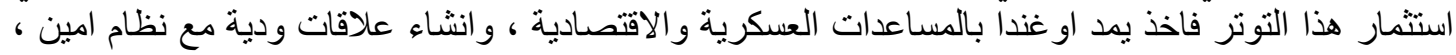
لكن في نهاية الامر تم الاطاحة بامين بعد فرض حصار اقتصادي عليه من قبل بريطانيا والدول الغربية الغين

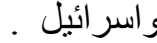

الهوامش والمصادر 1 ـ احمد الزروق ، مشكلة الاندماج الوطني في او غندا ، اطروحة دكتوراه غير منشورة ، معهد البحوث والدراسات الافريقية ،

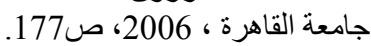

2- John kiyaga - Nsubuga , , Political and Struggle for Control Uganda 1970-1990 . PHD .Department of Political Science, University of Tornto , Canad ,1995,P. 83.

3 - CIA . Reflection on the Uganda Coup Department of State February 2, 1971.

4- John Kiyaga - Nsubuga, Op .Cit ,P. 82.

5 - Ibid ,P. 53.

6 - Ibid ,P. 82.

7- Phares Mutibwa Uganda Since Indepence, A Story Unfulfilled Hopes, Hurst Company, London, 1972.,P. 65.

8 - نجوى امين الفوال ، النظم العسكرية في افريقيا ( دراسة تطبيقية على اوغندا ) ، رسالة ماجستير غير منشورة ، معهد البحوث

9 - Hohn kiyaga - Nsubuga, Op .Cit ,P. 83.

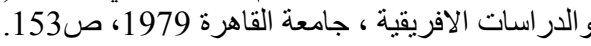

11 - Hohn kiyaga - Nsubuga, Op .Cit ,P. 84.

$$
\begin{aligned}
& \text { 10- نجوى امين الفوال ، الدصدر السابق ، ص157. } \\
& \text { 12 - نجوى امين الفوال ، المصدر السابق ، ص149. } \\
& 13 \text { - نجوى امين الفوال ، المصدر السابق ، ، صد150. ص150. }
\end{aligned}
$$

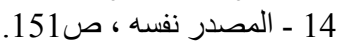

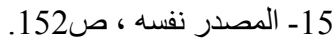

16-Ali .A.Mazrui , Soldiers and Kinsmen in Uganda the Making of Military Ethnocracy sage publications , London, 1975.,P. 123.

17 - Philip Short, Amin's Uganda Transition, No .40, December 1971.,P. 48.

18 -Obone A.E ,Coup in Uganda, Economic and Political weakly, Vol.6 , No .17, April 24, 1971,P. 850 .

$$
19 \text { - ينظر : جريدة الاهرام المصرية ، العدد } 3466 \text { ، } 27 \text { كائل كانون الثاني } 1971 .
$$

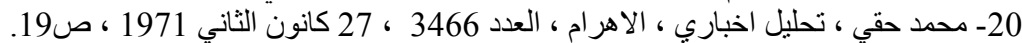

21 - Sarah . B.Mason, The Uganda People's Defense Force Portraying Regional Strength While Perpetuation Internal Instability, Master of Arts in Liberal Studies, Faculty of the School of Continuing Studies, Georgetown University, Washington D.C,2010,P. 29 .

$$
\begin{aligned}
& 22 \text { - جريدة الاهر ام المصرية ، العدد } 3466 \text { ، } 27 \text { كانون الثاني ، } 1971 .
\end{aligned}
$$

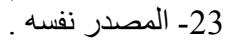

$$
\begin{aligned}
& 24 \text { - جريدة الاهر ام المصرية ، العدد } 3466 \text { ، } 27 \text { كانون الثاني ، } 1971 .
\end{aligned}
$$

25 - Brett .E.A , Neutralizing the USA of force In Uganda, the Role of the Military in Politice, the Journal of Modern African studies, Vol.33, No 1, Marsch . 1995.,p .138.

26- Ray Carina, Idi Amin and His British friends, New African, No 452 , June, 2006 ,P. 32.

27- Oliver Furley, Op .Cit . P. 276.

$$
\text { 28- جريدة الاهر ام المصرية ، العدد } 3466 \text { ، } 27 \text { كانون الثاني ، } 1971 .
$$

29- FCO. 31/1023 , Unclassified . to Priority Kampala, Tel No . 81 , of 27/1 UK Press Summary , 26 , January 1971 .

30 - Ray Carina, Idi Amin and His British friends, New African, No 452, June, 2006 , P.34.

31 - FCO. 31/ 1028 , From Peking, china, Unclassified, to priority FCO., Tel No . 82 of 2 February, 1971. 


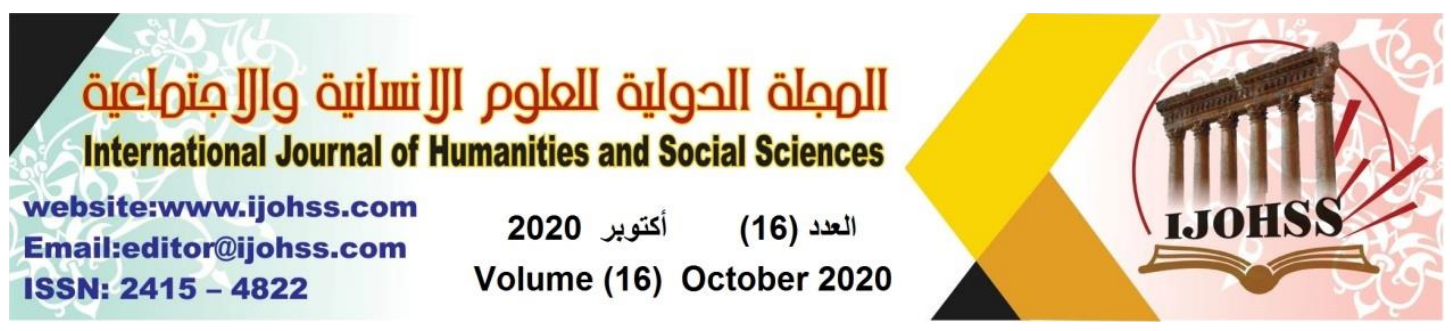

32- Curthberth Adyang Onek, Modes of British Imperial control of Africa, A case Study of Uganda, circa 1890 -1990, PHD , University of Connecticut, USA ,2009,P. 240.

33- Ray Carina, Op .Cit ,P. 35.

34- سيكوتوري يدعو القذافي لتأييد اعادة اوبوني لاو غندا ـ ينظر : جريدة الاهر ام المصرية ، العدد ، 10 شباط 1971.

35- Ray Carinal, Op .Cit ,P. 33.

36 - Ibid ,P. 34

37 - FCO. 31/1023, Report By Le Tocq ( East African Department ), 1 February, 1971.

38 - FCO. 31/ 1023 , Secret , E.G.Le Tocq ( East African Department ), 2 February , 1971.

39 - ولد جوزيف ديزي موبوتو في شمال غرب الكونغو في مدينة ليسالا أيام الاحتلال البلجيكي في 14 تشرين الاول. للمزيد من

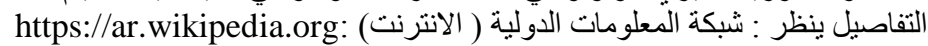

40- FCO. 31/1028, From FCO. Confidential , To Flosh Kampala , tel No , 161 of 4 February , 1971.

41 - Ray Carina, Op .Cit ,P. 33.

42 - Curthberth Adyanga, Onek, Op .Cit ,P.243.

43 - Ray Carina, Op .Cit ,P . 34.

44 - FCO. 31/ 1023 , Confidential Notes for secretary of state, The Situation in Uganda Cabinet on 28 Marchy 1971, from the East African Deparment, 27 Jarwary, 1971.

45- CIA . Geneva for Ambassader ferguson, Uganda Coup, Department of United State, USA , January $27,1971$.

46 - جيري بي لانيير ( Jerry P. Lanier) هو دبلوماسي أمريكي، ولا في 1948 في سانت لويس في الولايات المتحدة .للمزيد من التفاصيل ينظر : شبكة المعلومات الدولية ( الانترنت) : http://kampala.usembassy.gov/ambassador.html

47 - الجيش يستولي على الحكم في او غندا ، جريدة الاهر ام ، العدد 348010 الشباط 1971. 48- Dec Nzarwa katono, A History of Uganda - American Relations 1962-2002 , PHD , Maker ere University, 2009. ,P. 89.

49- Ibid ,P. 91.

50 - CIA . Uganda Coup, Telegrom from Amdassador Ferguson, to SSecretary of Atate Priority, Department of State, 27 Jan , 1971.

51. Ibid.

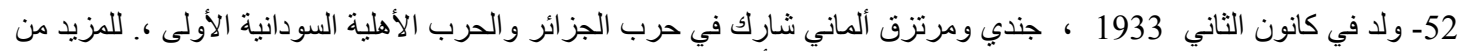

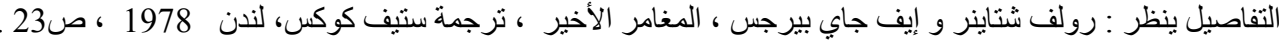

53- Michael .. F. Lofchie , the Uganda coup - class Aetion By the Militar , the Journal of modern African studies, Vol .10, No ,1 , may, 1972.,P. 35 ; Jahn Kiyaga - Nsubga , Op .Cit ,P. 85.

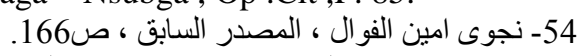

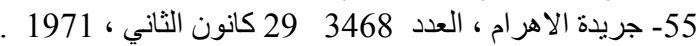

56 - CIA . Uganda Coup Telegram From Ambassador Ferguson, To Secretary of state Priority , Department of state, 27 Jan , 1971.

57 - Joshua . b. Rubongoya , Regime Hegemony in Museveni's Uganda . Palgrave Macmillan , New York, 2007 ,P. 23.

58- Joshua B. Rubongoya, Regime Hegemony in Museveni's Uganda . Palgrave Macmillan, New York, 2007,P. 35.

59 - Delbert. W . Baker, from Exile to Prime Minister, Hew Samson kisekka, Achristian Physician, Washington , 1977,P. 75.

60 - Brett .E.A, Op .Cit ,P. 137.

61- احمد الزروق ،المصدر السابق ، صوب193 ؛ ابر اهيم نصر الدين ، المصدر السابق ، ص34.

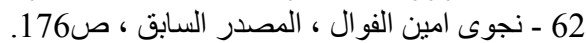

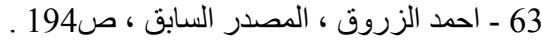

64- Phares Mutibwa, Op .Cit ,P. 85..

65 - Thomas . P. Ofcansky, Ugands Tarnished Pearl of Africa, Westview Press , USA ,1996,P. 44.

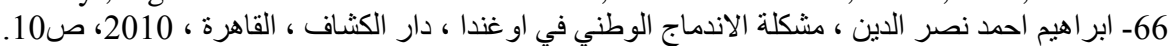

67- CIA . The Situation in Uganda, Memorandum from Henry A. Kissinger to the President, the White House, Washington, 1 November , 1972. 


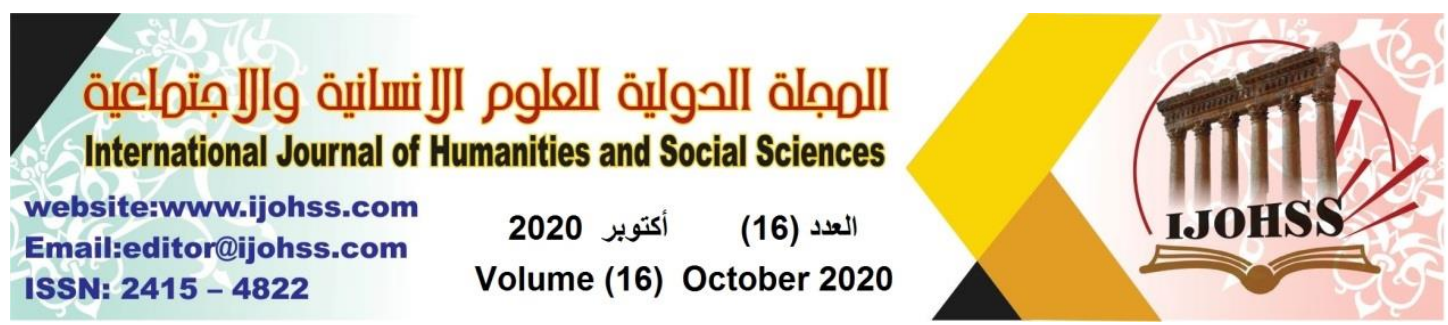

68. African Contemporary Record, Uganda In Colin Legum (Editor ),Annual Survey and Documents , Volume 5 , 1971-1972, Rex Collings , London ,1973,P. 246.

69- Yash Tandon, An Analysis of the foreign policy of African states, A case study I Uganda, In Kenneth ingham ( Editor ), Foreign Relations of Afvican states , London , 1974 ,P. 203.

70- Curthberth Adyanga onek, Op .Cit, 247.

71- Ibid ,P. 249.

72 - Brett . E.A, Op .Cit ,P. 138.

73- Curt berth Adyanga onek, Op .Cit ,P. 247.

74 - Oliver Furley, Britain from Uganda to Museveni , Blind Eye Diplomaey, kumar Rupesinghe , Conflict Resolution In Uganda, International Peace Research In stiute, Oslo ,1989,P. 277.

75- FCO. 59/ 806 , Lord Aldington Report, 5 Aprli , 1972.

76 - FCO. 59/ 806 , Lord Aldington Report, 5 Aprli , 1972.

77- James . H. Mittelman , op .cit ,p. 185 ; Gutteridge William, Military Regimes in Africa , New York , 1975,P. 184.

78- Arya Oded, Israel Ugandan Relations In the time of Idi Amin, Jewish Political studies reviw 18: 13 -4, Jerusalem center of Affairs , 2006 ,P. 70.

79 - Phares Mutibwa, Op .Cit,P. 92.

80- James . H. Mittlem, Op .Cit ,P. 184.

81- Oliver Furley, Op .Cit ,P. 277.

82- Phares Mutibwa, Op .Cit,P. 93.

83- Arye Oded, Israel - Ugandan Relations In The time of idi amin , Jewish Political Studies Review 18: 3-4, Jerusalem Center of Affairs, Fall 2006 ,P. 72.

84 - Martin Walker, Uganda on Search of an African Perspective , the Guardian, January 19 , 1973 ,P. 4.

85 - Oliver Furley, op . cit .p. 278.

86 - New York Times, 20 August, 1972 ,P.13.

87 - Itsvan Bakony, The Jewish Fifth column In India, The library of Political Secrets , christion Defense League , Louisiana, 2010 ,P. 35.

88 - Ali .A . Mazrui, Op .Cit ,p .235.

89-Anirudha Gupta, Uganda Asians , Britain, India and the commonwealth, Africa Affairs , Vol . 73 , Issu 292 , Julay, 1974.

90 - Do. 201-13 , Uganda High commissioner's first Impressions , from D. W . Stather Hunt, British High commissioner In Uganda to the secretary of state for commonwealth the Relations, C.R. O . Ref Ega 23/3411 , No . 98m, 28 December 1962.

91- ارجعت احدى الوثائق البريطانية السبب في طرد الاسيويين من او غندا الى ان موقف الاسيويين كان غير مستقر في شرق افريقات الفيا

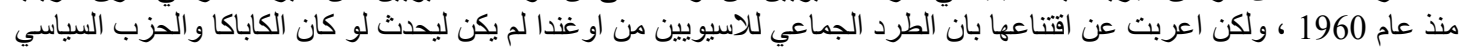

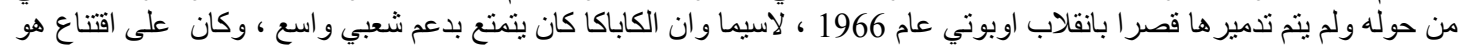

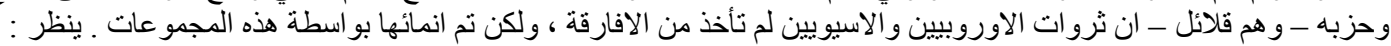
FCO. 59/806 , Message from P.T.Bauer to keith , 4 September, 1972.

92 - Ibid.

93- Africa contemporary Record, Uganda, In Colin Legum ( Editor ), Annual Survey and Documents , Vol.5 , 1972 -1973, Rex colingse, London, 1973 ,P. 87.

94-. African Contemporary Record, Uganda In Colin Legum, Behind the clown's mask , transition , No 75/ 76 , the Anniversary Hssue, Selections from transition , 1961 -1976 , 1976 ,P. 250.

95 - African Contemporary Record, Uganda In Colin Legum (Editor ), Annual Survey and Documents , Volume 5 , 1972-1973, Rex Callings , London ,1973,P. 28.

96- FCO. 59/ 806 , Message From C.A.K cullimore ( Financial Policy \& Aid Dept. ) to Mr. Wood ( East African Department ) 30 August, 1972.

97- FCO. 59/ 806, Asian community In Uganda, To Immediate Certain Mission Tel No Guidance 212 of 31 August, 1972.

98- FCO. 31/1353, Loan to Uganda, From Foreign and commonwealth secretary to prime Minister, 9 November , 1972 ; FCO. 59/ 806 , Foreign secret at and Uganda Asians , Verbatim Service 275/ 72 Thursday 31 August, 1972. 


\section{المجلة اللدولية اللملوم الآنسانية والامتماعية}

International Journal of Humanities and Social Sciences

website:www.ijohss.com

Email:editor@ijohss.com

ISSN: 2415 - 4822

\author{
العدد (16) أكتوبر 2020 (16) \\ Volume (16) October 2020
}

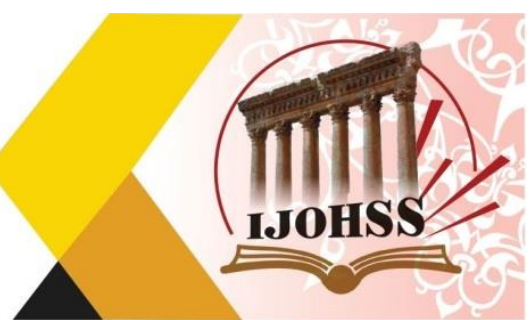

99- Anirudha Gupta , Op . Cit ,P. 85.

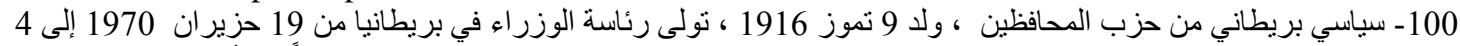

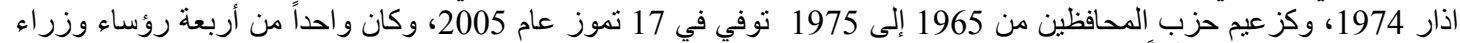

بريطانيين لم يتزوجوا أبداً . للمزيد من التفاصيل ينظر : موسوعة بريتانيكا ، شبكة المعلومات الدولية ( الانترنت) : https://www.britannica.com/biography/Edward-Heath

101- FCO. 59/ 806 , Message From Prime Minister to President Amin , 11 Augnst, 1972 .

102- Margolis Laurence. S, Uganda : A Foolish Trust the Guardian, 18 August, 1972 ,P.12.

103- Africa Contemporary Record, Uganda 1972- 1973, Op .Cit ,P. 286.

104 - FCO. 59/ 806 , Mipt Mr . Rippon's Visit , 10 August, 1972.

105- سياسي بريطاني من حزب المحافظين ، ولد 2 تموز 1903 ، شغل منصب رئيس وزر اء. للمزيد من التفاصيل ينظر : شبكة

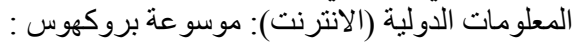

https://brockhaus.de/ecs/enzy/article/douglas-home-alexander-frederick

106- FCO. 31/ 1353, Loan to Uganda, from Alec Douglas Hom ( Foreign and Commonweth office ), to Prime Minister, 9 November, 1972.

107- FCO. 31/ 1353 , Loan to Uganda, from A.A.Acland, to East African Department , 7 November , 1972.

108- Africa Cotemporary Record 1972-1973, Op .Cit . P. 286.

109-FCO. 59/ 806 , Mr. Rippon's Mission, From Dawbarn, to Flash FCO. Tel No . 396 of 14 Augst, 1972.

110 - FCO. 59/806, Miptmr Rippom's Visito 16 August 1972.

111 - Ibid .

112 - FCO. 59/ 806 , Delhi telegram no 73 , Uganda Asian of Indian Origin, To Priority FCO. Tel No . 2094 of 5 September 1972.

113 - Patrick Keatly, Whitehall to List Uganda Assets , the Guardian , December 21 , 1972 ,P. 2.

114- Martin Adeney, Asians Ivited to Register Assets Left in Uganda, The Guardian, September 1 , 1972 ,P. 6.

115 - Africa Contemporary Record , Uganda , 1972-1973 , Op .Cit ,P. 287.

116 - Africa Contemporary Record, Uganda , 1972-1973 , Op .Cit ,P. 288.

117 - Peter Col , Resettlement Board claeaper than Aid to Uganda, the Guardian , January 12 , 1974,P.5.

118- FCO. 59/806 ,Uganda Asians Icem , to Immediate Ukmis Geneva , Telegram No . 290 , 11 September , 1972 .

119- Joanna Herbert, the British Uganda Asian Diaspora, Negotiating Belomgings, Cronem / Ahre Conference, Held At Queen Mary, University of London, 2009 ,P. 4.

120- FCO. 59/ 806 , Uganda and the world Bank, From Mr. D.M.Kerr (Financial Policy \& Aid Department ), To Mr. Dawbarn, 23 October 1972.

121 - FCO. 59/ 806 , Uganda Asians - Icem , To Immediate FCO. Tel No . 471 of 21 September, 1971.

122 - FCO. 59/ 806 , Uganda Asians - Icem, Fceem, From J .G Wallace (East Department ) to Mr. Marshall , 29 September, 1972.

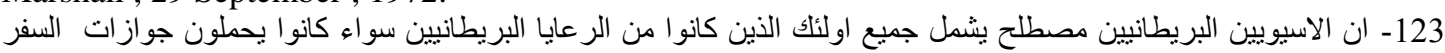

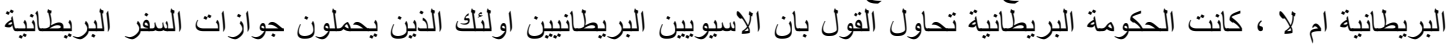

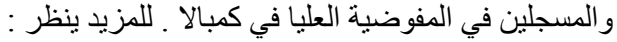
John Fairhall, Uganda Ready to Round Up Asians, the Guardian 14 September , 1972. 124- Ibid.

125 - مجلة السياسة لدولية ، العدد تشرين الاول ، 1972 ، ص1720 1970 . 172

126- FCO. 59/ 806 , To Immediate Kampala Tel No Modern 340 of 4 October 1972.

127- Africen Contemporary Record, Uganda , 1971973, Op .Cit ,P. 287.

128- FCO. 59/ 806 , Oganda Asians lcem to Immediate Ukmis Geneva , Telegram No . 290 , 11 September 1972.

129- Uganda Refugees Intimidate in UK, The Guardian , 2 . Jun , 1973.

130- African Contemporary Record, Uganda , 1972-1973, Op .Cit ,P. 287. 


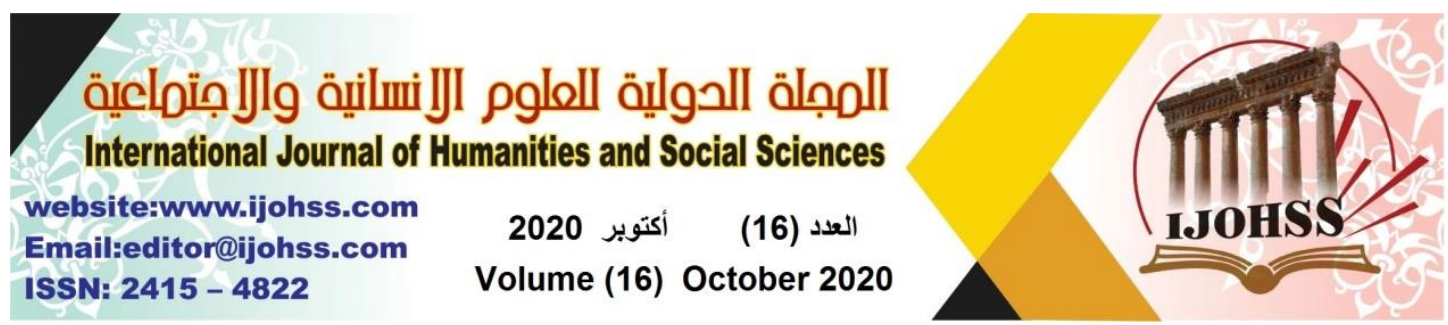

131- John Fair hall , Amin warns Uganda of British Blot , To Assassinate Him , The Guardian , 6 . sep , 1972 ,P. 2.

132 - FCO. 59/ 806 , Message From Prime Minister to President Amin 11 October , 1972.

133- FCO. 59/ 806 , Message From Prime Minister to President Amin 11 October, 1972.

134 - Uganda Lets Un Issue Passports, The Guardian 23 October, 1972.

135- Asians Urge Uganda Freze, The Guardian 4 August, 1973,P. 5.

136 - Joanna R . Quinn, Ethnic conflict in Uganda ,P. 566.

137 - Fafael Jimenez, Op .Cit ,P. 33.

138 -Africa cantenporary Record, Uganda in colin legume ( Editor ), Annual survey and Document , Vol , 5 , 1976-1977, Rex callings , London , 1977 ,P. 380.

139 - FCO. 59/ 806 , Message from C.A.K Cullimore ( Financial Policy of Aid Dept. ) to Mr. A.B .Moore ( central of Southern African Dept ), 11October , 1972.

140- Peter Cole, Op .Cit ,P. 5.

141 - Kasozi Abdo , The Social origins of Violence in Uganda 1964-1985 m Fountain Publishers , kampala , 1994. P. 87.

142- Roger Southall , Federalism and tligher Education in East Africa , East African Publishing House , Nairobi , Kenya , 1974,P. 99,P. 633.

143 - FCO. 59/ 806 , Message from prim Minister to President Amin , 11 October , 1972.

144- African Contemporary Record, Uganda, 1972-1973 , Op .Cit ,P. 275.

145- Uganda Denies Hounding, The Guardian, September 19 , 1972 ,P. 9.

146 - FCO. 59/ 806 , Message from Prime Minister to President Amin , 11 October , 1972.

147 - FCO. 59/ 806 , Message from Prime Minister to President Amin , 11 October , 1972.

148- African Contemporary Record, Uganda, 1972-1973 , Op .Cit ,P. 287.

149 - CIA . The Situation In Uganda Memorandum from Henry A. Kissinger to the President, The white House, Washington, November 1, 1972.

150 - Jacobs L, Uganda's Second Republic, The First two Years, Africa Today . Vol . 20 , No 2 , 1973 ,P. 54.

151- James H. Mittelman, Op .Cit ,P. 185.

152 - Janathan Rollow, Uganda's Amin, An African leader, the Washington post, May ,1974.

153- James H. Mittelman, Op .Cit ,P .186.

154 - Tomas . P. Ofeansky, Ugands Tarnished Pearl of Africa, Westview Press, USA ,1996 ,P. 45.

155 - Oliver Furley, Op .Cit ,P. 278.

156 - African Contemporary Record, Uganda , 1972- 1973 , Op .Cit ,P. 282.

157- Peter Woodward, Ambiguous Amin, African Affairs, vol.77, No .307, Aprile .1978-,P. 153.

158- Oliver Furley, Op .Cit ,P. 278 ;

159 - معارض او غندي نفي الى تنز انيا وشارك في العمليات العسكرية ضد عيدي امين ، وهو مؤسس جبهة الانقاذ الوطني عام

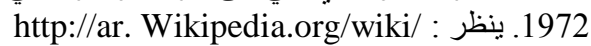
160 - FCO. 31/ 1788 , Gen Calls for Mutuality At copper Mine, Voice of Uganda , 17 December , 1974.

161-Ibid.

162-Ibid.

163 - Ibid.

164- James . H. Mittelman, Op .Cit ,P. 185.

165 - African Contemporary Record, Uganda in Colin Legum, Annual Survey and Documents, vol.8 , 1975-1976, Rex collings , London , 1978 ,P. 348.

166- Wanume kibedi, the story continues, kibedi's open Letter to Amin , Transition , No 49 , 1975,P.29.

167 - African Contemporary Record, Uganda 1975-1976, Op .Cit ,P. 368.

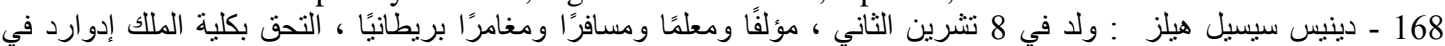

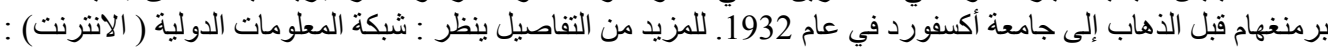
https://en.wikipedia.org/wiki/Denis_Hills

169 - Uganda Rejects British Protest, The Guardian, May 31, 1975 ,P. 3.

170- Uganda Britons, The Observer, June 15 , 1975 ,P. 10. 


\section{المجلة الدولية اللهلور الآنسانية والإمتماعية}

International Journal of Humanities and Social Sciences website:www.ijohss.com Email:editor@ijohss.com ISSN: $2415-4822$

\section{العدد (16) أكتوبر 2020} Volume (16) October 2020

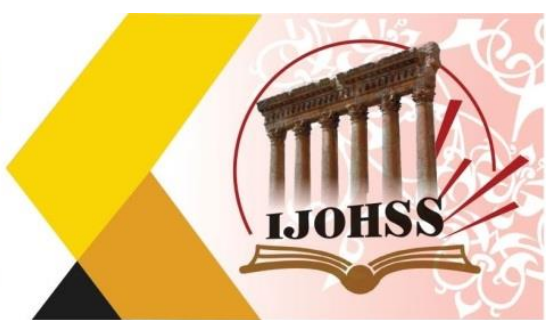

171 - Thomas .P. Ofcansky, Op .Cit ,P. 45.

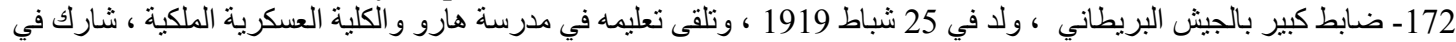

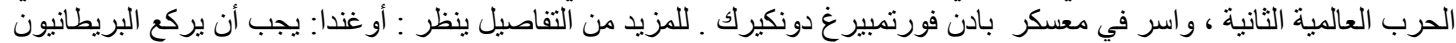

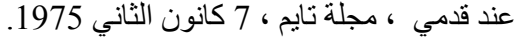

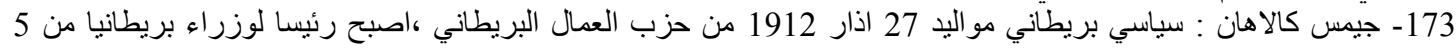

174 - Oliver Furley, Op .Cit ,P. 278. https://ar.wikipedia.org/wiki: نيسان 1976- 4 ايار 1979. للمزيد ينظئ

175- African Contemporary Record, Uganda 1975-1976, Op .Cit ,P. 367.

176- Ibid, Op .Cit ,P. 368.

177 - John Kiyaga - Nsubuga , Op .Cit ,P. 117.

178- FCO. 31/ 1979 , Letter from Crosland to immediate Priority Certain Missions and Department Territories Anglo / Uganda Relations , 27 July 1976.

179- FCO. 31/1979 ,President Amin Message, from R.N. Dales to P.R.H . Wright ( Private Secretary ) , 5 December, 1975. 